\title{
AVALIAÇÃO E IDENTIFICAÇÃO DA TOXICIDADE (AIT) DO SEDIMENTO DAS REGIÕES DE UBATUBA E CARAGUATATUBA, SP, BRASIL.
}

Tese apresentada ao Instituto Oceanográfico da Universidade de São Paulo, como parte dos requisitos para a obtenção do título de Doutor em Ciências, área de Oceanografia Biológica.

Orientadora:

Prof $^{a}$. Eduinetty Ceci Pereira Moreira de Sousa 
Universidade de São Paulo

Instituto Oceanográfico

\section{AVALIAÇÃO E IDENTIFICAÇÃO DA TOXICIDADE (AIT) DO SEDIMENTO DAS REGIÕES DE UBATUBA E CARAGUATATUBA, SP, BRASIL \\ LUÍS FABIANO JOAQUIM DE OLIVEIRA}

Tese apresentada ao Instituto Oceanográfico da Universidade de São Paulo, como parte dos requisitos para obtenção do título de Doutor em Ciências, área de Oceanografia Biológica.

Julgada em

$\operatorname{Prof(a).~Dr(a).~}$

Conceito

Prof(a). Dr(a).

Conceito

Prof(a). Dr(a).

Conceito

Prof(a). Dr(a).

Conceito

Prof(a). Dr(a).

Conceito 
OLIVEIRA, LUÍS FABIANO JOAQUIM DE

AVALIAÇÃO E IDENTIFICAÇÃO DA TOXICIDADE (AIT) DO SEDIMENTO DAS REGIÕES DE UBATUBA E CARAGUATATUBA, SP, BRASIL. Luís Fabiano Joaquim de Oliveira - São Paulo, 2014. 110p.

Tese apresentada ao Instituto Oceanográfico da Universidade de São Paulo, como parte dos requisitos para obtenção do título de Doutor em Ciências, área de Oceanografia Biológica.

1. Ensaio de toxicidade; 2. Água intersticial; 3. Lytechinus variegatus; 4. AIT, 5. Ubatuba, 6. Caraguatatuba. 
"The greatness of a man is not in how much wealth he acquires, but in his integrity and his ability to affect those around him positively"

"A grandeza de um homer não está na quantidade de riqueza que el acquire, mas em sur integridade e sur capacidade de afetar positivamente aqueles que o rodeiamn

Bob Marley 
SUMÁRIO

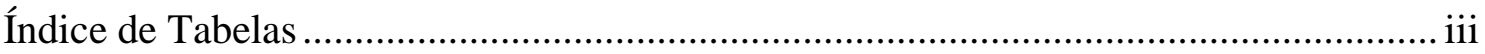

Índice de Figuras ........................................................................................... vii

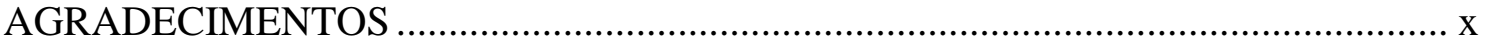

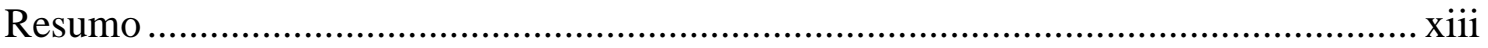

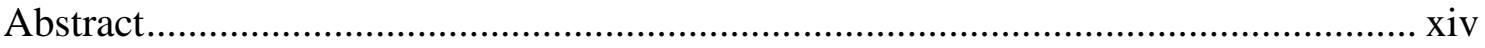

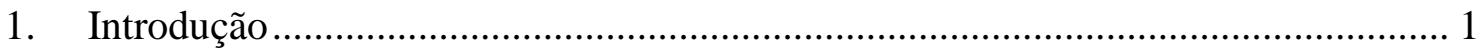

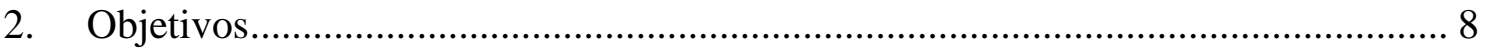

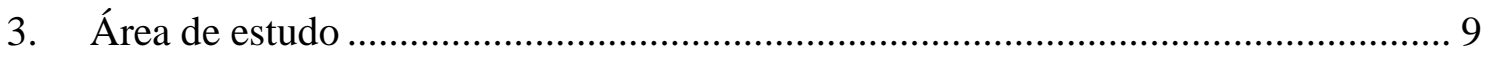

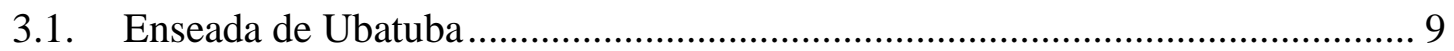

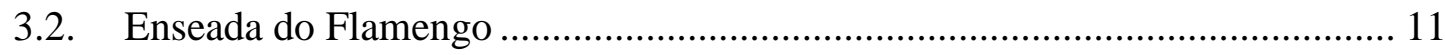

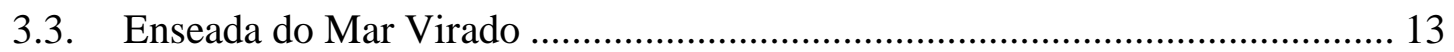

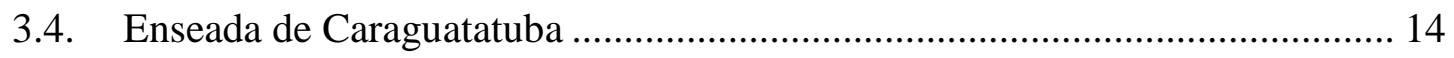

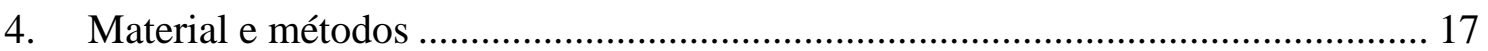

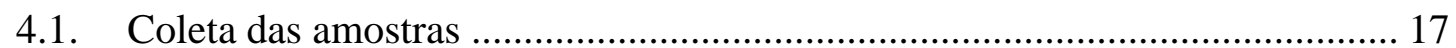

4.2. Extração e Preparo da Água Intersticial....................................................... 18

4.3. Procedimentos da Avaliação e Identificação da toxicidade - AIT .................. 19

4.4. Ensaio ecotoxicológico com Lytechinus variegatus ........................................ 24

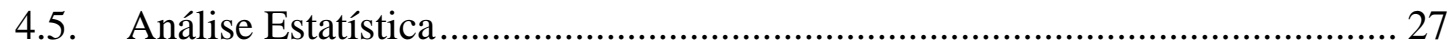

4.5.1. Validação dos resultados da AIT ........................................................ 27

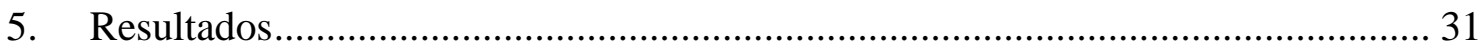


5.1. Avaliação e Identificação da Toxicidade - AIT 31

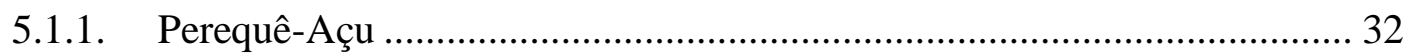

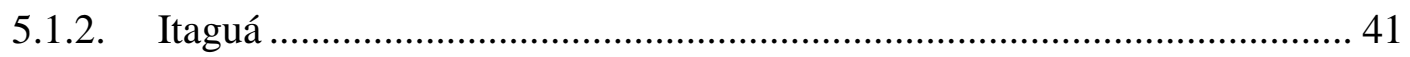

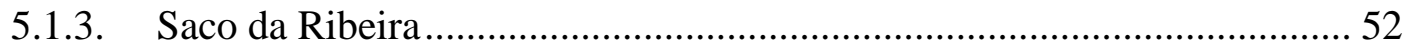

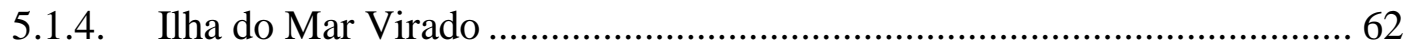

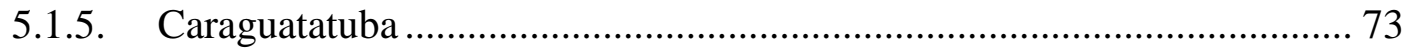

5.2. Compilação dos resultados da AIT ............................................................... 84

5.3. Toxicidade das amostras e a sazonalidade da toxicidade ................................ 86

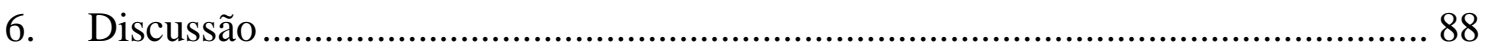

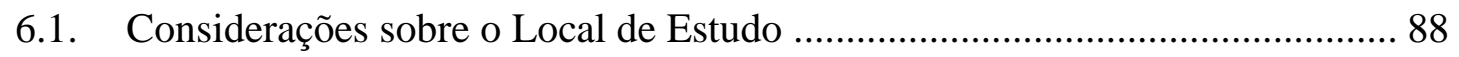

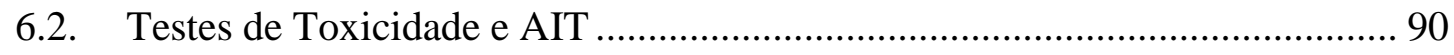

6.3. Caracterização das classes de contaminantes responsáveis pela toxicidade.... 91

6.3.1. Perequê-Açu ............................................................................. 91

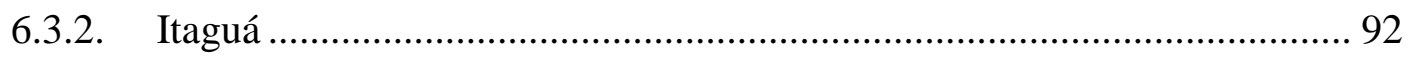

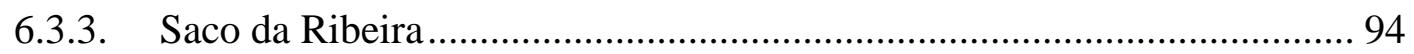

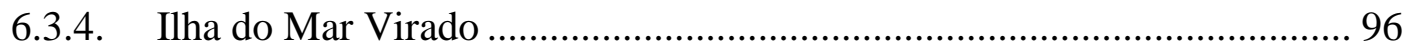

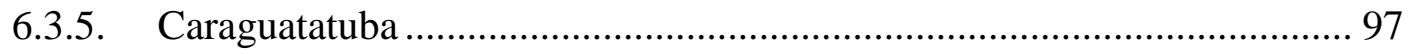

6.4. Toxicidade dos sedimentos e a variação ao longo do ano $(2011 / 2012)$.......... 99

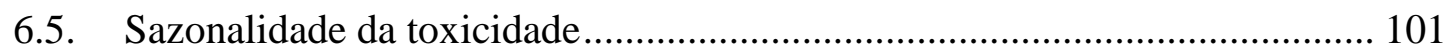

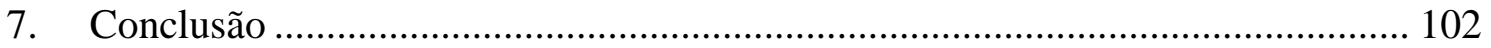

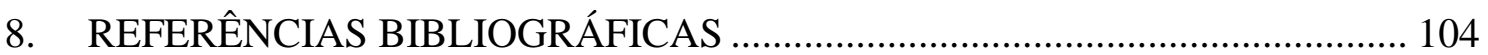


Índice de Tabelas

TABELA 1. COORDENADAS DE LOCALIZAÇÃO DOS PONTOS DE COLETAS. 16

TABELA 2. SÍNTESE DAS MANIPULAÇÕES REALIZADAS E SUAS VALIDAÇÕES SEGUNDO CRITÉRIOS PARA VALIDAÇÃO DA AIT 31

TABELA 3. RESULTADO DAS ANÁLISES DAS VARIÁVEIS DA AMOSTRA DE ÁGUA INTERSTICIAL E NAS DIFERENTES MANIPULAÇÕES DA CAMPANHA DE OUTONO DE 2011, COLETADA NO PEREQUÊ-AÇU. ...32

TABELA 4. PORCENTAGEM MÉDIA E DESVIO PADRÃO DE LARVAS NORMAIS DE LYTECHINUS VARIEGATUS NO OUTONO DE 2011, NAS VÁRIAS CONCENTRAÇÕES TESTADAS EM CADA MANIPULAÇÃO DA ÁGUA INTERSTICIAL DO PEREQUÊ-AÇU. (ER= ENSAIO REFERÊNCIA).

TABELA 5. RESUlTADO DAS ANÁLISES DAS VARIÁVEIS DA AMOSTRA DE ÁGUA INTERSTICIAL E NAS DIFERENTES MANIPULAÇÕES DA CAMPANHA DE INVERNO DE 2011, COLETADA NO PEREQUÊ-AÇU... 35

TABELA 6. PORCENTAGEM MÉDIA E DESVIO PADRÃO DE LARVAS NORMAIS DE LYTECHINUS VARIEGATUS DO INVERNO DE 2011, NAS VÁRIAS CONCENTRAÇÕES TESTADAS EM CADA MANIPULAÇÃO DA ÁGUA INTERSTICIAL DO PEREQUÊ-AÇU. .36

TABELA 7. RESULTADO DAS ANÁLISES DAS VARIÁVEIS DA AMOSTRA DE ÁGUA INTERSTICIAL E NAS DIFERENTES MANIPULAÇÕES DA CAMPANHA DE VERÃO DE 2012, COLETADA NO PEREQUÊ-AÇU.......38

TABELA 8. PORCENTAGEM MÉDIA E DESVIO PADRÃO DE LARVAS NORMAIS DE LYTECHINUS VARIEGATUS DO VERÃO DE 2012 E NAS VÁRIAS CONCENTRAÇÕES TESTADAS EM CADA MANIPULAÇÃO DA ÁGUA INTERSTICIAL DO PEREQUÊ-AÇU.

TABELA 9. RESULTADO DAS ANÁLISES DAS VARIÁVEIS DAS AMOSTRAS DE ÁGUA INTERSTICIAL E NAS DIFERENTES MANIPULAÇÕES DA CAMPANHA DE OUTONO DE 2011, COLETADA NO ITAGUÁ. 41

TABELA 10. PORCENTAGEM MÉDIA E DESVIO PADRÃO DE LARVAS NORMAIS DE LYTECHINUS VARIEGATUS NO OUTONO DE 2011, NAS VÁRIAS CONCENTRAÇÕES TESTADAS EM CADA MANIPULAÇÃO DA ÁGUA INTERSTICIAL DO ITAGUÁ. 42

TABELA 11. RESULTADO DAS ANÁLISES DAS VARIÁVEIS DA AMOSTRA DE ÁGUA INTERSTICIAL E NAS DIFERENTES MANIPULAÇÕES DA CAMPANHA DE INVERNO DE 2011, COLETADA NO ITAGUÁ. 44

TABELA 12. PORCENTAGEM MÉDIA E DESVIO PADRÃO DE LARVAS NORMAIS DE LYTECHINUS VARIEGATUS NO INVERNO DE 2011, NAS VÁRIAS CONCENTRAÇÕES TESTADAS EM CADA MANIPULAÇÃO DA ÁGUA INTERSTICIAL DO ITAGUÁ. 
TABELA 13. RESULTADO DAS ANÁLISES DAS VARIÁVEIS DA AMOSTRA DE ÁGUA INTERSTICIAL E NAS DIFERENTES MANIPULAÇÕES DA CAMPANHA DA PRIMAVERA DE 2011, COLETADA NO ITAGUÁ...........46

TABELA 14. PORCENTAGEM MÉDIA E DESVIO PADRÃO DE LARVAS NORMAIS DE LYTECHINUS VARIEGATUS NA PRIMAVERA DE 2011, NAS VÁRIAS CONCENTRAÇÕES TESTADAS EM CADA MANIPULAÇÃO DA ÁGUA INTERSTICIAL DO ITAGUÁ. 47

TABELA 15. RESULTADO DAS ANÁLISES DAS VARIÁVEIS DA AMOSTRA DE ÁGUA INTERSTICIAL E NAS DIFERENTES MANIPULAÇÕES DA CAMPANHA DO VERÃO DE 2012, COLETADA NO ITAGUÁ. 49

TABELA 16. PORCENTAGEM MÉDIA E DESVIO PADRÃO DE LARVAS NORMAIS DE LYTECHINUS VARIEGATUS NO VERÃO DE 2012, NAS VÁRIAS CONCENTRAÇÕES TESTADAS EM CADA MANIPULAÇÃO DA ÁGUA INTERSTICIAL DO ITAGUÁ. 50

TABELA 17. RESULTADO DAS ANÁLISES DAS VARIÁVEIS DA AMOSTRA DE ÁGUA INTERSTICIAL E NAS DIFERENTES MANIPULAÇÕES DA CAMPANHA DE OUTONO DE 2011, COLETADA NO SACO DA RIBEIRA.

TABELA 18. PORCENTAGEM MÉDIA E DESVIO PADRÃO DE LARVAS NORMAIS DE LYTECHINUS VARIEGATUS NO OUTONO DE 2011, NAS VÁRIAS CONCENTRAÇÕES TESTADAS EM CADA MANIPULAÇÃO DA ÁGUA INTERSTICIAL DO SACO DA RIBEIRA.

TABELA 19. RESULTADO DAS ANÁLISES DAS VARIÁVEIS DA AMOSTRA DE ÁGUA INTERSTICIAL E NAS DIFERENTES MANIPULAÇÕES DA CAMPANHA DE INVERNO DE 2011, COLETADA NO SACO DA RIBEIRA.

TABELA 20. PORCENTAGEM MÉDIA E DESVIO PADRÃO DE LARVAS NORMAIS DE LYTECHINUS VARIEGATUS NO INVERNO DE 2011, NAS VÁRIAS CONCENTRAÇÕES TESTADAS E EM CADA MANIPULAÇÃO DA ÁGUA INTERSTICIAL DO SACO DA RIBEIRA.

TABELA 21. RESULTADO DAS ANÁLISES DAS VARIÁVEIS DA AMOSTRA DE ÁGUA INTERSTICIAL E NAS DIFERENTES MANIPULAÇÕES DA CAMPANHA DE PRIMAVERA DE 2011, COLETADA NO SACO DA RIBEIRA.

TABELA 22. PORCENTAGEM MÉDIA E DESVIO PADRÃO DE LARVAS NORMAIS DE LYTECHINUS VARIEGATUS NA PRIMAVERA DE 2011, NAS VÁRIAS CONCENTRAÇÕES TESTADAS EM CADA MANIPULAÇÃO DA ÁGUA INTERSTICIAL DO SACO DA RIBEIRA.

TABELA 23. RESULTADO DAS ANÁLISES DAS VARIÁVEIS DA AMOSTRA DE ÁGUA INTERSTICIAL E NAS DIFERENTES MANIPULAÇÕES DA CAMPANHA DE VERÃO DE 2012, COLETADA NO SACO DA RIBEIRA. 60 
TABELA 24. PORCENTAGEM MÉDIA E DESVIO PADRÃO DE LARVAS NORMAIS DE LYTECHINUS VARIEGATUS NO VERÃO DE 2012, NAS VÁRIAS CONCENTRAÇÕES TESTADAS EM CADA MANIPULAÇÃO DA ÁGUA INTERSTICIAL DO SACO DA RIBEIRA. 61

TABELA 25. RESULTADO DAS ANÁLISES DAS VARIÁVEIS DA AMOSTRA DE ÁGUA INTERSTICIAL NAS DIFERENTES MANIPULAÇÕES DA CAMPANHA DE OUTONO DE 2011, COLETADA NA ILHA DO MAR VIRADO.

TABELA 26. PORCENTAGEM MÉDIA E DESVIO PADRÃO DE LARVAS NORMAIS DE LYTECHINUS VARIEGATUS NO OUTONO DE 2011, NAS VÁRIAS CONCENTRAÇÕES TESTADAS EM CADA MANIPULAÇÃO DA ÁGUA INTERSTICIAL DA ILHA DO MAR VIRADO.

TABELA 27. RESULTADO DAS ANÁLISES DAS VARIÁVEIS DA AMOSTRA DE ÁGUA INTERSTICIAL E NAS DIFERENTES MANIPULAÇÕES DA CAMPANHA DE INVERNO DE 2011, COLETADA NA ILHA DO MAR VIRADO,

TABELA 28. PORCENTAGEM MÉDIA E DESVIO PADRÃO DE LARVAS NORMAIS DE LYTECHINUS VARIEGATUS NO INVERNO DE 2011, NAS VÁRIAS CONCENTRAÇÕES TESTADAS EM CADA MANIPULAÇÃO DA ÁGUA INTERSTICIAL DA ILHA DO MAR VIRADO.

TABELA 29. RESULTADO DAS ANÁLISES DAS VARIÁVEIS DA AMOSTRA DE ÁGUA INTERSTICIAL E NAS MANIPULAÇÕES ENSAIO REFERÊNCIA E FILTRAÇÃO DA CAMPANHA DE PRIMAVERA DE 2011, COLETADA NA ILHA DO MAR VIRADO.

TABELA 30. PoRCENTAGEM MÉdiA E DESVIO PADRÃo DE LARVAS NORMAIS DE LYTECHINUS VARIEGATUS NA PRIMAVERA DE 2011, NAS VÁRIAS CONCENTRAÇÕES TESTADAS DAS MANIPULAÇÕES ENSAIO REFERÊNCIA E FILTRAÇÃO DA ÁGUA INTERSTICIAL DA ILHA DO MAR VIRADO.

TABELA 31. RESULTADO DAS ANÁLISES DAS VARIÁVEIS DA AMOSTRA DE ÁGUA INTERSTICIAL NAS DIFERENTES MANIPULAÇÕES DA CAMPANHA DE VERÃO DE 2012, COLETADA NA ILHA DO MAR VIRADO.

TABELA 32. PORCENTAGEM MÉDIA E DESVIO PADRÃO DE LARVAS NORMAIS DE LYTECHINUS VARIEGATUS NO VERÃO DE 2012, NAS VÁRIAS CONCENTRAÇÕES TESTADAS EM CADA MANIPULAÇÃO DA ÁGUA INTERSTICIAL DA ILHA DO MAR VIRADO.

TABELA 33. RESULTADO DAS ANÁLISES DAS VARIÁVEIS DA AMOSTRA DE ÁGUA INTERSTICIAL E NAS DIFERENTES MANIPULAÇÕES DA CAMPANHA DE OUTONO DE 2011, COLETADA EM CARAGUATATUBA. 
TABELA 34. PORCENTAGEM MÉDIA E DESVIO PADRÃO DE LARVAS NORMAIS DE LYTECHINUS VARIEGATUS NO OUTONO DE 2011, NAS VÁRIAS CONCENTRAÇÕES TESTADAS EM CADA MANIPULAÇÃO DA ÁGUA INTERSTICIAL DE CARAGUATATUBA. .75

TABELA 35. RESULTADO DAS ANÁLISES DAS VARIÁVEIS DA AMOSTRA DE ÁGUA INTERSTICIAL E NAS DIFERENTES MANIPULAÇÕES DA CAMPANHA DE INVERNO DE 2011, COLETADA EM CARAGUATATUBA.

TABELA 36. PORCENTAGEM MÉDIA E DESVIO PADRÃO DE LARVAS NORMAIS DE LYTECHINUS VARIEGATUS NO INVERNO DE 2011, NAS VÁRIAS CONCENTRAÇÕES TESTADAS EM CADA MANIPULAÇÃO DA ÁGUA INTERSTICIAL DE CARAGUATATUBA.. 78

TABELA 37. RESULTADO DAS ANÁLISES DAS VARIÁVEIS DA AMOSTRA DE ÁGUA INTERSTICIAL NAS DIFERENTES MANIPULAÇÕES DA CAMPANHA DE PRIMAVERA DE 2011, COLETADA EM Caraguatatuba.

TABELA 38. PORCENTAGEM MÉDIA E DESVIO PADRÃO DE LARVAS NORMAIS DE LYTECHINUS VARIEGATUS NA PRIMAVERA DE 2011, NAS VÁRIAS CONCENTRAÇÕES TESTADAS EM CADA MANIPULAÇÃO DA ÁGUA INTERSTICIAL DE CARAGUATATUBA 80

TABELA 39. RESULTADO DAS ANÁLISES DAS VARIÁVEIS DA AMOSTRA DE ÁGUA INTERSTICIAL NAS DIFERENTES MANIPULAÇÕES DA CAMPANHA DE VERÃO DE 2012, COLETADA EM CARAGUATATUBA.

TABELA 40. PORCENTAGEM MÉDIA E DESVIO PADRÃO DE LARVAS NORMAIS DE LYTECHINUS VARIEGATUS NO VERÃO DE 2012, NAS VÁRIAS CONCENTRAÇÕES TESTADAS EM CADA MANIPULAÇÃO DA ÁGUA INTERSTICIAL DE CARAGUATATUBA.

TABELA 41. FREQUÊNCIA DE TOXICIDADE (\%) PARA CADA MANIPULAÇÃO DAS AMOSTRAS EM TODAS AS CAMPANHAS REALIZADAS E EM TODAS AS CONCENTRAÇÕES TESTADAS.

TABELA 42. IDENTIFICAÇÃo DAS AMOSTRAS TÓXICAS (T) E NÃO TÓXICAS (NT), NAS QUATRO CAMPANHAS DE COLETA. 
Índice de Figuras

FigURA 1. LOCALIZAÇÃo DA ÁREA DE ESTUDO (IMAGEM: GOOGLE EARTH). . .9

Figura 2. ENSEAdA DE UbATUBA COM INDiCAÇão doS PONTOS DE COLETA (IMAGEM: GOOGLE EARTH). 10

FigURA 3. ENSEADA DO FLAMENGO COM INDICAÇão DO PONTO DE COLETA (IMAGEM: GOOGLE EARTH)... 12

FigURA 4. ENSEADA DO MAR VIRADO COM INDICAÇÃO DO PONTO DE COLETA- ILHA DO MAR VIRADO (IMAGEM: GOOGLE EARTH).

Figura 5. ENSEAdA DE CARAguatatuba COM INDiCAÇÃo DO PONTO DE COLETA (IMAGEM: GOOGLE EARTH).

Figura 6. EMBARCAÇÃo Velliger II E O PEGADOR DE FUNDO MODELO VAN-VEEN UTILIZAdOS PARA AS COLETAS DAS AMOSTRAS (Foto: Lú́s Fabiano J. DE OliveIRA).

Figura 7. EXTRAÇÃo da ÁGUA INTERSTICIAL (Foto: LAB. DE ECOTOXICOLOGIA MARINHA - IOUSP), ..18

FigURA 8. FLUXOGRAMA DA AIT FASE I. 20

FiguRA 9. OVO DE LyTECHINUS VARIEGATUS (A) E LARVA PLUTEUS NORMAL COM CERCA DE 24 H DE DESENVOLVIMENTO (B).( FOTO: LAB. DE ECOTOXICOLOGIA MARINHA - IOUSP)... .26

FIGURA 10. FLUXOGRAMA MOSTRANDO O PROCEDIMENTO ESTATÍ́STICO UTILIZADO PARA VALIDAÇÃO DAS MANIPULAÇÕES. .28

FIGURA 11. FLUXOGRAMA MOSTRANDO O PROCEDIMENTO ESTATÍSTICO UTILIZADO PARA CLASSIFICAÇÃO DA AMOSTRA COMO TÓXICA OU NÃO TÓXICA. .29

FIGURA 12. RESULTADOS DOS ENSAIOS ECOTOXICOLÓGICOS DO OUTONO 2011, NAS VÁRIAS CONCENTRAÇõES TESTADAS EM CADA MANIPULAÇão DA ÁGUA INTERSTICIAL DO PEREQUÊ-AÇU...34

FIGURA 13. RESULTADOS DOS ENSAIOS ECOTOXICOLÓGICOS DO INVERNO 2011 NAS VÁRIAS CONCENTRAÇÕES TESTADAS EM CADA MANIPULAÇão DA ÁGUA INTERSTICIAL DO PEREQUÊ-AÇU....37

FigURA 14. RESULTADOS DOS ENSAIOS ECOTOXICOLÓGICOS DO VERÃO 2012, NAS DIFERENTES CONCENTRAÇÕES TESTADAS EM CADA MANIPULAÇão DA ÁGUA INTERSTICIAL DO PEREQUÊ-AÇU...40

FigURA 15. RESULTADOS DOS ENSAIOS ECOTOXICOLÓGICOS DO OUTONO 2011, NAS VÁRIAS CONCENTRAÇÕES TESTADAS EM CADA MANIPULAÇÃO DA ÁGUA INTERSTICIAL DO ITAGUÁ. 43

FIGURA 16. RESULTADOS DOS ENSAIOS ECOTOXICOLÓGICOS DO INVERNO 2011, NAS VÁRIAS CONCENTRAÇÕES TESTADAS EM CADA MANIPULAÇÃO DA ÁGUA INTERSTICIAL DO ITAGUÁ. 45 
FIGURA 17. RESUltados dos ENSAIOS ECOTOXICOLÓGICOS DA PRIMAVERA 2011, NAS VÁRIAS CONCENTRAÇÕES TESTADAS EM CADA MANIPULAÇÃO DA ÁGUA INTERSTICIAL DO ITAGUÁ. 48

FIGURA 18. RESULTADOS DOS ENSAIOS ECOTOXICOLÓGICOS DO VERÃO DE 2012, NAS VÁRIAS CONCENTRAÇÕES TESTADAS EM CADA MANIPULAÇÃO DA ÁGUA INTERSTICIAL DO ITAGUÁ. 51

FIGURA 19. RESULTADOS DOS ENSAIOS ECOTOXICOLÓGICOS DO OUTONO 2011, NAS VÁRIAS CONCENTRAÇÕES TESTADAS EM CADA MANIPULAÇÃO DA ÁGUA INTERSTICIAL DO SACO DA RIBEIRA.

FIGURA 20. RESULTADOS DOS ENSAIOS ECOTOXICOLÓGICOS DO INVERNO DE 2011, NAS VÁRIAS CONCENTRAÇÕES TESTADAS EM CADA MANIPULAÇÃO DA ÁGUA INTERSTICIAL DO SACO DA RIBEIRA.

FIGURA 21. RESUlTAdOS DOS ENSAIOS ECOTOXICOLÓGICOS DA PRIMAVERA DE 2011, NAS VÁRIAS CONCENTRAÇÕES TESTADAS EM CADA MANIPULAÇÃO DA ÁGUA INTERSTICIAL DO SACO DA RIBEIRA.

FigURA 22. RESUlTADOS DOS ENSAIOS ECOTOXICOLÓGICOS DO VERÃO DE 2012, NAS VÁRIAS CONCENTRAÇÕES TESTADAS EM CADA MANIPULAÇÃO DA ÁGUA INTERSTICIAL DO SACO DA RIBEIRA.

FIGURA 23. RESULTADOS DOS ENSAIOS ECOTOXICOLÓGICOS DO OUTONO 2011, NAS VÁRIAS CONCENTRAÇÕES TESTADAS EM CADA MANIPULAÇÃO DA ÁGUA INTERSTICIAL DA ILHA DO MAR VIRADO.

FIGURA 24. RESULTADOS DOS ENSAIOS ECOTOXICOLÓGICOS DO INVERNO DE 2011, NAS VÁRIAS CONCENTRAÇÕES TESTADAS EM CADA MANIPULAÇÃO DA ÁGUA INTERSTICIAL DA ILHA DO MAR VIRADO.

FiguRA 25. RESUlTAdOS DOS ENSAIOS ECOTOXICOLÓGICOS DA PRIMAVERA DE 2011, NAS VÁRIAS CONCENTRAÇÕES TESTADAS DAS MANIPULAÇÕES ENSAIO REFERÊNCIA E FILTRAÇÃO DA ÁGUA INTERSTICIAL DA ILHA DO MAR VIRADO.

FIGURA 26. RESUlTAdOS DOS ENSAIOS ECOTOXICOLÓGICOS DO VERÃO DE 2012, NAS VÁRIAS CONCENTRAÇÕES TESTADAS EM CADA MANIPULAÇÃO DA ÁGUA INTERSTICIAL DA ILHA DO MAR VIRADO. 
FIGURA 27. RESULTADOS DOS ENSAIOS ECOTOXICOLÓGICOS DO OUTONO DE 2011, NAS VÁRIAS CONCENTRAÇÕES TESTADAS EM CADA MANIPULAÇÃO DA ÁGUA INTERSTICIAL DE CARAGUATATUBA. 75

FIGURA 28. RESULTADOS DOS ENSAIOS ECOTOXICOLÓGICOS DO INVERNO DE 2011, NAS VÁRIAS CONCENTRAÇÕES TESTADAS EM CADA MANIPULAÇÃO DA ÁGUA INTERSTICIAL DE CARAGUATATUBA.

FigURA 29. Resultados dos ENSAIOS ECOTOXICOLÓGICOS DA PRIMAVERA DE 2011, NAS VÁRIAS CONCENTRAÇÕES TESTADAS EM CADA MANIPULAÇÃO DA ÁGUA INTERSTICIAL DE CARAGUATATUBA. 81

Figura 30. RESUltados doS ENSAIOS ECOTOXICOLÓGICOS DO VERÃO DE 2012, NAS VÁRIAS CONCENTRAÇÕES TESTADAS EM CADA MANIPULAÇÃO DA ÁGUA INTERSTICIAL DE CARAGUATATUBA. 


\section{AGRADECIMENTOS}

Agradeço a PROFESSORA CECI pela oportunidade, confiança, dedicação e orientações nesses 10 anos de trabalhos em conjunto depois que caiu de paraquedas em seu laboratório, pelo apoio nas horas difíceis que muito precisei tanto na realização deste trabalho como na vida pessoal.

Um milhão de agradecimento a minha MÃE Dona Matilde e meu PAI Seu Oliveira, amo vocês demais, a meus irmãos Zé e Paulinha.

Obrigado FAMILIA - A BASE DE TUDO DA MINHA VIDA!!!!! VOCES SÃO TUDO EM MINHA VIDA.

Dedico essa TESE a vocês.... Agradeço a uma mulher que surgiu pra completar minha vida logo no começo dessa etapa da minha vida. Valeu Vanessa!! TEAMO!!

A Marcia Regina Gasparro por me proporcionar anos de conhecimentos técnico-científicos e pessoais... Valeu pelos inúmeros cafés.

Um agradecimento mais que especial CAU, Carina W. Rodrigues, irmã que a vida me deu e que tem enorme participação nesse trabalho e responsável pelo meu ingresso na pós-graduação e na vida como pesquisador.

A todos do Lecotox - Laboratório de Ecotoxicologia Marinha e microfitobentos que formam a família Lecotox: Lelê, Bauer, Marilia, Renato (DORI), Claudinha, Chris, Milena, Jessica, Claudio, Talita e Profa. Bia que me 
ajudaram com idéias, coletas, testes, cafés, risadas e que me apoiaram em muitos momentos..... VALEU GALERA!!!!

Ao Manuel em nome de todos da base de Ubatuba que ajudaram e muitos nos trabalhos, principalmente as meninas da cozinha Dona Cida, Bete e Vânia.

E ao pessoal da tripulação do Velliger II Ozi (Oziel), Daíco e Adriano que com eles qualquer coleta fica tranquila.

Aos técnicos Tomazinho, André e Davi. A todos os funcionários da Biblioteca, ao pessoal do transporte, apoio logístico e serviço de base.

Agradecimento mais que especial a FAUSTO SILVESTRI que foi responsável da melhor coisa que já aconteceu na minha vida!!! MORAR NA ITÁLIA!!! Grazie mille !!! E por me apresentar as melhores pizzas e pizzarias de Nápoles! Além das coisas do Lucio.

Agradeço ao Prof. Gionanni Sansone por me receber e abrir as portas da Itália. Agradeço a Dra. Adele Fabroccini por me aceitar em seu laboratório durante meu estagio na Itália e me ensinar coisas jamais imaginada. Não tem como esquecer o pessoal do CNR ISMAR-Lesina que sempre foram atenciosos mesmo quando ainda não falava italiano. A Angela e Nicola, amigos que fiz nessa passagem pela Itália. 
Aos meus amigos do IO: Thais, Caia, Mau, Sandrinha, Juliano, Carol loirão, Betina, Karen, Paula, Paulinha, aos Uruguaios Pablo e Naty, Newtão e Cassia, Frango, Caio, Batata, Piseta, Fabricio, Pitu, Jason, Jonhy, as Carols do Phan, Priscila, Alex, Juliana, Debora, Alisson, Rodela, os Arthur do lab. do Prof. Sumida, Danilo Baltazar, aos que nesse momento me fogem da mente, todos do futebol de segunda no Areião!!! Ao Marujo, Rafael Araújo, parceiro nos roles em Amsterdam e norte da Itália! Agradeço ao Fabio Japonês, Luciano (Cabelo) e Luis (Pato) - amigos que fize sempre estiveram ao meu lado acreditando, ajudando de varias formas $e$ épocas.

Aos meus amigos do REDÊ....meu salve!!!!!

A dois amigos que na verdade são dois Irmãos que conheci no Mackenzie: Carlinha e Binho.

As brejas de sexta na BIO, em muitas vezes de segunda a sexta. Agradeço ao CNPQ pela bolsa estudo concedida e ao Intituto Oceanográfico pela infraestrutura oferecida. Agradeço a CAPES pela bolsa de doutorado sanduíche concedida. 
Resumo

\section{AVALIAÇÃO E IDENTIFICAÇÃO DA TOXICIDADE (AIT) DO SEDIMENTO DAS REGIÕES DE UBATUBA E CARAGUATATUBA, SP, BRASIL.}

O Litoral Norte de São Paulo é uma região pouco impactada e com elevada sensibilidade ecológica e que reúne perspectivas de grande crescimento econômico com novas instalações de empresas ligadas à exploração do PRÉ-SAL. O presente estudo tem como objetivo analisar a toxicidade dos sedimentos dos Municípios de Ubatuba e Caraguatatuba com os procedimentos da Avaliação e Identificação da Toxicidade (AIT), somente a fase I, proposto pela USEPA (1991; 2007). O ensaio de toxicidade crônico de desenvolvimento embriolarval do ouriço do mar Lytechinus variegatus. Foi extraída a água intersticial dos sedimentos, coletados em quatro enseadas, pelo método de sucção descrito por Winger \& Lasier (1991), sendo dois pontos de coleta na Enseada de Ubatuba - Perequê-Açu e Itaguá, um na Enseada do Flamengo, um na Enseada do Mar Virado e uma na Enseada de Caraguatatuba. A AIT evidenciou como agente causador da toxicidade, de modo geral, os compostos $\mathrm{pH}$ dependentes e dos metais. As amostras do Perequê-Açu e de Caraguatatuba apresentaram toxicidade em todas as amostras analisadas, as demais amostras não apresentaram nenhuma relação entre a toxicidade e a sazonalidade.

Palavras chaves: Ensaio de toxicidade, água intersticial, Lytechinus variegatus, AIT, Ubatuba, Caraguatatuba. 


\begin{abstract}
TOXICITY IDENTIFICATION EVALUATION (TIE) OF SEDIMENT IN UBATUBA AND CARAGUATATUBA, SP, BRAZIL
\end{abstract}

São Paulo north coast is a poor impacted region and with high ecological sensitivity which gathers perspectives of great economic growth with new facilities related to the operation of the Pre-Salt companies. The aim of the present study is to analyze the toxicity of sediments from the municipalities of Ubatuba and Caraguatatuba with the procedures of the Toxicity Identification Evaluation (TIE), only the phase I, proposed by USEPA $(1991,2007)$. The test of chronic toxicity of embriolarval development of sea urchin Lytechinus variegates. Pore water was extracted from the sediments collected in four bays, by the suction method described by Winger \& Lasier (1991), being two collection points in Ubatuba Bay - Perequê-Açu and Itaguá, one in Flamengo Bay, one the Mar Virado Bay and one in Caraguatatuba Bay. The TIE evidenced as a causative agent of toxicity, in general, the compounds of $\mathrm{pH}$ dependent and of metals. The samples of Perequê-Açu and Caraguatatuba showed toxicity in all samples, the other samples showed no relationship between toxicity and seasonality.

Key words: toxicity test, pore water, Lytechinus variegates, TIE, Ubatuba, Caraguatatuba. 


\section{INTRODUÇÃO}

O problema relativo à poluição vem se agravando no mundo e em nosso país acompanhando os avanços industriais. As águas, inclusive, as marinhas, não escapam das tragédias que ocasionalmente ocorrem. Vários são os compostos introduzidos no oceano, não sendo conhecidas as suas rotas, consequências e efeitos no ambiente marinho (Rachid, 2002).

O crescente acúmulo de substâncias no ambiente marinho, principalmente oriundos de atividades petrolíferas e descarte de efluentes urbanos e indústrias, causam efeitos tóxicos para a biota e interferem no equilíbrio do ecossistema. Os compostos tóxicos podem ser acumulados e transferidos através da cadeia alimentar, fazendo com que a contaminação represente risco para o homem (Sousa, 2002).

Atividade de monitoramento permanente e sistemático do ambiente marinho aliado ao conhecimento científico trará a possibilidade de adoção de medidas de prevenção, no que se refere à qualidade da água, dos sedimentos e à saúde dos seres vivos. Especial atenção deve ser dedicada às áreas ecologicamente mais sensíveis e à qualidade das praias e das áreas portuárias e industriais (CGEE, 2008).

Esses problemas nos trazem grandes preocupações com regiões de importância econômica e/ou áreas altamente impactadas que demandam atividade de monitoramento. Porém, especial atenção deve ser dada às áreas atualmente pouco impactadas, face à necessidade de preservação do patrimônio ecológico existente, bem como para formulação de políticas de gestão da exploração dos recursos naturais, com mitigação de danos causados pela atividade humana.

A preocupação com a contaminação ambiental tem aumentado em virtudes de grande quantidade de poluentes lançados no ambiente nos últimos anos. Dentre as 
maiores fontes de poluição do meio aquático encontram-se os efluentes domésticos e industriais lançados sem o devido tratamento (Sousa, 2013; Zagatto \& Bertolleti, 2006) e a complexidade causada pela interação dos agentes químicos. Para a avaliação dos os efeitos biológicos desses efluentes se faz necessário o uso integrado de análises físicas, químicas e ecotoxicológicas (Zagatto \& Bertolleti, 2006; Cariello, 2012; Sousa 2013).

O sedimento constitui importante compartimento dos ecossistemas aquáticos, sendo reconhecido como o principal destino das substâncias introduzidas nos oceanos (Adams et al., 1992; Swartz et al., 1985), tornando-se um depósito de contaminantes que entram nos estuários e sistemas costeiros (Rodríguez-Obeso et al, 2007 e Ho \& Burgess, 2009), assim acumulando estes compostos em níveis muito mais elevados que aqueles observados na coluna de água adjacente (Nipper et al., 1989).

Além disso, inúmeros processos químicos, físicos e biológicos podem ocasionar a liberação dos contaminantes inorgânicos e orgânicos persistentes presentes nos sedimentos para a coluna d'água (DelValls et al, 2004; Montero et al., 2013), trazendo riscos à biota que nela vive, sendo que esses processos ocorrem por ação da natureza e/ou por ação do homem.

A caracterização química de sedimentos marinhos não é suficiente para determinar a toxicidade deste para a biota, pois não analisa a quantidade de contaminantes que estão potencialmente biodisponível nos mesmos (Goodsir et al., 2013).

Integração de dados sobre a carga química em sedimentos com dados sobre os efeitos toxicológicos das substâncias químicas sobre os organismos bentônicos fornece a melhor ferramenta disponível para uma avaliação completa do estado de contaminação desses sedimentos (Khosrovyan et al., 2013). 
Como os sedimentos representam substrato para uma grande variedade de espécies e locais de alimentação para muitas outras, avaliação da qualidade de sedimentos constitui uma estratégia confiável na verificação da qualidade ambiental (Araujo et al., 2013). Por sua capacidade de acumular contaminantes ao longo do tempo e pela sua importância ecológica, os sedimentos têm sido utilizados como importantes indicadores da qualidade dos ecossistemas aquáticos, sendo considerados tão importantes quanto à coluna d'água em avaliações ambientais ou bioacumulação dos compostos nos organismos (Chapman \& Mann, 1999; Linkov, 2001; Abessa, 2002).

Os ensaios ecotoxicológicos são reconhecidos como instrumentos eficazes para a determinação do significado biológico da contaminação de sedimentos costeiros (Carr et al., 1996a, 1996b, 2000). Em muitos casos há necessidade de integração das diversas metodologias de análises ambientais com o objetivo de identificar o composto causador da toxicidade, como as metodologias descritas para a Avaliação da Redução de Toxicidade desenvolvida pela USEPA (1989), que descrevem manipulações físicoquímicas de amostras direcionadas com as características dos possíveis contaminantes, como por exemplo, para redução da toxicidade de metais adiciona-se solução de EDTA, um quelante de metais, posteriormente faz-se o ensaio ecotoxicológicos para verificar se houve a redução da toxicidade.

Últimos estudos sobre a implementação da gestão de protocolos na Europa destaca a importância de diferentes linhas de evidências e ferramentas, por exemplo, ensaios ecotoxicológicos, biomarcadores, biomonitoramento, modelagem, etc. para a avaliação adequada de contaminação dos sedimentos e seus efeitos (Bocchetti et al, 2008; Schipper et al, 2010; Montero et al., 2013a).

Nos estudos com sedimento, as rotas de exposição podem ser quatro: sedimento total ou integral, água intersticial, elutriato e interface sedimento/água: 
Sedimento total ou integral: consiste na exposição de organismos bentônicos ao sedimento sem alteração, mantendo suas características físicas originais, não submetidas a tratamento prévio;

Água intersticial: consiste na água que ocupa os espaços entre as partículas sólidas do sedimento. O ensaio consiste na exposição de organismos de coluna de água à fração de contaminantes nela contidos. A água intersticial é considerada como a rota dominante de exposição para muitos organismos;

Elutriato: é a solução aquosa obtida após lavagem de uma amostra de sedimento. O ensaio ecotoxicológico é o mesmo utilizado para água intersticial;

Interface sedimento/água: exposição de organismos a água sobrejacente em recipientes contendo sedimentos. É utilizado para avaliar os efeitos de contaminantes na interface do sedimento com a água; (Nipper, 1997).

Os contaminantes responsáveis pela toxicidade podem ser observados e determinados através de procedimentos da Avaliação e Identificação da Toxicidade AIT (TIE - Toxicity Identification Evaluation) (Carr et al., 2001). A AIT é um método utilizado para caracterizar e identificar substâncias tóxicas em amostras ambientais e efluentes (USEPA, 1991c; Burgess et.al., 2000).

A AIT é um método importante para uso no processo do estudo de risco ecológico, pois fornece meios de investigação direta na identificação das causas da toxicidade, utilizando manipulações ou procedimentos que evidenciam ou excluem compostos tais como metais, amônia e substancias químicas orgânicas.

Esse método foi desenvolvido pela USEPA - Agência de Proteção Ambiental Norte Americana, como parte dos protocolos de Avaliação da Redução de Toxicidade (TRE - Toxicity Reduction Evaluation) para efluentes industriais (USEPA, 1989) e para efluentes municipais (USEPA, 1991b, 1999). O método foi desenvolvido para uso com 
amostras de águas, incluindo os efluentes urbanos e industriais, corpo receptor e águas intersticiais de sedimentos (Ankley et al., 1990; Ankley et al., 1991; Norberg-King et al., 1991; U.S. EPA 1991b; Amato JR et al, 1992; U.S. EPA 1993a, 1993b; Ankley \& Schubauer-Berigan, 1995; Burgess et al, 1995; Ho et al, 1997; Burgess et al., 2000).

Nas manipulações, comparando os resultados da amostra manipulada com a amostra do sedimento original, denominada linha de base, ou ensaio referência, identificamos os contaminantes ou mistura de contaminantes responsáveis pelos efeitos adversos observados (Montero et al., 2013). Os resultados dos ensaios ecotoxicológicos, após cada manipulação indicam ou não redução na toxicidade (USEPA, 2007; Ho \& Burgess, 2009).

Os procedimentos TIE são rotineiramente utilizados nos EUA, Canadá e Austrália para a avaliação do material dragado e a realização de avaliações de risco ambiental (Ho et al, 2002.; Anderson et al, 2007.; Simpson et al, 2007.; Ho e Burgess, 2009). A maioria dos estudos europeus foram realizados em água intersticial ou elutriates como os de Stronkhorst et al, 2003.; Fernández et al, 2008.; Macken et al, 2009.; Picone et al., 2009, devido à sua simplicidade na comparação com as manipulações do sedimento integral.

De acordo com Burgess et al. (2000) os esforços para desenvolver a AIT de sedimento são baseados no conceito de que três classes de substâncias tóxicas predominam neste substrato: amônia, metais e/ou orgânicos apolares. Este esforço resultou em uma abordagem de pesquisa em três vertentes divididas por essas classes de substâncias tóxicas.

A AIT apresenta a metodologia dividida em três fases distintas:

A) fase I (caracterização) consiste no fracionamento da amostra submetendo-a à identificação de agentes tóxicos, baseado na manipulação da amostra em suas 
características físico-químicas que alteram a biodisponibilidade dos agentes tóxicos e seguido de ensaios ecotoxicológicos, deste modo se verifica qual a manipulação que resultou em alguma alteração da toxicidade;

B) fase II (identificação) consiste no uso de técnicas analíticas convencionais específicas para cada grupo de compostos tóxicos;

C) fase III (confirmação) após a identificação dos prováveis compostos tóxicos estes podem ser confirmados por análises de correlações ou por resultados dos ensaios ecotoxicológicos padronizados para a mesma concentração do composto identificado, podendo assim considerar real a toxicidade causada pelo composto identificado.

A partir da segunda metade do século XIX o Brasil passou a apresentar elevação em taxas de crescimento econômico, em decorrência do incremento da atividade industrial, o que acaba também acarretando no crescimento dos impactos antrópicos. Como exemplo de regiões pouco impactadas e com elevada sensibilidade ecológica cita-se o Litoral Norte do Estado de São Paulo. Trata-se de região que reúne perspectivas de grande crescimento econômico com novas instalações de empresas, principalmente com atividades da exploração de poços de petróleo do PRÉ-SAL, bem como exploração de gás. Frise-se que o potencial de novas instalações e plantas industriais não pode ser dissociado de instalações antigas com altos impactos ambientais como o Porto e o Terminal Petrolífero, ambos com mais de 50 anos de operação, localizados no Canal de São Sebastião. Este crescimento local também faz com que ocorra a expansão imobiliária, que se não for ordenada também potencializará impactos antrópicos para a região.

A carência de estudos dos impactos causados pelo homem no Litoral Norte do Estado de São Paulo ressalta a necessidade de maiores conhecimentos da região em relação às atividades antrópicas poluidoras. Nessas circunstâncias, o objetivo deste 
trabalho é avaliar a toxicidade do sedimento das Enseadas de Ubatuba, do Flamengo, do Mar Virado e da Enseada de Caraguatatuba realizando ensaios ecotoxicológicos com água intersticial e embriões de Lytechinus variegatus, e identificar a toxicidade utilizando a Fase I do método de AIT (caracterização).

A Enseada de Ubatuba é um local sob influência de ocupação urbana contínua, com predomínio de população fixa e atividades de comércio e serviços, como pequenas marinas e garagens náuticas. Nesta enseada estão localizados dois pontos de estudos, um ponto na Praia do Perequê-Açu e outo na Praia do Itaguá. Na Enseada do Flamengo, o local de estudo está localizado próximo ao Saco da Ribeira com presença de uma grande marina náutica e outras de porte menor. O ponto de estudo da Enseada do Mar Virado está localizado na Ilha do Mar Virado. Este ponto apresenta, como característica, pouca atividade impactante direta, uma vez que não possui marina e ocupação urbana. A Enseada de Caraguatatuba apresenta características de ações antrópicas semelhantes à da Enseada de Ubatuba, com influência da ocupação urbana contínua, presença de população fixa e atividades industriais, de comércio e serviços (CETESB, 2012). 


\section{OBJETIVOS}

Este estudo tem como objetivo a avaliação ecotoxicológica e identificação dos grupos de compostos químicos, presentes no sedimento e responsáveis pela toxicidade, através do estudo da toxicidade da água intersticial nos municípios de Ubatuba e Caraguatatuba, pela aplicação do método Avaliação e Identificação da Toxicidade AIT.

De forma mais específica:

Avaliar a toxicidade de amostras de água intersticial de sedimentos de Ubatuba e Caraguatatuba, aplicando os procedimentos da Avaliação e Identificação de Toxicidade (AIT),

Identificar os grupos de compostos químicos responsáveis pela toxicidade da água intersticial,

Verificar a variabilidade sazonal dos efeitos observados 


\section{3. ÁREA DE ESTUDO}

A região de estudo está localizada no litoral norte do Estado de São Paulo, no Município de Ubatuba, nas enseadas de Ubatuba, do Flamengo e do Mar Virado e no Município de Caraguatatuba, Enseada de Caraguatatuba. (Figura 1).

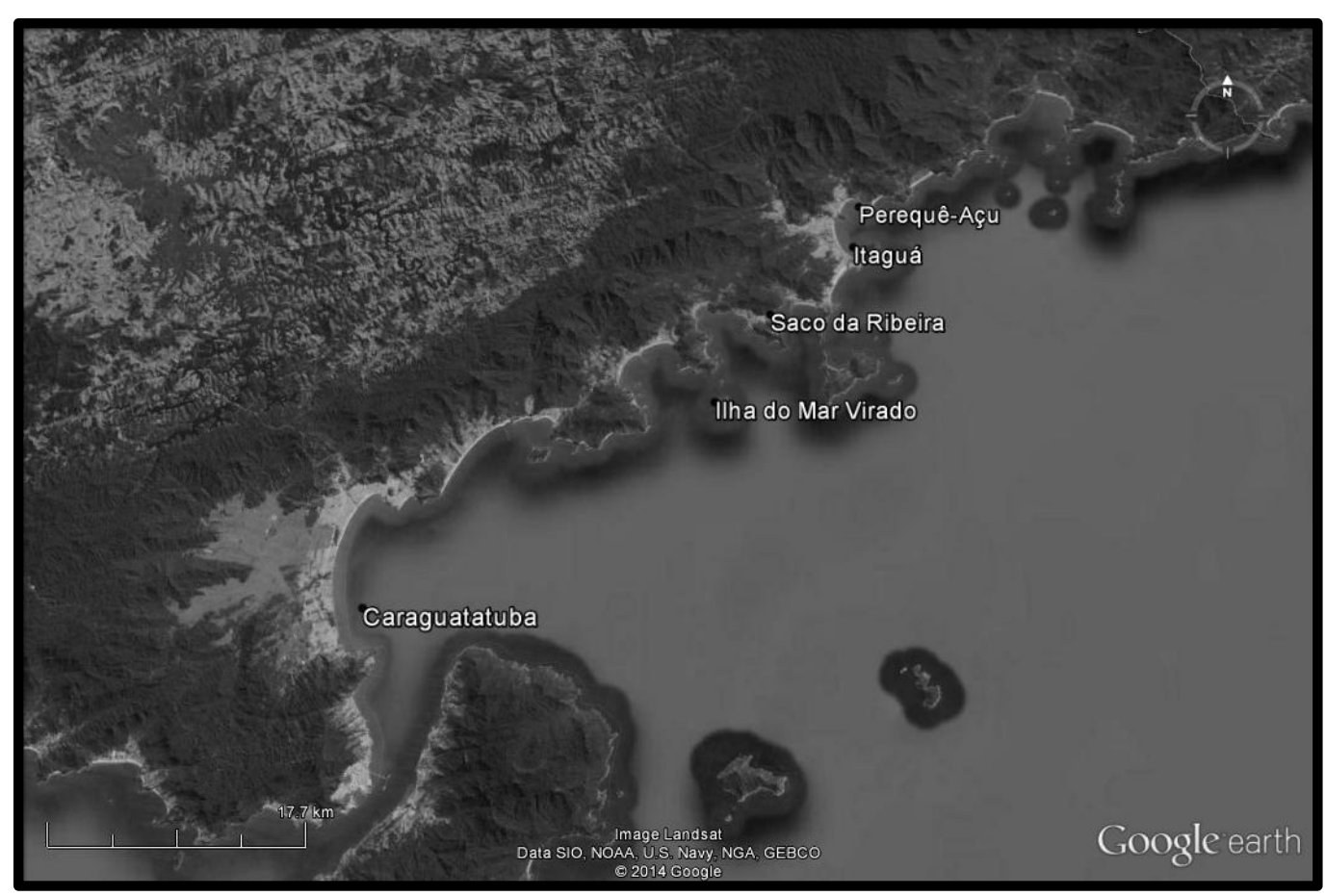

Figura 1. Localização da área de estudo (imagem: Google Earth).

\subsection{Enseada de Ubatuba}

A Enseada de Ubatuba situa-se defronte à sede do município de Ubatuba, entre a Ponta Grossa ao sul e a Ponta do Alegre ao norte. Suas águas abrigam as praias de Itaguá, Iperoig, Prainha do Matarazzo, Perequê-Açu e Barra Seca. Trata-se de praias urbanas, com ocupação contínua predominante de população fixa e atividades de comércio e serviços. No seu interior, estão localizados o Farol da Ponta Grossa e o cais do Porto de Ubatuba. Nela deságuam os rios Acaraú, Lagoa (ou Tavares), Grande e Indaiá (CETESB, 2012) e se caracteriza por apresentar uma linha de costa muito 
recortada, com várias enseadas e baías semiconfinadas. Essa característica faz com que o processo de troca de água e material sedimentar entre a zona costeira e a plataforma adjacente seja restrito, quando comparadas às do litoral sul (Mahiques, 1995) (Figura 2).

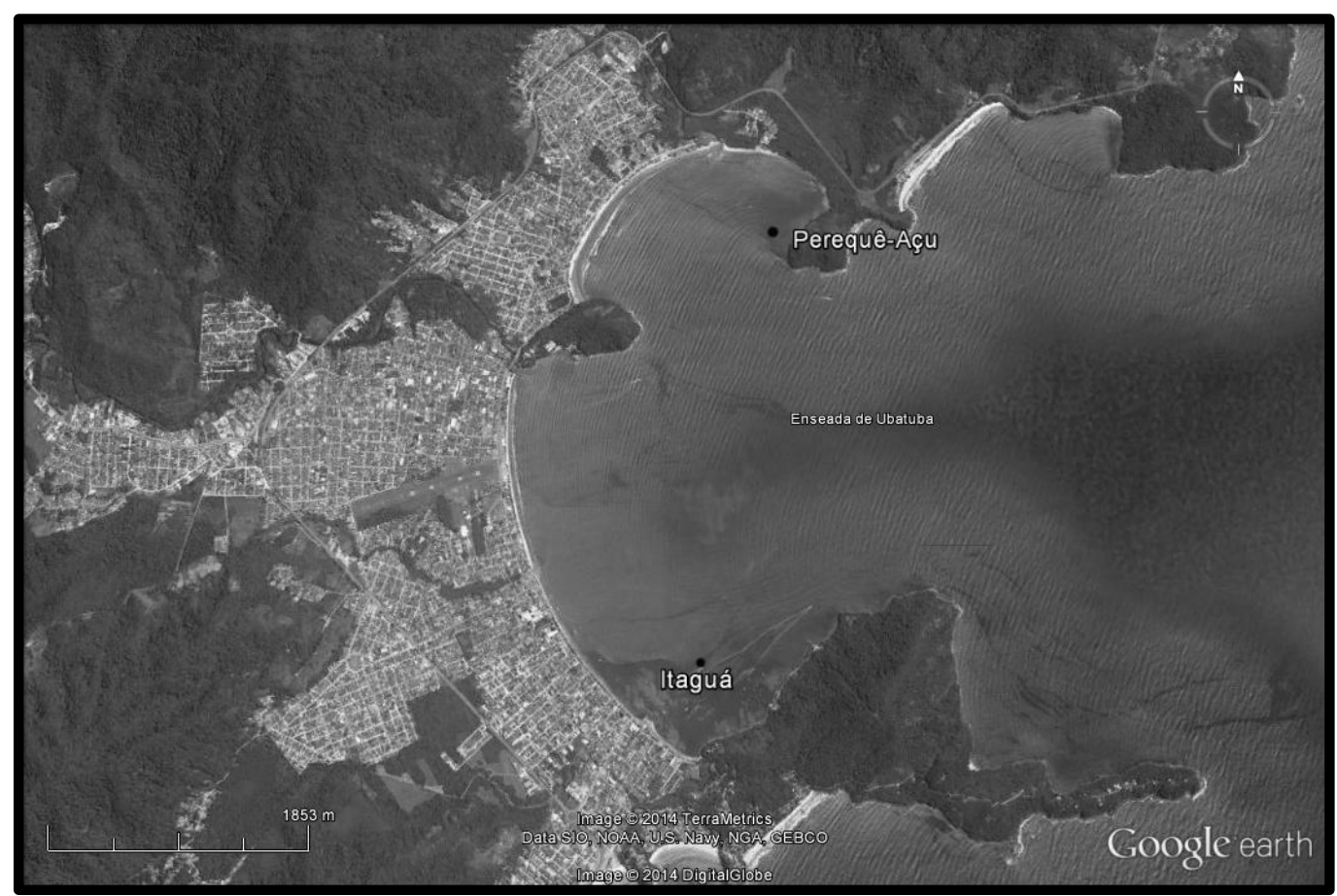

Figura 2. Enseada de Ubatuba com indicação dos pontos de coleta (imagem: Google Earth).

Segundo Mahiques et al. (1998) a Enseada de Ubatuba possui uma abertura de 4,4 km delimitada pela Ponta do Respingador e pela Ponta Grossa, sendo assim protegida das ondas de sul e sudoeste. No seu interior observam-se dois estrangulamentos, o primeiro delimitado pela Ponta Alegre e Ponta Surutuva, limite da porção externa para a interna, e o segundo marcado pela Ponta Alegre e Ponta do Curuçá, formando o Saco do Perequê-Açú (Muniz, 2003).

Neste local a circulação ocorre em sentido horário com entrada de água pelo sul. A entrada de sedimentos pelos rios é fortemente dependente do regime de chuvas (Mahiques, 1998). Os quatro rios que desembocam na Enseada de Ubatuba influenciam de maneira substancial na qualidade das águas, especialmente durante os períodos de 
chuvas, quando grandes quantidades de esgoto não tratado, proveniente da cidade de Ubatuba são introduzidas na Enseada (Burone, 2002).

Segundo Mahiques (1992) a Enseada de Ubatuba apresenta grande heterogeneidade granulométrica. Os sedimentos mais grossos se concentram em uma faixa margeando o costão em direção norte e leste da Ponta Surutuva. Os sedimentos mais finos depositam-se em um núcleo localizado entre as isóbata de 5 e 10 metros a noroeste da Ponta Surutuva.

\subsection{Enseada do Flamengo}

A Enseada do Flamengo possui aproximadamente $18 \mathrm{Km}^{2}$ de superfície e, em média 2,5 km de largura, com profundidade máxima de $14 \mathrm{~m}$. Com direção norte-sul tem uma praia extensa a noroeste e duas pequenas baías: Saco do Perequê-Mirim e Saco da Ribeira (Ghiseli Jr, 2006) (Figura 3). Nesta região temos a Marina Píer do Saco da Ribeira, pública, administrada pela Fundação Florestal que oferece serviços de garagem náutica, atracação para carga e descarga, pesca e transporte para o Parque Estadual da Ilha Anchieta, além de postos de abastecimento flutuantes para embarcações; abriga também uma base do Instituto Oceanográfico da Universidade de São Paulo, localizada no interior da Baía do Flamengo, no trecho sul do município de Ubatuba, onde predomina uma ocupação descontínua por população flutuante. Este local apresenta grande concentração de estabelecimentos voltados para o turismo e atividades náuticas, devido à instalação de píeres e atracadouros. Em decorrência do intenso uso e ocupação, sua praia foi praticamente destruída, reduzida a poucos metros de faixa de areia (CETESB, 2012). 


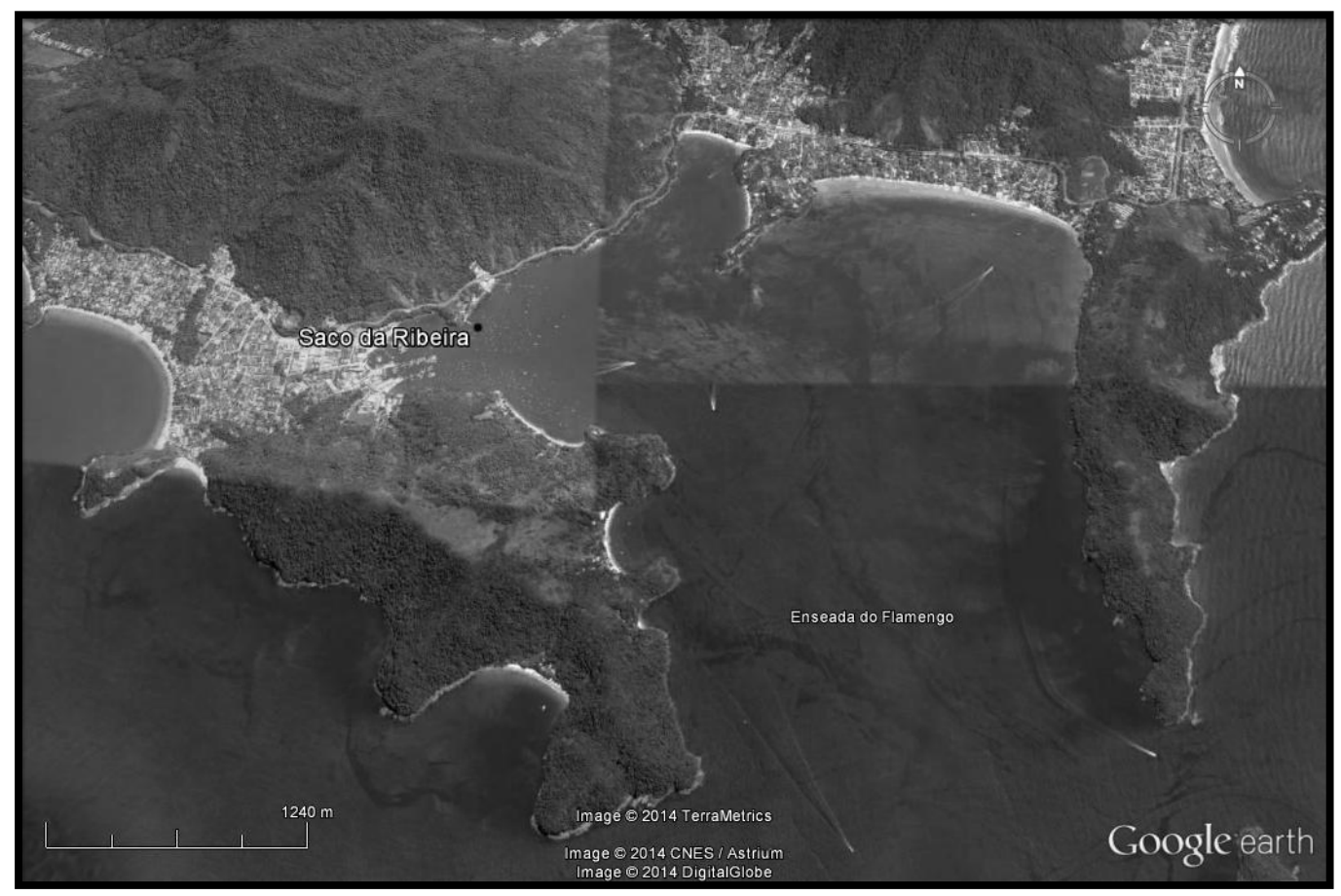

Figura 3. Enseada do Flamengo com indicação do ponto de coleta (imagem: Google Earth).

Essa enseada apresentando-se como um ambiente semiconfinado, com circulação padrão caracterizada pela entrada de correntes vindas de sul e, seu lado ocidental, margeando a costa ocidental, bifurca-se em direção ao Saco da Ribeira, cujo padrão de circulação exerce pouca influência (Magliocca \& Kurtner, 1965). Tal padrão de circulação reflete-se na distribuição dos sedimentos, ocorrendo deposição de sedimentos de granulometria maior na parte ocidental. Os sedimentos são geralmente uma mistura de areia fina, ocorrendo areia grossa apenas onde há contribuição local, o que indica um ambiente de baixa energia (Eichler, 1982; Mahiques, 1992; Ghiselli Jr, 2006). 


\subsection{Enseada do Mar Virado}

A Enseada do Mar Virado (figura 4) apresenta-se voltado para sudeste, com desembocadura com cerca de seis (6) $\mathrm{km}$ de largura, onde se encontra as maiores profundidade, cerca de 10 metros. A parte interna recebe a descarga de duas bacias de drenagem, sendo uma do rio Maranduba e a outra do rio Lagoinha. Existe o domínio de duas massas d’água, a Agua Costeira (AC) e a Agua da Plataforma (AP) com salinidade em torno de 35 e a temperatura $25^{\circ} \mathrm{C}$ (Mahiques, 1992).

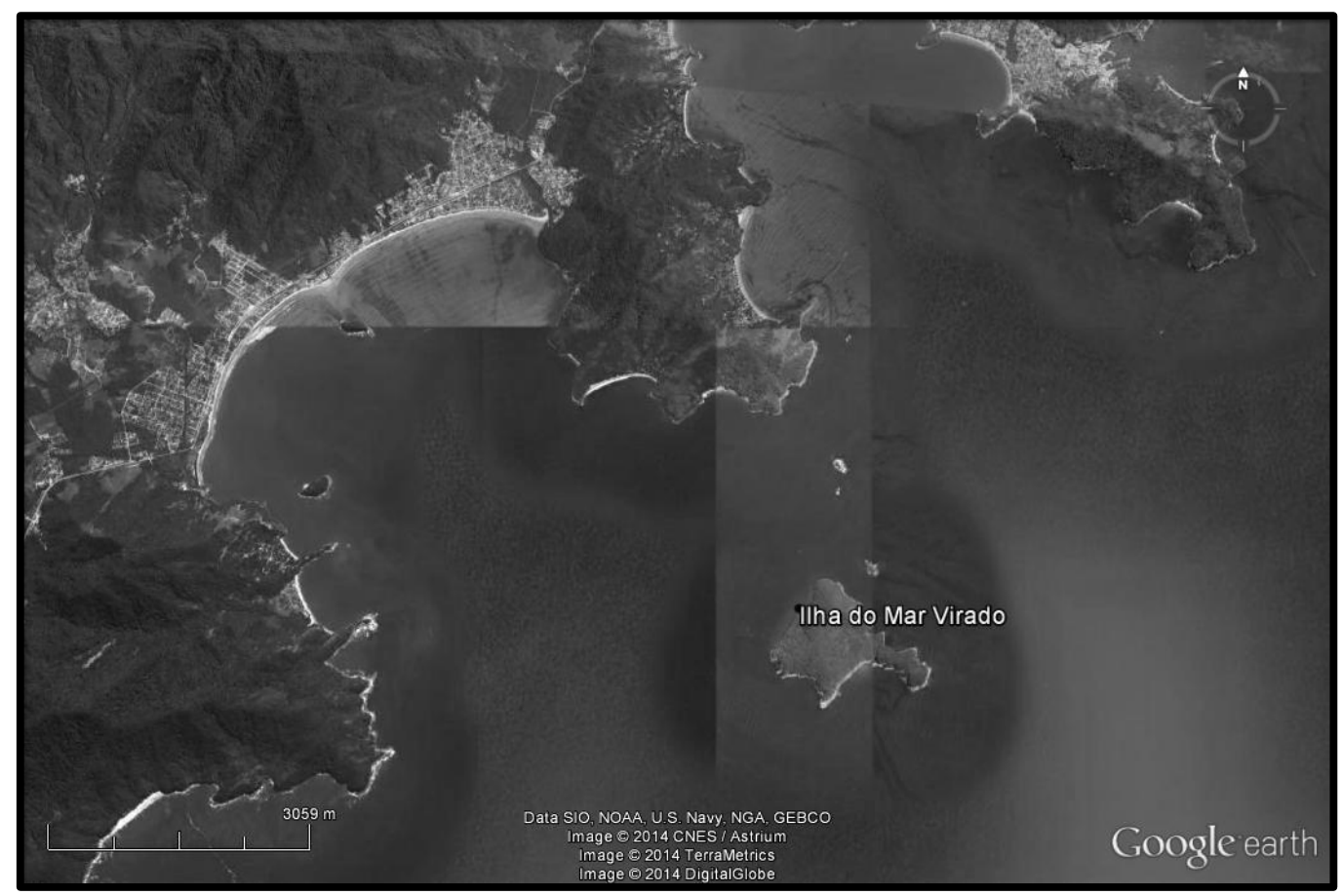

Figura 4. Enseada do Mar Virado com indicação do ponto de coleta- Ilha do Mar Virado (imagem: Google Earth).

No verão ocorre a presença de águas frias atribuída ao deslocamento da Água Central do Atlântico Sul (ACAS) sobre a plataforma continental sudeste (Furtado et al., 1987) originária do talude continental, avança sobre as regiões mais internas da plataforma, formando uma termoclina marcante, a profundidades de 10 e 20 metros. 
Segundo Mahiques (1992), a distribuição de sedimentos, em relação argila/silte, mostra diferenciação ente a área interna e externa (localização do ponto amostral), com aumento dessa relação na parte externa da enseada.

\subsection{Enseada de Caraguatatuba}

A Enseada de Caraguatatuba encontra-se protegida da incidência direta das ondas devido à presença da Ilha de São Sebastião. É uma área rasa de baixa energia que possui sedimentos finos e pouco selecionados (Souza, 1990). Na porção sul existe uma extensa planície de maré irrigada por uma importante rede fluvial, sendo o Juqueriquerê o principal rio. Nesta planície os processos deposicionais são bastante efetivos (Furtado, 1995) (Figura 5).

Esta enseada situa-se defronte à sede do município de Caraguatatuba, abriga as praias de Porto Novo, Fleixeiras, Romance, Palmeiras, Lagoa, Aruan, Indaiá, Centro e Camaroeiro. Todas essas praias são urbanas, com ocupação contínua predominante de população fixa e atividades de comércio e serviços e vem aumentando com a atividade industrial da Unidade de Tratamento de Gás do Campo de Mexilhão (Petrobras). Os principais rios que deságuam na baía são o Rio Santo Antônio, o Rio Lagoa e o Rio Juqueriquerê, o maior dos três (CETESB, 2012).

A bacia de drenagem do Rio Juqueriquerê meandra a planície costeira de Caraguatatuba, atravessando depósitos fornecedores de material em suspensão e sedimentos que são transportados para fora da planície de maré. Devido à baixa hidrodinâmica associada aos fluxos de maré, que não possuem competência para remobilizar e transportar os sedimentos mais grosseiros trazidos pelo rio, estes se 
depositam nas proximidades da desembocadura, promovendo frequentemente a formação de uma barra arenosa paralela à praia (Souza, 1990).

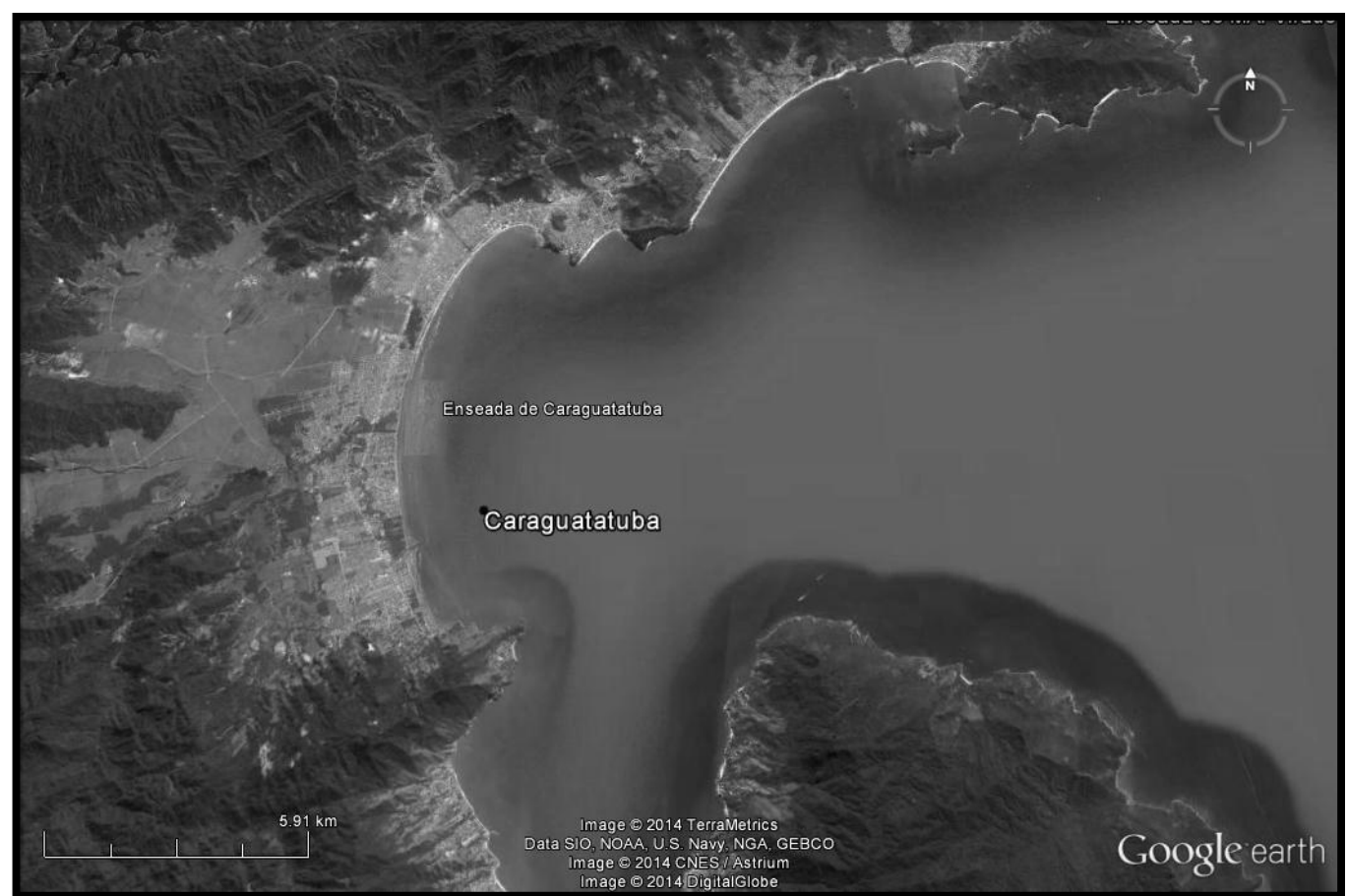

Figura 5. Enseada de Caraguatatuba com indicação do ponto de coleta (imagem: Google Earth).

Os nomes dos pontos e sua localização são: na Enseada de Ubatuba os pontos Perequê-Açu e Itaguá, na Enseada do Flamengo o ponto Saco da Ribeira, na Enseada do Mar Virado o ponto Ilha do Mar Virado (IMV) e na Enseada de Caraguatatuba o ponto Caraguatatuba.

Abaixo estão listadas as coordenadas de localização dos pontos de coleta. 
Tabela 1. Coordenadas de localização dos pontos de coletas.

\begin{tabular}{ccc} 
Estação & Latitude & Longitude \\
\hline Perequê-Açu & $23^{\circ} 25.374$ & $45^{\circ} 03.049$ \\
Itaguá & $23^{\circ} 27.167$ & $45^{\circ} 03.289$ \\
Saco da Ribeira & $23^{\circ} 30.091$ & $45^{\circ} 07.086$ \\
I. do Mar Virado & $23^{\circ} 33.777$ & $45^{\circ} 09.599$ \\
Caraguatatuba & $23^{\circ} 41.926$ & $45^{\circ} 24.508$ \\
\hline
\end{tabular}




\section{MATERIAL E MÉTODOS}

\subsection{Coleta das amostras}

Nas campanhas, em 2011, as coletas foram realizadas nos meses de abril (outono), julho (inverno) e outubro (primavera) enquanto em 2012 foram coletadas em fevereiro/março (verão), utilizando a embarcação de pesquisa Velliger II do Instituto Oceanográfico - USP (figura 6). As amostras, para extração da água intersticial foram coletadas com pegador Van Veen. Após coletadas as amostras foram acondicionadas em sacos plásticos, devidamente etiquetados, e permaneceram em caixas de isopor com gelo até chegarem ao laboratório da Base Norte (Clarimundo de Jesus) do Instituto Oceanográfico - USP. Logo que chegaram ao laboratório, as amostras foram submetidas à extração da água intersticial.

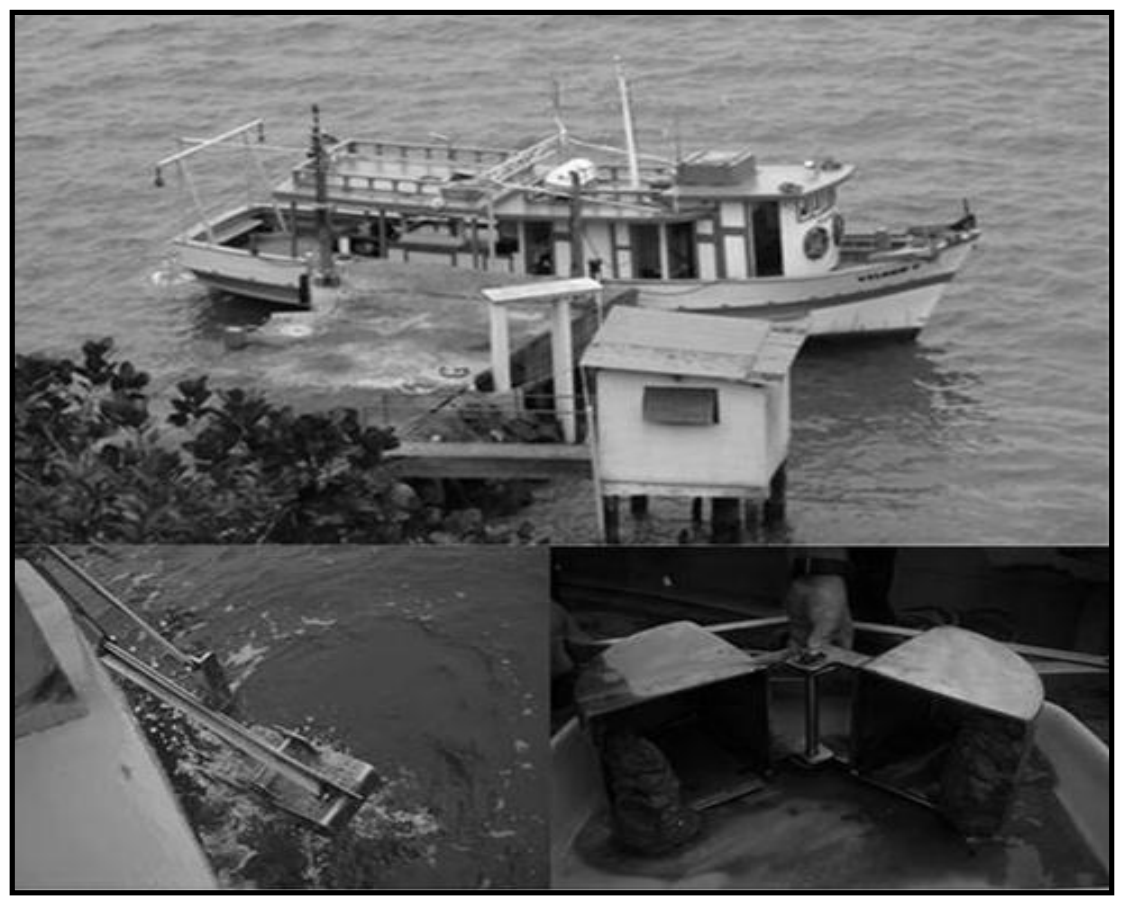

Figura 6. Embarcação Velliger II e o pegador de fundo modelo Van-Veen utilizados para as coletas das amostras (Foto: Luís Fabiano J. de Oliveira). 


\subsection{Extração e Preparo da Água Intersticial}

A extração da água intersticial foi realizada pelo método de sucção descrito por Winger \& Lasier (1991) (Figura 7). De acordo com este método, foram usadas seringas hipodérmicas de $60 \mathrm{~mL}$, ligadas a pedras porosas por meio de uma cânula de silicone de aproximadamente $20 \mathrm{~cm}$. As cânulas com as pedras porosas na ponta foram inseridas no sedimento e os êmbolos das seringas foram puxados e travados o que possibilitou exercer uma pressão negativa dentro da seringa fazendo a água passar lentamente pelo sistema, sendo então armazenada na seringa. Após a obtenção do volume necessário para os ensaios as amostras de água intersticial foram mantidas em temperatura de $4^{\circ} \mathrm{C}$ até a sua utilização, o que ocorreu até 24 horas após a extração em todos os pontos amostrados exceto três pontos, Saco da Ribeira, Ilha do Mar Virado e Caraguatatuba coletados na campanha da primavera de 2011, que após a extração da água intersticial essas amostras foram colocadas em geladeira $\left(4^{\circ} \mathrm{C}\right)$ por 24 horas para decantar as partículas em suspensão. Após a decantação a parte superior das amostras foi retirada e congelada sendo utilizada posteriormente.

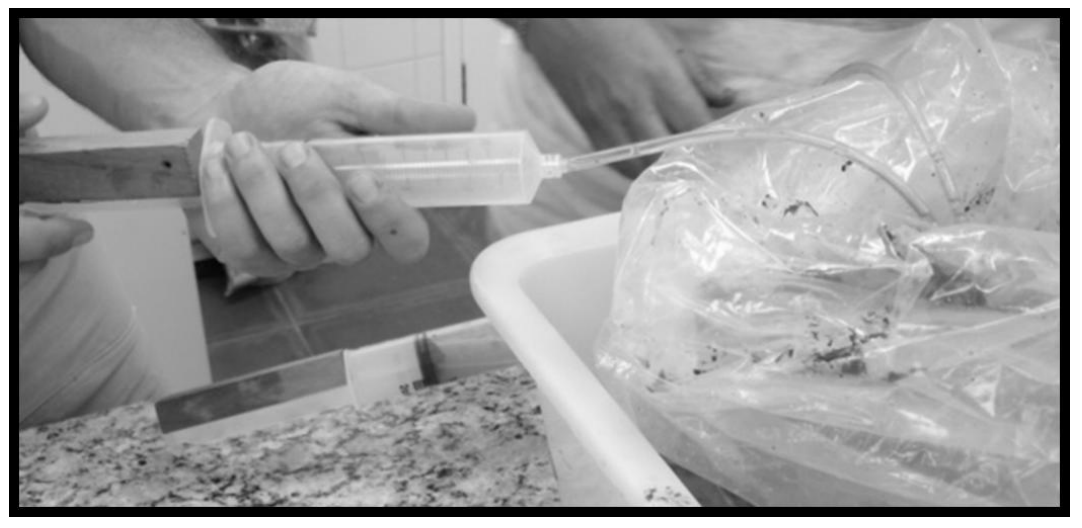

Figura 7. Extração da água intersticial (Foto: Lab. de Ecotoxicologia Marinha IOUSP). 
As manipulações realizadas da Fase I (caracterização), foram:

* Ensaio de Referência (ER);

* Aeração;

* Adição de EDTA;

* Adição de tiossulfato de sódio;

* Manipulação do pH para 7;

* Manipulação do pH para 9;

* Filtração;

* Extração em fase sólida por coluna de C18;

* Manipulação do pH para 3 seguido de filtração e

* Manipulação do pH para 11 seguido de filtração.

Na Figura 7, abaixo, está representada a ordem de atividades realizadas. 


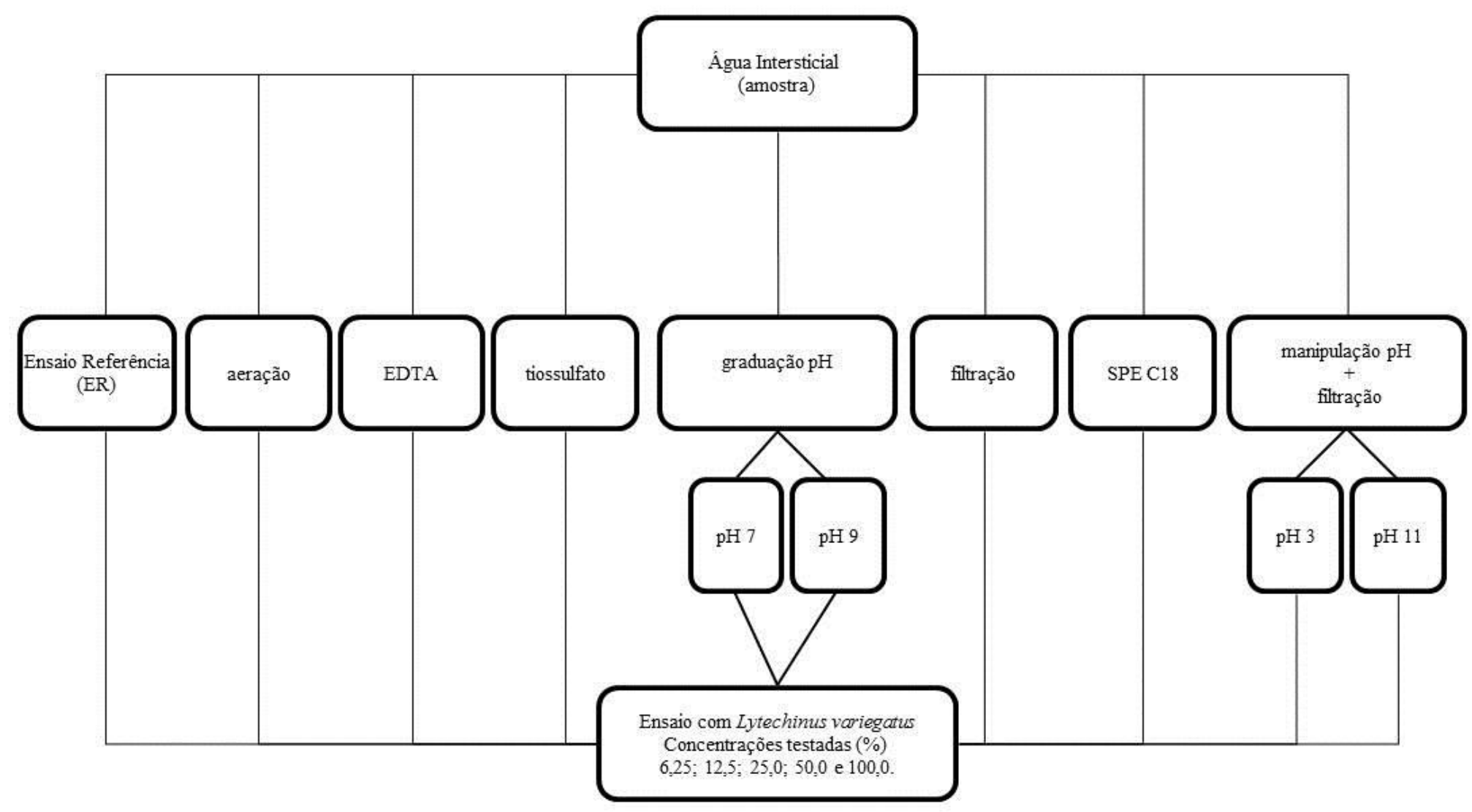

Figura 8. Fluxograma da AIT Fase I. 
Os princípios gerais de cada manipulação estão descritos abaixo (USEPA, 1991a, b e 2007):

Ensaio Referência (ER): No ensaio referência a subamsotra foi diluída nas concentrações 6,$25 ; 12,5 ; 25,0 ; 50,0$ e $100 \%$ e realizado ensaio de toxicidade crônica com desenvolvimento embriolarval de Lytechinus variegatus (ver pag. 25).

Aeração: Esta manipulação tem como função a eliminação ou redução dos compostos voláteis ou oxidáveis das amostras, tais como hidrocarbonetos voláteis, $\mathrm{H}_{2} \mathrm{~S}$, ou outros. A subamostra foi submetida à areação, feita com bombas de aquário, com fluxo de ar controlado por reguladores, para uma aeração suave com produção de bolhas pequenas por um período de uma hora. Após esse procedimento a subamostra foi diluída nas concentrações 6,$25 ; 12,5 ; 25,0 ; 50,0$ e $100 \%$ e utilizada no ensaio de toxicidade crônica com Lytechinus variegatus.

Adição de EDTA (ácido etilenodiaminotetracético): Este procedimento foi realizado com o objetivo de redução da disponibilidade de metais na amostra. O ETDA é um agente quelante muito forte, assim cátions são fortemente quelados, principalmente os de alumínio $\left(\mathrm{Al}^{3+}\right)$, cádmio, cobalto, cobre, estrôncio, ferro, chumbo, manganês $\left(\mathrm{Mn}^{2+}\right)$, níquel e zinco. O EDTA tem baixa especificidade para prata, cromo e complexos não metais aniônicos. O EDTA também pode reduzir a toxicidade de surfactantes catiônicos. Inicialmente preparou-se uma solução estoque de 27,8 g.L ${ }^{-1}$ de EDTA, sendo adicionado à subamostra um volume de $150 \mu \mathrm{L}$ para cada $100 \mathrm{~mL}$ da mesma, o que segundo Burgess et al.(1996) e Badaró-Pedroso (1999) fica abaixo do limite de tolerância para a espécie utilizada neste trabalho, sendo a quantidade de EDTA adicionada suficiente para se associar aos metais e reduzir a toxicidade, sem causar efeito tóxico. Após a adição do EDTA esperou-se 3 horas para que os compostos 
metálicos reagissem, e posteriormente realizou-se o ensaio de toxicidade crônica com Lytechinus variegatus, com as diluições 6,$25 ; 12,5 ; 25,0 ; 50,0$ e $100 \%$.

Adição de Tiossulfato de Sódio: A adição deste sal tem como objetivo reduzir a concentração de alguns compostos oxidantes como cloro, ozônio, dióxidos, mono e dicloroaminas, brominas, íons de manganês, iodo e alguns orgânicos hidrofílicos. Alguns cátions também podem ser quelados pelo tiossulfato de sódio, reduzindo também a toxicidade de alguns metais como cobre, cádmio, mercúrio, prata e selênio. Neste procedimento preparou-se uma solução estoque de tiossulfato de sódio contendo 23,5 g.L $\mathrm{L}^{-1}$ de $\mathrm{Na}_{2} \mathrm{~S}_{2} \mathrm{O}_{3}$. A quantia de $250 \mu \mathrm{L}$ foi adicionada para cada $100 \mathrm{~mL}$ de subamostra. Após a adição da solução à subamostra aguardou-se no mínimo 1 hora para as reações de redução fossem realizadas, testando então as subamostras nas diluições 6,$25 ; 12,5 ; 25,0 ; 50,0$ e $100 \%$ em ensaio de toxicidade crônica com Lytechinus variegatus.

Manipulação do $\mathrm{pH}$ : A variação induzida do $\mathrm{pH}$ tem como finalidade promover a redução ou aumento da toxicidade através da alteração do equilíbrio de alguns compostos presentes na amostra, principalmente amônia $\left(\mathrm{NH}_{3}{ }^{+}\right)$que na forma não ionizada $\left(\mathrm{NH}_{3}\right)$, mais tóxica, predomina em pH básico e o sulfeto de hidrogênio $\left(\mathrm{H}_{2} \mathrm{~S}\right)$ onde a sua toxicidade é maior em $\mathrm{pH}$ ácido. As alterações de $\mathrm{pH}$ também podem afetar a toxicidade de muitos pesticidas ionizáveis, e alterar a biodisponibilidade e toxicidade de alguns metais e surfactantes. $\mathrm{O}$ pH da amostra foi alterado para 7 e para 9 . A redução do pH foi realizada com a adição de uma solução de ácido clorídrico 0,1 e/ou 1N, enquanto para aumento do pH foi adicionado uma solução de hidróxido de sódio 0,1 e/ou $1 \mathrm{~N}$, utilizando-se um agitador magnético com uma barra magnética e um $\mathrm{pH}$ metro. Após as alterações foi realizado o ensaio de toxicidade crônica com Lytechinus variegatus com as diluições 6,$25 ; 12,5 ; 25,0 ; 50,0$ e $100 \%$ desta subamostra. 
Filtração: Este procedimento é utilizado para verificar se a toxicidade é em função da presença de material particulado e/ou adsorvido a estas partículas. Utilizando uma bomba de vácuo com baixa pressão, foi efetuada uma filtração utilizando filtros de éster de celulose, tipo Millipore ${ }^{\circledR}$ com porosidade de $0,45 \mu \mathrm{m}$, retirando assim o material sólido em suspensão. Após esta manipulação a subamostra foi diluída nas concentrações 6,$25 ; 12,5 ; 25,0 ; 50,0$ e $100 \%$ e testada posteriormente em ensaio de toxicidade crônica com Lytechinus variegatus.

Extração da fase sólida em coluna de C18 (coluna de octadecil): Este procedimento tem como finalidade reduzir ou eliminar compostos orgânicos e complexos metálicos não polares e surfactantes. A redução ou eliminação ocorre, com os compostos citados acima, com a ligação à resina da coluna de $\mathrm{C} 18$, fazendo com que eles fiquem retidos na coluna não sendo mais disponíveis para a fase líquida restante. Para ativar a coluna, foram utilizadas $20 \mathrm{~mL}$ de metanol, que foi passada pela coluna seguida de $15 \mathrm{~mL}$ de água destilada. Posteriormente a passou a subamostra do branco e em seguida a subamostra a ser manipulada, sem deixar a coluna secar. Os primeiros 20 $\mathrm{mL}$ da subamostra do branco devem ser descartados para evitar uma possível contaminação pelo metanol. Após este procedimento a subamostra foi submetida ao ensaio de toxicidade crônica com Lytechinus variegatus e nas diluições 6,25; 12,5; 25,0; 50,0 e $100 \%$.

Manipulação do $\mathrm{pH}+$ filtração: Essas alterações no $\mathrm{pH}$ podem alterar a solubilidade, polaridade, volatilidade, estabilidade e biodisponibilidade dos compostos e com isso a toxicidade, principalmente de ácidos e bases. Muitos compostos orgânicos e inorgânicos podem ser degradados em função da alteração de $\mathrm{pH}$, com consequente perda da toxicidade. Especialmente em $\mathrm{pH}$ 11, pode haver precipitação de compostos metálicos e orgânicos pelo processo de adsorção, levando à diminuição da toxicidade. A 
alteração do $\mathrm{pH}$ foi para 3 e para 11, após essa alteração a subamostra foi filtrada utilizando-se uma bomba de vácuo e filtros de éster de celulose, tipo Millipore ${ }^{\circledR}$ com porosidade de $0,45 \mu \mathrm{m}$. A redução do $\mathrm{pH}$ foi realizada com a adição de uma solução de ácido clorídrico 0,1 e/ou $1 \mathrm{~N}$, e o aumento do $\mathrm{pH}$ foi realizado adicionando-se uma solução de hidróxido de sódio de o,1 e/ou 1N. Estes procedimentos foram realizados utilizando um agitador magnético com uma barra magnética e um pH-metro. Posteriormente fez-se as diluições da subamostra $(6,25 ; 12,5 ; 25,0 ; 50,0$ e $100 \%)$ realizando o ensaio de toxicidade crônica com Lytechinus variegatus.

Em paralelo, amostras de água do mar, filtradas em filtros de éster de celulose, tipo Millipore ${ }^{\circledR}$ com porosidade de $0,45 \mu \mathrm{m}$, coletadas em locais livres de contaminação foram manipuladas para cada procedimento a fim de se obter uma amostra denominada de BRANCO e suas diluições $(6,25 ; 12,5 ; 25,0 ; 50,0$ e $100 \%)$ para comparações com os procedimentos realizados. Estas foram utilizadas para o ensaio de toxicidade crônica com desenvolvimento embriolarval de Lytechinus variegatus (ver pag. 25).

\subsection{Ensaio ecotoxicológico com Lytechinus variegatus}

Para a avaliação da toxicidade da água intersticial o método usado foi o ensaio de toxicidade crônico, de curta duração, com embriões do ouriço-do-mar da espécie Lytechinus variegatus, padronizado pela ABNT: NBR 15350 (2006).

Ouriços-do-mar adultos foram coletados, por meio de mergulho livre em Ubatuba e transportados dentro de caixas térmicas com cerca de cinco (5) cm de água do mar. Ao chegar à base de pesquisa do IOUSP, os ouriços-do-mar foram transferidos e mantidos em tanque com água do mar e aeração constante. A alimentação foi feita com folhas de alface e pedaços de cenoura. A manutenção da qualidade da água dos 
tanques foi realizada diariamente com a limpeza do fundo do tanque e verificação da salinidade e volume de água do mesmo.

Os ouriços-do-mar foram induzidos a liberar seus gametas através da injeção de 3,0 mL de $\mathrm{KCl}$ (cloreto de potássio a 0,5 M) na região peri-oral de cada organismo. Foram utilizados espermas e óvulos de pelo menos três machos e três fêmeas, respectivamente, sendo os óvulos previamente selecionados pela observação de seu grau de maturação sob microscópio com aumento de 100X.

A coleta dos óvulos foi realizada com a superfície aboral do animal voltada para baixo em um béquer de $400 \mathrm{~mL}$ contendo água do mar filtrada em Millipore ${ }^{\circledR} \mathrm{HA}$ 0,45 $\mu \mathrm{m}$. Posteriormente, os óvulos foram lavados com auxílio de uma peneira, e então colocados em outro béquer com água do mar filtrada.

O líquido espermático de três machos foi coletado a seco com o auxílio de uma pipeta Pasteur e colocado em um béquer com capacidade para $25 \mathrm{~mL}$, mantido em caixa isotérmica com gelo até o momento de sua utilização.

Para promover a fecundação, $0,5 \mathrm{~mL}$ do esperma coletado foi diluído em 24,5 $\mathrm{mL}$ de água do mar filtrada, e dessa solução espermática, 1,0 mL foi adicionado à solução de óvulos. A fecundação foi constatada pela formação da membrana de fecundação, visível em microscópio com aumento de 100X. Após a fecundação foi determinada a concentração de ovos na solução por meio da contagem de 3 subamostras desta solução diluídas em água do mar filtrada na razão de 1/100. Após este procedimento foi adicionada uma alíquota da solução de ovos com concentração com cerca de 300 a 400 ovos em cada tubo de ensaio contendo as amostras a serem testadas, sendo quatro réplicas por concentração testada. $\mathrm{O}$ volume adicionado em cada tubo não ultrapassou $100 \mu \mathrm{L}$. 
$\mathrm{O}$ ensaio foi mantido em temperatura constante de $25 \pm 2^{\circ} \mathrm{C}$ por meio de sala climatizada. Entre 24 a 26 horas após o início do mesmo, quando $80 \%$ ou mais embriões no controle atingiram o estágio de plúteos (Figura 9), o experimento foi encerrado e o material de cada réplica foi fixado em recipientes de acrílico, com 4 gotas de formol a 40\%, tamponado com bórax, para posterior contagem das 100 primeiras larvas encontradas. A contagem foi realizada em microscópio óptico com aumento de 100X, com auxílio de uma câmara de contagem do tipo Sedgwick-Rafter.

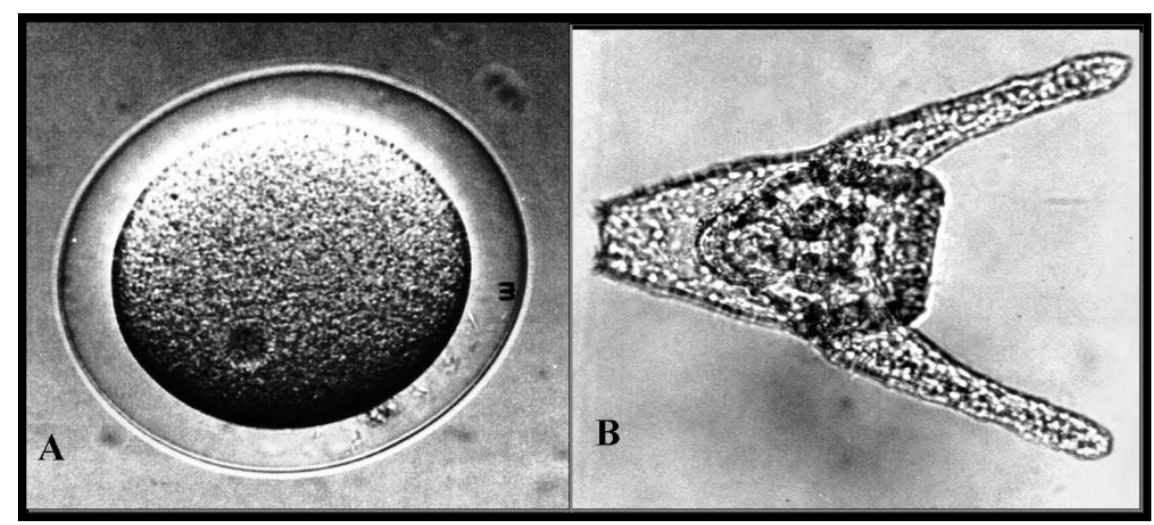

Figura 9. Ovo de Lytechinus variegatus (A) e larva pluteus normal com cerca de $24 \mathrm{~h}$ de desenvolvimento (B).( Foto: Lab. de Ecotoxicologia Marinha - IOUSP)

A sensibilidade do lote de embriões utilizado no ensaio de toxicidade foi avaliada por um ensaio com substância de referência, o tensoativo aniônico Dodecil Sulfonato de Sódio - DSS. O procedimento foi o mesmo descrito anteriormente, porém, neste ensaio os organismos foram expostos a cinco diferentes concentrações de DSS $(5,0 ; 2,5 ; 1,25 ; 0,63 ; 0,32 \mathrm{mg} / \mathrm{L}$ de DSS $)$ com quatro réplicas para cada concentração. Como água de diluição foi utilizada água-do-mar natural filtrada em filtros Millipore ${ }^{\circledR}$ HA $0,45 \mu \mathrm{m}$. 


\subsection{Análise Estatística}

Para efetuar as análises estatísticas foi utilizado o pacote estatístico BioEstat 5.3 .

\subsubsection{Validação dos resultados da AIT}

Para validar as manipulações realizadas neste trabalho, foram realizadas as mesmas manipulações com á agua usada como controle/branco, assim verificando que as manipulações não são os causadores da toxicidade.

A validação dos resultados obtidos nas manipulações da AIT com a agua controle seguiram dois critérios, sendo o primeiro critério foi:

1. Obter média das réplicas igual ou superior a $80 \%$ de larvas normais na concentração de $100 \%$;

2. Analisar estatisticamente os resultados obtidos na concentração de $100 \%$ de cada manipulação com média inferior a $80 \%$ com o controle, denominado branco para verificação de semelhança significativa.

Para a validação dos resultados da AIT, realizados com a agua do controle, foi analisada a normalidade dos dados através do teste de Lilliefors.

Para os dados com normalidade usou os Test t Student com índice de diferença significativa $\mathrm{p}<0,05$. Para os dados que se apresentam com não normalidade utilizou o Teste Mann-Whitney (teste u) com $\mathrm{p}<0,05$ de índice de diferença significativa, portanto a manipulação não se apresentou válida, como demostrado na figura abaixo. 


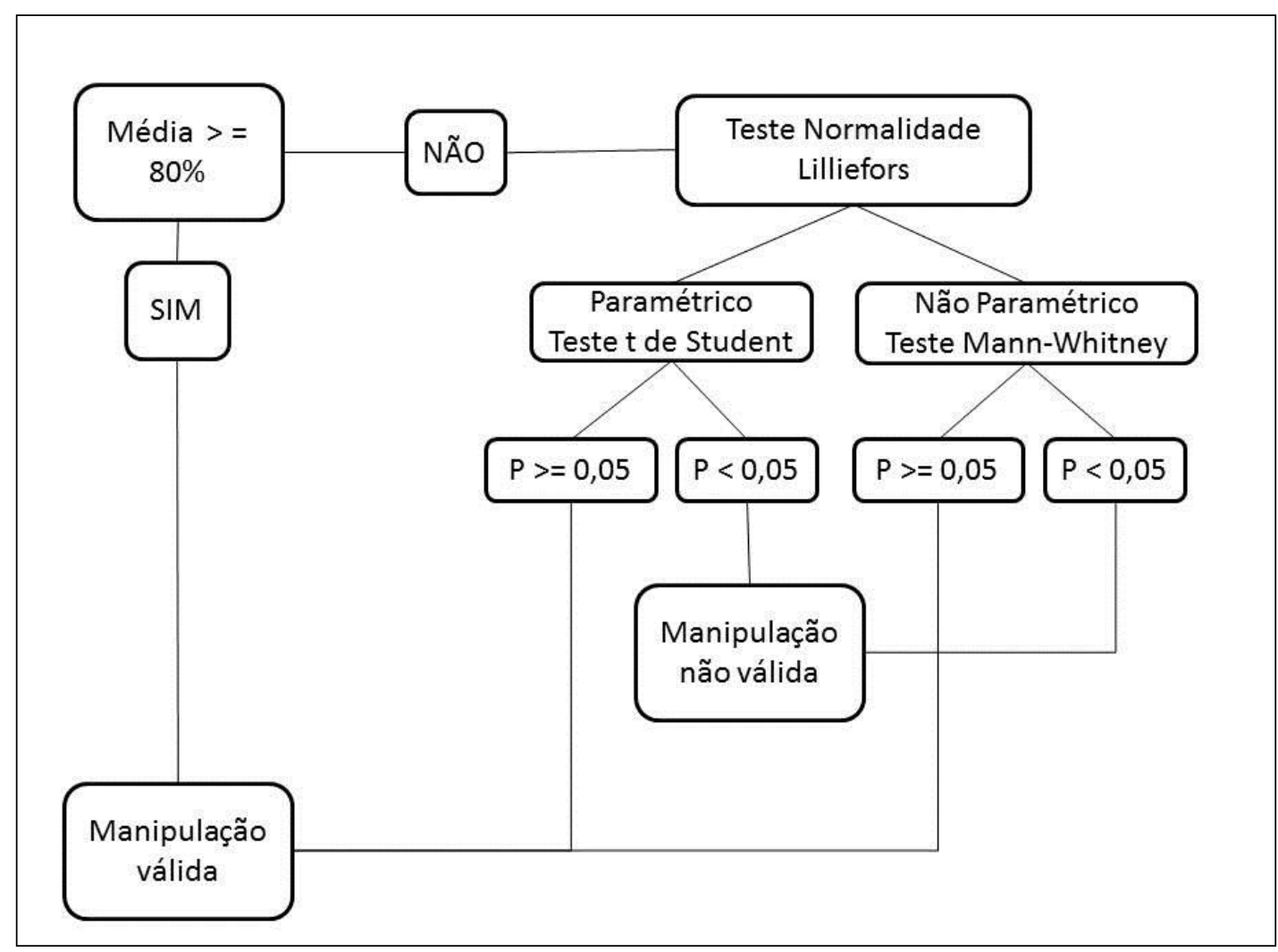

Figura 10. Fluxograma mostrando o procedimento estatístico utilizado para validação das manipulações.

Classificação da Toxicidade

A classificação de toxicidade dos resultados foi definida analisando a normalidade dos resultados de todas as concentrações de cada manipulação através do teste de Lilliefors.

Para os dados com normalidade foi utilizado o Test t Student com índice de diferença significativa $\mathrm{p}<0,05$.

Quando os resultados apresentaram-se heterocedásticos ou sem normalidade, os dados foram transformados em raiz quadrada, para obter-se a normalidade e homocedasticidade, uma vez que os dados em porcentagem não são comumente transformados em $\log (\mathrm{x}+1)$. 
Para os dados que não apresentaram normalidade e/ou homecedasticidade utilizou-se o Teste Mann-Whitney (teste $\mathrm{u}$ ) com $\mathrm{p}<0,05$ de índice de diferença significativa, portanto os dados que obtiveram $\mathrm{p}<0,05$ foram considerados tóxico, como demostrado na figura 11.

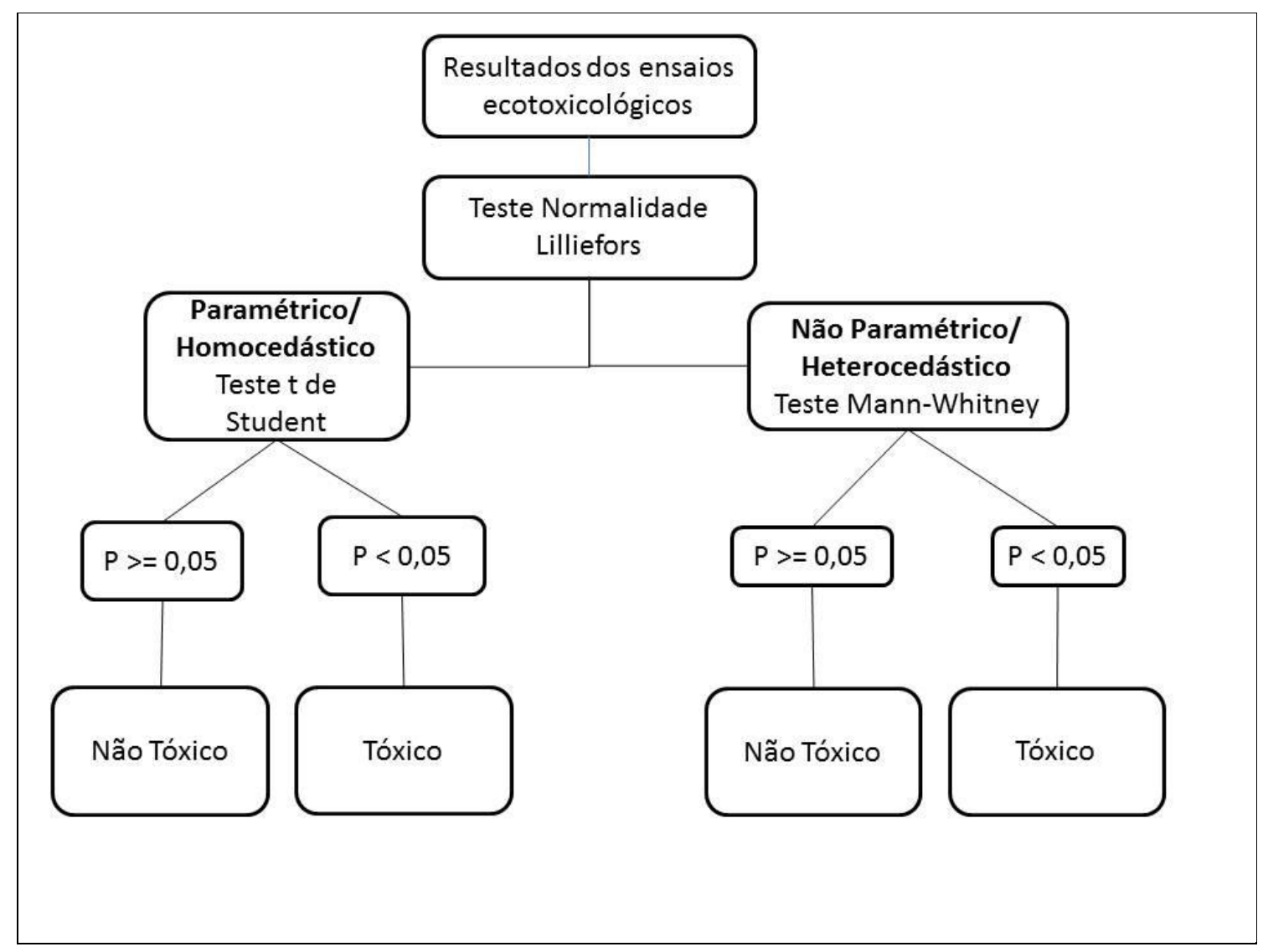

Figura 11. Fluxograma mostrando o procedimento estatístico utilizado para classificação da amostra como tóxica ou não tóxica.

A amostra considerada toxica foi aquela que apresentou toxicidade (diferença significativa) em três das cinco concentrações testadas ou duas concentrações tóxicas entre 25,50 e $100 \%$.

Foi calculada a porcentagem de frequência de toxicidade, para todas as manipulações válidas de cada ponto de coleta, em todas as campanhas utilizando o seguinte cálculo: 
\% Freq. Toxicidade $=\left(\mathrm{N}^{\mathrm{o}}\right.$ de manipulações tóxicas $/ \mathrm{N}^{\mathrm{o}}$ total de manipulação testada) x 100 . 


\section{RESULTADOS}

\subsection{Avaliação e Identificação da Toxicidade - AIT}

Para cada amostra e a água do controle foram realizados os procedimentos das manipulações, descritos anteriormente.

Com relação à Validação dos Resultados da AIT (pag. 29) as manipulações que apresentaram diferença significativa entre o controle do ensaio e o controle das manipulações não foram consideradas válidas (tabela 2) .

Desta forma 95\% da manipulação Coluna C18, 100\% da manipulação pH3 + filtração, e 75\% da manipulação pH 11+ filtração realizadas em todas as estações de coleta não foram consideradas válidas e portanto não foram analisadas, o mesmo ocorrendo com a amostra dos pontos Perequê-Açu na campanha da Primavera de 2011 e para outras manipulações, em menores porcentagem, nas diversas campanhas.

Tabela 2. Síntese das manipulações realizadas e suas validações segundo critérios para validação da AIT.

\begin{tabular}{|c|c|c|c|c|c|c|c|c|c|c|c|c|c|c|c|c|}
\hline Pereque & outono & inverno pri & imavera & verão & \multicolumn{2}{|c|}{ Itaguá } & outono & inverno & primavera & verão & \multicolumn{2}{|c|}{ Saco da Ribeira } & outono & inverno & primavera & verão \\
\hline ER & & & & & \multicolumn{2}{|c|}{ ER } & & & & & \multicolumn{2}{|c|}{\begin{tabular}{|l} 
ER \\
\end{tabular}} & & & & \\
\hline Aeração & & & & & \multicolumn{2}{|c|}{ Aeração } & & & & & \multicolumn{2}{|c|}{ Aeração } & & & & \\
\hline EDTA & 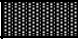 & & & & \multicolumn{2}{|c|}{ EDTA } & & & & & \multicolumn{2}{|c|}{ EDTA } & & & & \\
\hline Tiossulfato & & & & & \multicolumn{2}{|c|}{ Tiossulfato } & & & & & \multicolumn{2}{|c|}{ Tiossulfato } & & & & \\
\hline $\mathrm{pH} 7$ & & 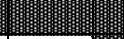 & & & \multicolumn{2}{|c|}{$\mathrm{pH} 7$} & & & & & \multicolumn{2}{|c|}{$\mathrm{pH} 7$} & & & & \\
\hline $\mathrm{pH} 9$ & & & & & \multicolumn{2}{|c|}{$\mathrm{pH} 9$} & & & & & \multicolumn{2}{|c|}{$\mathrm{pH} 9$} & & & & \\
\hline Filtração & & & & & \multicolumn{2}{|c|}{ Filtração } & & & & & \multicolumn{2}{|c|}{ Filtração } & & & & \\
\hline Coluna C18 & & & & & \multicolumn{2}{|c|}{ Coluna C18 } & & 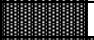 & & & \multicolumn{2}{|c|}{ Coluna C18 } & & & & \\
\hline pH3+filtração & & & & & \multirow{2}{*}{\multicolumn{2}{|c|}{\begin{tabular}{|c|} 
pH3+filtração \\
pH11+filtração
\end{tabular}}} & & & & & \multirow{2}{*}{\multicolumn{2}{|c|}{\begin{tabular}{|l} 
pH3+filtração \\
pH11+filtração
\end{tabular}}} & & & & \\
\hline \multirow{12}{*}{ pHI1+filtraçao } & & & & & & & 10 & & & & & & & & & \\
\hline & & IMV & outono & inverno & primavera & verão & \multicolumn{2}{|c|}{ Caragua } & outono & inverno & primavera & verão & & & & \\
\hline & & ER & & & & & \multicolumn{2}{|c|}{ ER } & & & & & & & & \\
\hline & & Aeração & & & & & \multicolumn{2}{|c|}{ Aeração } & & & & & & & & \\
\hline & & EDTA & & & & & \multicolumn{2}{|c|}{ EDTA } & & & & & & & & \\
\hline & & iossulfato & & & & & \multicolumn{2}{|c|}{ Tiossulfato } & & & & & & & & \\
\hline & & $\mathrm{pH} 7$ & & & & & \multicolumn{2}{|c|}{$\mathrm{pH} 7$} & & & & & & & & \\
\hline & & $\mathrm{pH} 9$ & & & & & \multicolumn{2}{|c|}{$\mathrm{pH} 9$} & & & & & & & & \\
\hline & & Filtração & & & & & \multicolumn{2}{|c|}{ Filtração } & & & & & & & & \\
\hline & & oluna C18 & & & & & \multicolumn{2}{|c|}{ Coluna C18 } & & & & & & & & \\
\hline & $\mathrm{pH} 3$ & 3+filtração & & & & & $\mathrm{pH} 3+$ & filtração & & & & & & & & \\
\hline & $\mathrm{pH} 1$ & 11+filtração & & & & & pH11 & filtração & & & & & & & & \\
\hline
\end{tabular}




\subsubsection{Perequê-Açu}

\section{$\underline{\text { Outono de } 2011}$}

Foram medidos na concentração $100 \%$, de cada manipulação, no início dos ensaios ecotoxicológicos, as variáveis físicas e químicaspH, salinidade e amônia total. A temperatura do ensaio foi mantida constante em $25^{\circ} \mathrm{C}$. A partir destes valores, a amônia não ionizada foi calculada. Os resultados dessas variáveis da amostra, obtidos em cada manipulação da campanha do Outono 2011 estão apresentados na Tabela 3.

Tabela 3. Resultado das análises das variáveis da amostra de água intersticial e nas diferentes manipulações da campanha de Outono de 2011, coletada no Perequê-Açu.

\section{Perequê-Açu - Outono/ 2011}

\begin{tabular}{ccccc}
\hline manipulação & Salinidade & Amônia total & $\mathrm{pH}$ & Am. N Ionizada \\
\hline ER & 32 & 1.00 & 7.20 & 0.01 \\
Aeração & 32 & 1.00 & 7.43 & 0.01 \\
EDTA & 32 & 1.00 & 7.43 & 0.01 \\
Tiossulfato & 32 & 1.00 & 7.77 & 0.00 \\
pH 7 & 32 & 1.00 & 7.00 & 0.01 \\
pH 9 & 32 & 1.00 & 9.00 & 0.14 \\
Filtração & 32 & 1.00 & 7.60 & 0.02 \\
Controle & 33 & 0.05 & 8.40 & 0.05 \\
\hline
\end{tabular}

valor acima do limite de sensibilidade para a espécie

Am. N Ionizada - Amônia não ionizada

Observando os resultados verificou-se que não houve variação da salinidade nas diversas manipulações e que o controle apresentou o maior valor, para esta variável, 33 de salinidade. Com relação à amônia total somente o controle apresentou resultado diferente com a manipulação. $\mathrm{O}$ pH apresentou pequena variação nas manipulações, exceto naquelas que são alterados os valores propositadamente, o controle apresentou maior valor com $\mathrm{pH} 8,40$. 
A amônia não ionizada com valores $>0,05$ é considerada acima do limite de sensibilidade para as larvas de Lytechinus variegatus segundo ABNT NBR 15350:2006, o que ocorreu nos resultados do controle e da manipulação pH9.

A porcentagem média e o desvio padrão, de larvas normais de Lytechinus variegatus para cada concentração testada e para cada manipulação da campanha de Outono de 2011 estão apresentados na tabela 4 e representados na figura 12.

Tabela 4. Porcentagem média e desvio padrão de larvas normais de Lytechinus variegatus no Outono de 2011, nas várias concentrações testadas em cada manipulação da água intersticial do Perequê-Açu. (ER= Ensaio Referência).

\section{Perequê-Açu - Outono/2011}

\begin{tabular}{|c|c|c|c|c|c|c|c|}
\hline & & & \multicolumn{5}{|c|}{ Concentrações da água intersticial testada (\%) } \\
\hline & & & 6.25 & 12.5 & 25 & 50 & 100 \\
\hline \multirow{16}{*}{ 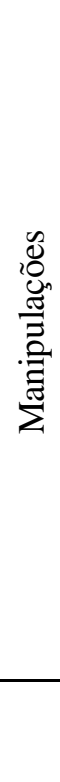 } & \multirow[t]{2}{*}{ ER } & Média & 79.25 & 72.50 & 65.75 & 34.50 & 0.00 \\
\hline & & Desv. Pad. & 7.18 & 25.05 & 12.50 & 14.93 & 0.00 \\
\hline & \multirow[t]{2}{*}{ Aeração } & Média & 88.00 & 71.25 & 20.50 & 0.00 & 0.00 \\
\hline & & Desv. Pad. & 4.55 & 2.36 & 8.23 & 0.00 & 0.00 \\
\hline & \multirow[t]{2}{*}{ EDTA } & Média & 93.00 & 79.00 & 68.00 & 0.00 & 0.00 \\
\hline & & Desv. Pad. & 0.82 & 8.68 & 9.38 & 0.00 & 0.00 \\
\hline & \multirow[t]{2}{*}{ Tiossulfato } & Média & 92.25 & 95.50 & 79.25 & 45.00 & 0.00 \\
\hline & & Desv. Pad. & 1.26 & 2.65 & 8.42 & 14.72 & 0.00 \\
\hline & \multirow[t]{2}{*}{$\mathrm{pH} 7$} & Média & 69.00 & 69.50 & 68.25 & 60.00 & 0.00 \\
\hline & & Desv. Pad. & 16.02 & 15.44 & 10.31 & 13.88 & 0.00 \\
\hline & \multirow[t]{2}{*}{$\mathrm{pH} 9$} & Média & 61.50 & 57.25 & - & 48.75 & 0.00 \\
\hline & & Desv. Pad. & 25.09 & 15.95 & - & 13.02 & 0.00 \\
\hline & \multirow[t]{2}{*}{ Filtração } & Média & 83 & 28.75 & - & 0 & 15.25 \\
\hline & & Desv. Pad. & 9.49 & 14.06 & - & 0.00 & 2.50 \\
\hline & \multirow[t]{2}{*}{ Controle } & Média & & & & & 92.00 \\
\hline & & Desv. Pad. & & & & & 4.08 \\
\hline
\end{tabular}

- amostra não analisada 


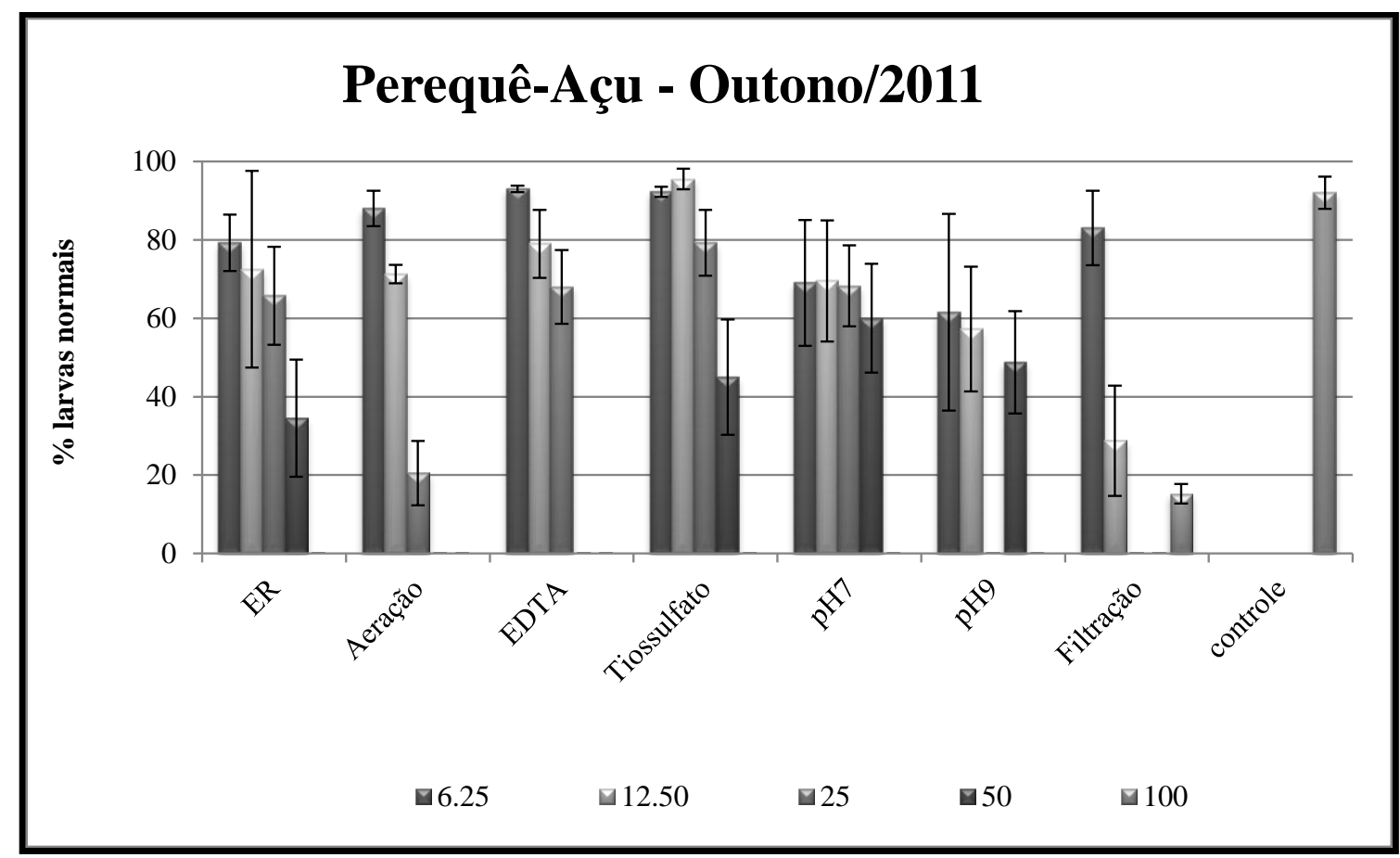

Figura 12. Resultados dos ensaios ecotoxicológicos do Outono 2011, nas várias concentrações testadas em cada manipulação da água intersticial do Perequê-Açu.

As manipulações EDTA e pH7 realizadas nesta amostra não se apresentaram válidas, com toxicidade no controle da manipulação, portando os resultados destas manipulações não foram aceitos e assim não foram descritos.

O Ensaio Referência apresentou-se tóxico, apresentando diferença significativa, $\mathrm{p}<0,05$, em relação ao controle, nas concentrações 6,25; 12,5; 50 e $100 \%$ sendo que na 6,25\% também ocorreu alta porcentagem média de larvas normais.

$\mathrm{Na}$ manipulação Aeração, nas concentrações 12,5; 25; 50 e $100 \%$ houve diferença significativa em relação ao controle. A manipulação Tiossulfato apresentou diferença significativa do controle em três das cinco concentrações testadas, sendo elas a 25,50 e $100 \%$, sendo que na concentração $25 \%$ foi obtida alta porcentagem média de larvas normais.

No ensaio realizado com a manipulação pH9 e com a Filtração, a concentração $25 \%$ não foi analisada, pois apresentou problemas no encerramento do ensaio. Estas 
manipulações apresentaram diferença significativa em relação ao controle nas concentrações 12,$5 ; 50$ e $100 \%$.

\section{$\underline{\text { Inverno de } 2011}$}

Foram medidos na concentração $100 \%$, de cada manipulação, no início dos ensaios ecotoxicológicos, as variáveis físicas e químicas $\mathrm{pH}$, salinidade e amônia total. A temperatura do ensaio foi mantida constante em $25^{\circ} \mathrm{C}$. A partir destes valores a amônia não ionizada foi calculada. Os resultados dessas variáveis da amostra, em cada manipulação da campanha do Inverno 2011 estão apresentados na Tabela 5.

Tabela 5. Resultado das análises das variáveis da amostra de água intersticial e nas diferentes manipulações da campanha de Inverno de 2011, coletada no Perequê-Açu.

Perequê-Açu - Inverno/ 2011

\begin{tabular}{ccccc}
\hline manipulação & Salinidade & Amônia total & pH & Am. N Ionizada \\
\hline ER & 35 & $0,5-1,0$ & 8.78 & $0,109-0,218$ \\
Aeração & 35 & $0,5-1,0$ & 8.43 & $0,055-0,111$ \\
EDTA & 35 & 0.50 & 8.54 & 0.07 \\
Tiossulfato & 35 & 1.00 & 8.61 & 0.16 \\
pH 7 & 35 & 1.00 & 7.00 & 0.00 \\
pH 9 & 35 & $1,0-3,0$ & 9.00 & $0,316-0,949$ \\
Filtração & 35 & $1,0-3,0$ & 8.72 & $0,195-0,586$ \\
Controle & 35 & $<0,01$ & 8.52 & $<0,0002$ \\
\hline
\end{tabular}

valor acima do limite de sensibilidade para a espécie

Am. N Ionizada - Amônia não ionizada

Não houve variação da salinidade nas manipulações e no controle. Com relação à amônia total, os maiores valores foram verificados nas manipulações pH9 e Filtração, entre 1,0 e 3,0 .

$\mathrm{O}$ pH apresentou pequena variação nas manipulações, exceto naquelas em que os valores foram alterados propositadamente. 
A amônia não ionizada com valores > 0,05 está acima do limite de sensibilidade para as larvas de Lytechinus variegatus, segundo ABNT NBR 15350:2006, fato este verificado na maioria das manipulações, exceto na EDTA, pH7 e Filtração.

A porcentagem média e o desvio padrão de larvas normais de Lytechinus variegatus por concentração de cada manipulação realizada na campanha de Outono de 2011 estão apresentados na Tabela 6 e representados na Figura 13

Tabela 6. Porcentagem média e desvio padrão de larvas normais de Lytechinus variegatus do Inverno de 2011, nas várias concentrações testadas em cada manipulação da água intersticial do Perequê-Açu.

\begin{tabular}{|c|c|c|c|c|c|c|c|}
\hline \multicolumn{8}{|c|}{ Perequê-Açu - Inverno/2011 } \\
\hline & & & \multicolumn{5}{|c|}{ Concentrações da água intersticial testada (\%) } \\
\hline & & & 6.25 & 12.5 & 25 & 50 & 100 \\
\hline \multirow{16}{*}{ 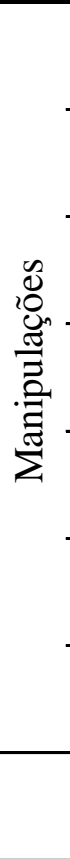 } & ER & Média & 88.33 & 86.67 & 77.67 & 83.33 & 49.33 \\
\hline & & Desv. Pad. & 5.51 & 2.89 & 5.77 & 7.23 & 5.03 \\
\hline & Aeração & Média & 79.50 & 73.25 & 73.50 & 71.75 & 37.75 \\
\hline & & Desv. Pad. & 8.39 & 6.70 & 6.14 & 4.65 & 2.36 \\
\hline & EDTA & Média & 77.25 & 89.75 & 84.00 & 84.50 & 60.00 \\
\hline & & Desv. Pad. & 9.67 & 8.26 & 1.15 & 4.20 & 13.74 \\
\hline & Tiossulfato & Média & 88.25 & 86.00 & 80.00 & 78.25 & 57.00 \\
\hline & & Desv. Pad. & 4.99 & 2.94 & 10.58 & 3.59 & 5.35 \\
\hline & $\mathrm{pH} 7$ & Média & 86.25 & 87.00 & 86.50 & 85.75 & 78.25 \\
\hline & & Desv. Pad. & 7.41 & 5.66 & 9.47 & 5.85 & 5.50 \\
\hline & pH9 & Média & 91.25 & 91.00 & 90.25 & 89.50 & 76.00 \\
\hline & & Desv. Pad. & 4.57 & 2.16 & 5.12 & 5.80 & 5.72 \\
\hline & Filtração & Média & 90.50 & 87.75 & 86.25 & 87.25 & 81.75 \\
\hline & & Desv. Pad. & 4.20 & 6.24 & 4.65 & 3.86 & 6.24 \\
\hline & Controle & Média & & & & & 86.25 \\
\hline & & Desv. Pad. & & & & & 4.99 \\
\hline
\end{tabular}




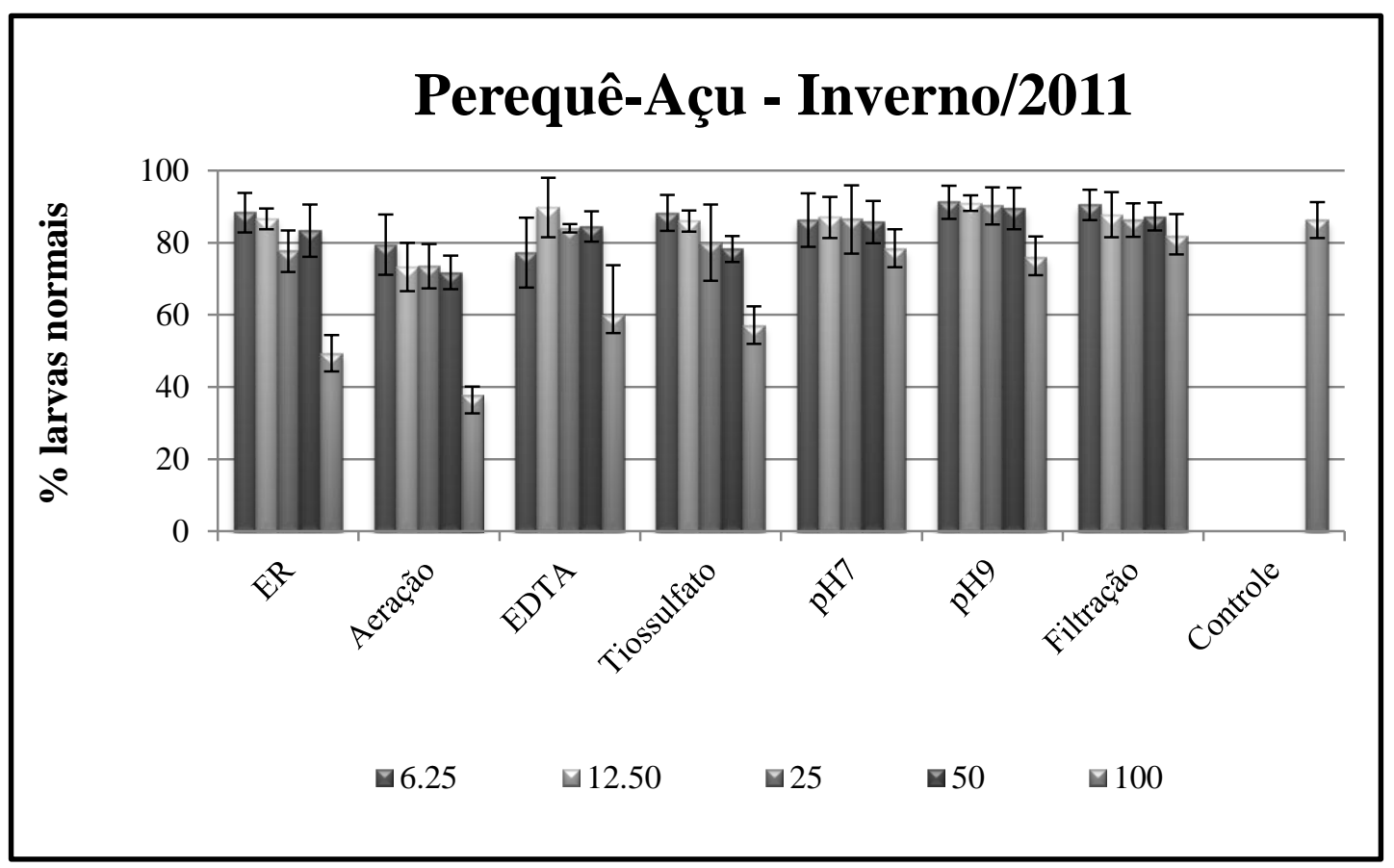

Figura 13. Resultados dos ensaios ecotoxicológicos do Inverno 2011 nas várias concentrações testadas em cada manipulação da água intersticial do Perequê-Açu.

Uma vez que o controle da manipulação $\mathrm{pH} 7$, realizada nesta amostra, foi classificado como não válida, os resultados desta manipulação não foram aceitos e assim não foram descritos.

Os resultados obtidos no Ensaio Referência apresentaram as concentrações 25 e $100 \%$ tóxicas, com diferença significativa em relação ao controle, $\mathrm{p}<0,05$, apesar de que na concentração $25 \%$ ocorreu alta porcentagem média de larvas normais.

A manipulação Aeração foi a que apresentou maior número de concentrações com diferenças significativas, sendo essas as concentrações 12,5; 25; 50 e $100 \%$.

Os resultados do ensaio ecotoxicológicos da manipulação Tiossulfato apresentou diferença significativa nas duas maiores concentrações, 50 e 100\%, mesmo com alta porcentagem média de larvas normais na concentração $50 \%$.

Já as manipulações EDTA e pH9 apresentaram diferença significativa em relação ao controle somente na maior concentração testada, a 100\%. A Filtração foi a 
manipulação que não apresentou nenhuma de suas concentração com diferença significativa.

\section{Primavera de 2011}

As amostras coletada na Primavera de 2011 não foram analisadas porque nesta companha, as manipulações realizadas com o controle apresentaram toxicidade, sendo considerada não válida.

\section{Verão de 2012}

Foram medidos na concentração $100 \%$, de cada manipulação, no início dos ensaios ecotoxicológicos, as variáveis físicas e químicas $\mathrm{pH}$, salinidade e amônia total. A temperatura do ensaio foi mantida constante em $25^{\circ} \mathrm{C}$. A partir destes valores a amônia não ionizada foi calculada. Os resultados dessas variáveis da amostra, e em cada manipulação da campanha do Verão de 2012 estão apresentados na Tabela 7.

Tabela 7. Resultado das análises das variáveis da amostra de água intersticial e nas diferentes manipulações da campanha de Verão de 2012, coletada no Perequê-Açu.

Perequê-Açu - Verão/2012

\begin{tabular}{ccccc}
\hline manipulação & Salinidade & Amônia total & $\mathrm{pH}$ & Am. N Ionizada \\
\hline ER & 36 & $>6,0$ & 7.64 & $>0,12$ \\
Aeração & 36 & $>6,0$ & 7.88 & $>0,20$ \\
EDTA & 36 & $>6,0$ & 7.62 & $>0,11$ \\
Tiossulfato & 36 & 0.10 & 7.78 & 0.00 \\
pH 7 & 36 & $>6,0$ & 7.73 & $>0,15$ \\
pH 9 & 36 & $>6,0$ & 8.66 & $>1,05$ \\
Filtração & 36 & $>6,0$ & 7.84 & $>0,19$ \\
Controle & 35 & 0.00 & 7.91 & 0.00 \\
\hline
\end{tabular}

valor acima do limite de sensibilidade para a espécie

Am. N Ionizada - Amônia não ionizada 
Não houve variação da salinidade nas manipulações, sendo que o controle apresentou valor diferente, 35. Com relação à amônia total, o menor valor foi obtido para o controle $\left(0,00 \mathrm{mg} \cdot \mathrm{L}^{-1}\right)$ e a manipulação Tiossulfato $\left(0,10 \mathrm{mg} \cdot \mathrm{L}^{-1}\right)$.

$\mathrm{O} \mathrm{pH}$ apresentou pequena variação nas manipulações, exceto naquelas que foram alterados propositalmente os valores para 7 ou para 9.

A amônia não ionizada, com valores > 0,05, está acima do limite de sensibilidade para as larvas de Lytechinus variegatus segundo ABNT NBR 15350:2006, o que ocorreu na maioria das manipulações, exceto na de Tiossulfato e no controle.

A porcentagem média e o desvio padrão de larvas normais de Lytechinus variegatus por concentração testada de cada manipulação da campanha de Verão de 2012 estão apresentados na Tabela 8 e representados na Figura 14.

Tabela 8. Porcentagem média e desvio padrão de larvas normais de Lytechinus variegatus do Verão de 2012 e nas várias concentrações testadas em cada manipulação da água intersticial do Perequê-Açu.

\begin{tabular}{|c|c|c|c|c|c|c|c|}
\hline \multicolumn{8}{|c|}{ Perequê-Açu - Verão/2012 } \\
\hline & & & \multicolumn{5}{|c|}{ Concentrações da água intersticial testada (\%) } \\
\hline & & & 6.25 & 12.5 & 25 & 50 & 100 \\
\hline \multirow{16}{*}{ 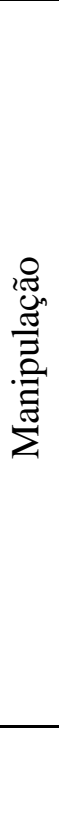 } & ER & Média & 80.00 & 79.50 & 76.00 & 74.50 & 52.75 \\
\hline & & Desv. Pad. & 4.08 & 5.20 & 4.24 & 5.92 & 6.34 \\
\hline & Aeração & Média & 78.25 & 77.50 & 79.75 & 93.00 & 64.25 \\
\hline & & Desv. Pad. & 2.99 & 6.24 & 2.87 & 0.82 & 11.35 \\
\hline & EDTA & Média & 94.75 & 93.50 & 95.75 & 89.50 & 79.50 \\
\hline & & Desv. Pad. & 1.50 & 3.87 & 2.22 & 2.38 & 3.70 \\
\hline & Tiossulfato & Média & 95.50 & 84.00 & 85.25 & 81.75 & 24.00 \\
\hline & & Desv. Pad. & 1.00 & 4.08 & 4.03 & 8.54 & 18.20 \\
\hline & $\mathrm{pH} 7$ & Média & 89.00 & 90.50 & 87.75 & 88.00 & 70.25 \\
\hline & & Desv. Pad. & 2.94 & 3.32 & 8.06 & 2.45 & 3.30 \\
\hline & pH9 & Média & 78.25 & 79.50 & 77.25 & 78.50 & 0.00 \\
\hline & & Desv. Pad. & 1.71 & 4.65 & 3.77 & 3.11 & 0.00 \\
\hline & Filtração & Média & 79.75 & 79.25 & 91.25 & 89.75 & 4.25 \\
\hline & & Desv. Pad. & 3.86 & 2.75 & 3.30 & 3.20 & 3.20 \\
\hline & Controle & Média & & & & & 89.75 \\
\hline & & Desv. Pad. & & & & & 1.71 \\
\hline
\end{tabular}




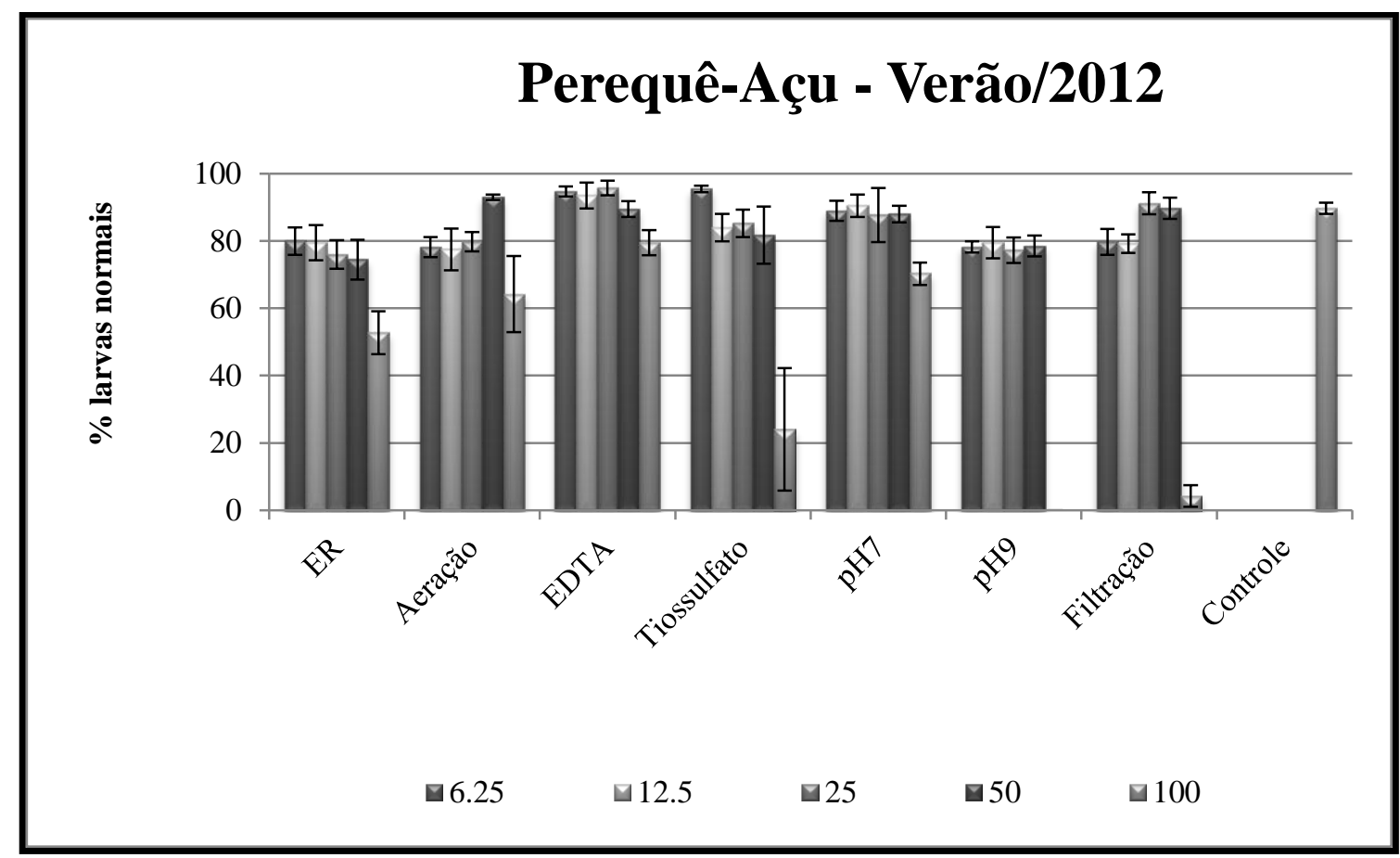

Figura 14. Resultados dos ensaios ecotoxicológicos do Verão 2012, nas diferentes concentrações testadas em cada manipulação da água intersticial do Perequê-Açu.

A manipulação EDTA, realizada nesta amostra, apresentou os resultados do controle com classificação não válida, portando os resultados desta manipulação não foram aceitos e portanto não foram descritos.

O Ensaio Referência e a manipulação pH9 apresentaram diferença significativa ao controle, $\mathrm{p}<0,05$, em todas as concentrações testadas, assim considerada tóxica. Entretanto, nas concentrações 6,25 e 12,5\% foram obtidas altas porcentagens média de larvas normais.

Com a manipulação Aeração, com exceção da concentração $50 \%$, as demais concentrações foram tóxicas, apesar de ser observado altas porcentagens de larvas normais nas três concentrações mais baixas.

Na manipulação Tiossulfato houve diferença significativa em relação ao controle em três concentrações, 12,$5 ; 50,0$ e $100 \%$., sendo que nas concentrações 12,5 e $50 \%$ foi verificada uma elevada porcentagem média de larvas normais. 
As concentrações 6,$25 ; 12,5$ e $100 \%$ da manipulação Filtração apresentaram toxicidade, mesmo apresentando elevada porcentagem média de larvas normais.

Na manipulação pH7 a única concentração com diferença significativa foi de $100 \%$, apesar da elevada porcentagem média de larvas normais.

\subsubsection{Itaguá}

\section{Outono de 2011}

Foram medidos na concentração $100 \%$, de cada manipulação, no início dos ensaios ecotoxicológicos, as variáveis físicas e químicas $\mathrm{pH}$, salinidade e amônia total. A temperatura do ensaio manteve-se constante em $25^{\circ} \mathrm{C}$. A partir destes valores, a amônia não ionizada foi calculada. Os resultados dessas variáveis da amostra e em cada manipulação da campanha do Outono 2011 estão apresentados na Tabela 9.

Tabela 9. Resultado das análises das variáveis das amostras de água intersticial e nas diferentes manipulações da campanha de Outono de 2011, coletada no Itaguá.

\begin{tabular}{ccccc}
\multicolumn{5}{c}{ Itaguá - Outono/2011 } \\
\hline manipulação & Salinidade & Amônia total & $\mathrm{pH}$ & Am. N Ionizada \\
\hline ER & 34 & 1.00 & 7.50 & 0.01 \\
Aeração & 34 & 1.00 & 8.15 & 0.06 \\
EDTA & 34 & 1.00 & 7.97 & 0.04 \\
Tiossulfato & 34 & 0.50 & 7.94 & 0.02 \\
pH 7 & 34 & 1.00 & 7.00 & 0.02 \\
pH 9 & 34 & 0.00 & 9.00 & 0.00 \\
Filtração & 34 & 1.00 & 8.35 & 0.10 \\
Controle & 33 & 0.05 & 8.32 & 0.00 \\
\hline
\end{tabular}

valor acima do limite de sensibilidade para a espécie

Am. N Ionizada - Amônia não ionizada 
Não houve variação da salinidade nas manipulações, sendo que o controle apresentou valor diferente, 33. Com relação à amônia total, dentre as manipulações, pH9 e Tiossulfato apresentaram menores valores, 0,00 e 1,0 respectivamente.

$\mathrm{O}$ pH apresentou pequena variação nas manipulações, exceto naquelas que são alterados os valor propositadamente. A amônia não ionizada com valores > 0,05 está acima do limite de sensibilidade para as larvas de Lytechinus variegatus, o que ocorreu nas manipulações Aeração e Filtração.

A porcentagem média e o desvio padrão de larvas normais de Lytechinus variegatus para cada concentração testada e para cada manipulação da campanha de Outono de 2011 estão apresentados na Tabela 10 e representados na Figura 15.

Tabela 10. Porcentagem média e desvio padrão de larvas normais de Lytechinus variegatus no Outono de 2011, nas várias concentrações testadas em cada manipulação da água intersticial do Itaguá.

Itaguá - Outono/2011

\begin{tabular}{|c|c|c|c|c|c|c|c|}
\hline & & & \multicolumn{5}{|c|}{ Concentrações da água intersticial testada (\%) } \\
\hline & & & 6.25 & 12.5 & 25 & 50 & 100 \\
\hline \multirow{16}{*}{ 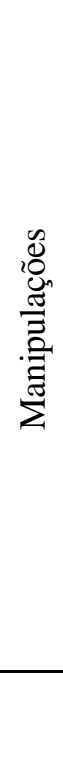 } & \multirow[t]{2}{*}{ ER } & Média & 89.25 & 87.50 & 82.50 & 75.25 & 0.00 \\
\hline & & Desv. Pad. & 4.35 & 6.24 & 9.11 & 14.52 & 0.00 \\
\hline & \multirow[t]{2}{*}{ Aeração } & Média & 91.75 & 88.50 & 84.50 & 87.75 & 1.50 \\
\hline & & Desv. Pad. & 5.12 & 7.55 & 18.08 & 6.40 & 3.00 \\
\hline & \multirow[t]{2}{*}{ EDTA } & Média & 85.25 & 74.75 & 74.75 & 30.00 & 0.00 \\
\hline & & Desv. Pad. & 8.38 & 14.10 & 10.47 & 22.93 & 0.00 \\
\hline & \multirow[t]{2}{*}{ Tiossulfato } & Média & 89.75 & 79.00 & 89.75 & 81.25 & 0.00 \\
\hline & & Desv. Pad. & 6.99 & 11.14 & 3.59 & 13.72 & 0.00 \\
\hline & \multirow[t]{2}{*}{$\mathrm{pH} 7$} & Média & 80.75 & 88.00 & 78.75 & 76.50 & 0.00 \\
\hline & & Desv. Pad. & 14.22 & 11.78 & 5.97 & 13.92 & 0.00 \\
\hline & \multirow[t]{2}{*}{$\mathrm{pH} 9$} & Média & 84.50 & 88.00 & 80.50 & 77.25 & 0.00 \\
\hline & & Desv. Pad. & 3.70 & 1.83 & 11.47 & 8.50 & 0.00 \\
\hline & \multirow[t]{2}{*}{ Filtração } & Média & 85.75 & 86.75 & 81.50 & 78.75 & 13.50 \\
\hline & & Desv. Pad. & 6.55 & 10.14 & 11.21 & 5.44 & 13.63 \\
\hline & \multirow[t]{2}{*}{ Controle } & Média & & & & & 87.75 \\
\hline & & Desv. Pad. & & & & & 0.96 \\
\hline
\end{tabular}




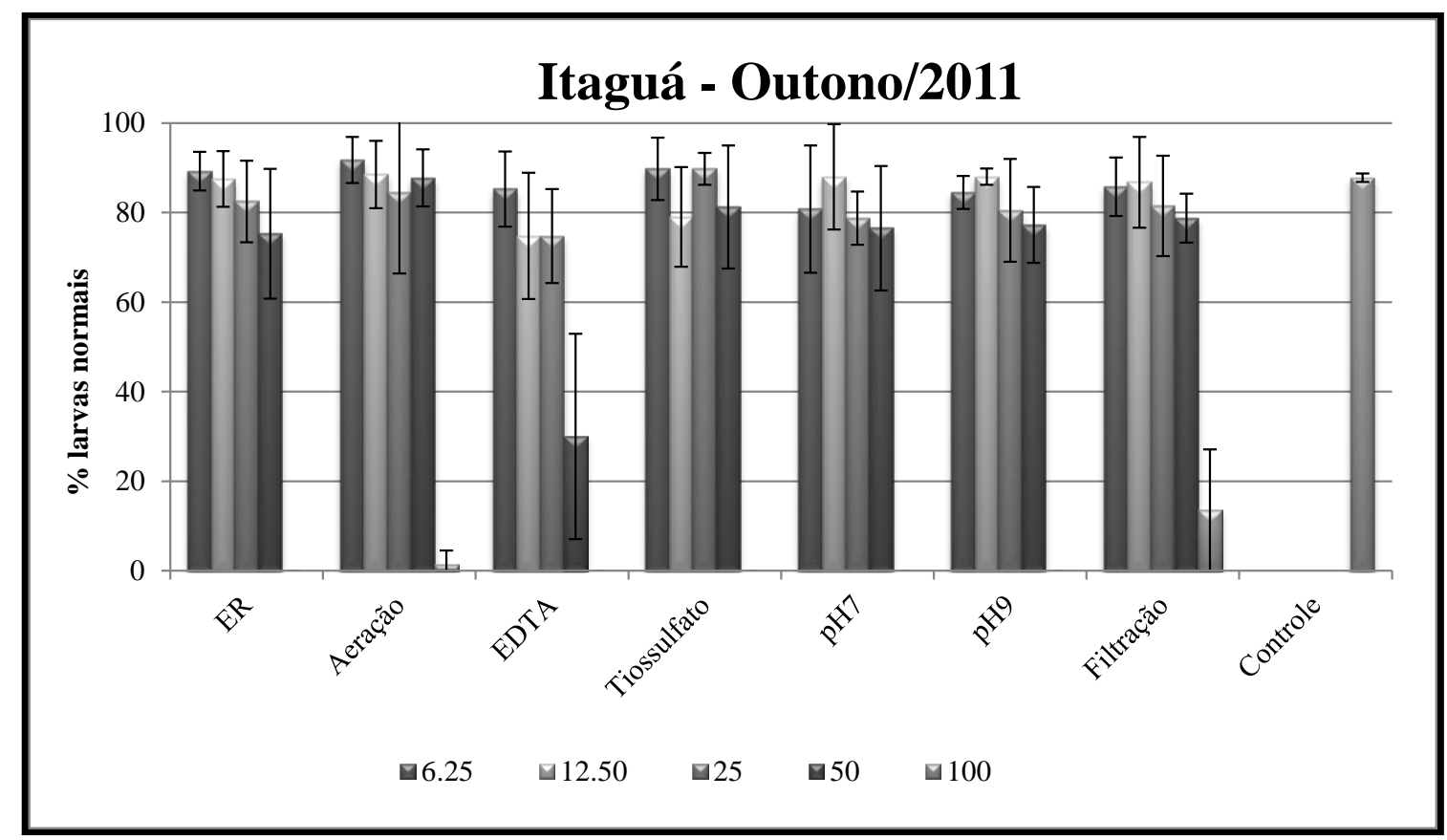

Figura 15. Resultados dos ensaios ecotoxicológicos do Outono 2011, nas várias concentrações testadas em cada manipulação da água intersticial do Itaguá.

Nesta amostra todas as manipulações foram consideradas válidas. O Ensaio Referência e as manipulações Aeração, Tiossulfato e pH9 apresentaram toxicidade somente na maior concentração testada, $100 \%$.

As três maiores concentrações testadas da manipulação EDTA obtiveram diferença significativa em relação ao controle, portanto foram tóxicas. Com a manipulação $\mathrm{pH} 7$, as concentrações 25 e $100 \%$ foram tóxicas apesar da alta porcentagem média de larvas normais na concentração $25 \%$.

A Filtração apresentou as concentrações 50 e $100 \%$ com toxicidade, mesmo sendo verificada alta porcentagem média de larvas normais na concentração $50 \%$.

\section{$\underline{\text { Inverno } 2011}$}

Foram medidos na concentração $100 \%$, de cada manipulação, no início dos ensaios ecotoxicológicos, as variáveis físicas e químicas pH, salinidade e amônia total. A temperatura do ensaio foi mantida constante em $25^{\circ} \mathrm{C}$. A partir destes valores, a 
amônia não ionizada foi calculada. Os resultados dessas variáveis da amostra e em cada manipulação da campanha do Inverno 2011 estão apresentados na Tabela 11.

Tabela 11. Resultado das análises das variáveis da amostra de água intersticial e nas diferentes manipulações da campanha de Inverno de 2011, coletada no Itaguá.

\begin{tabular}{ccccc}
\multicolumn{5}{c}{ Itaguá - Inverno/2011 } \\
\hline manipulação & Salinidade & Amônia total & $\mathrm{pH}$ & Am. N Ionizada \\
\hline ER & 35 & 1.00 & 8.23 & 0.07 \\
Aeração & 35 & 1.00 & 8.3 & 0.08 \\
EDTA & 35 & 1.00 & 7.9 & 0.04 \\
Tiossulfato & 35 & 1.00 & 8.33 & 0.09 \\
pH 7 & 35 & 1.00 & 8.16 & 0.06 \\
pH 9 & 35 & $0,5-1,0$ & 8.53 & $0,064-0,128$ \\
Filtração & 35 & 3.00 & 8.50 & 0.38 \\
Controle & 36 & $<0,01$ & 8.70 & $<0,002$ \\
\hline \multicolumn{5}{c}{ valor acima do limite de sensibilidade para a espécie }
\end{tabular}

Am. N Ionizada - Amônia não ionizada

Não houve variação da salinidade (35) nas manipulações e o controle apresentou valor de 36. Com relação à amônia total, as manipulações pH9 e Filtração apresentaram maiores valores.

$\mathrm{O}$ pH apresentou pequena variação nas manipulações, exceto naquelas que são alterados os valor propositadamente e nas manipulações $\mathrm{pH} 7$ e pH9 .

A amônia não ionizada com valores > 0,05 está acima do limite de sensibilidade para as larvas de Lytechinus variegatus, o que ocorreu na maioria das manipulações, exceto na EDTA.

A porcentagem média e o desvio padrão, de larvas normais de Lytechinus variegatus por concentração testada e para cada manipulação da campanha de Inverno de 2011 estão apresentados na Tabela 12 e representados na Figura 16. 
Tabela 12. Porcentagem média e desvio padrão de larvas normais de Lytechinus variegatus no Inverno de 2011, nas várias concentrações testadas em cada manipulação da água intersticial do Itaguá.

Itaguá - Inverno/2011

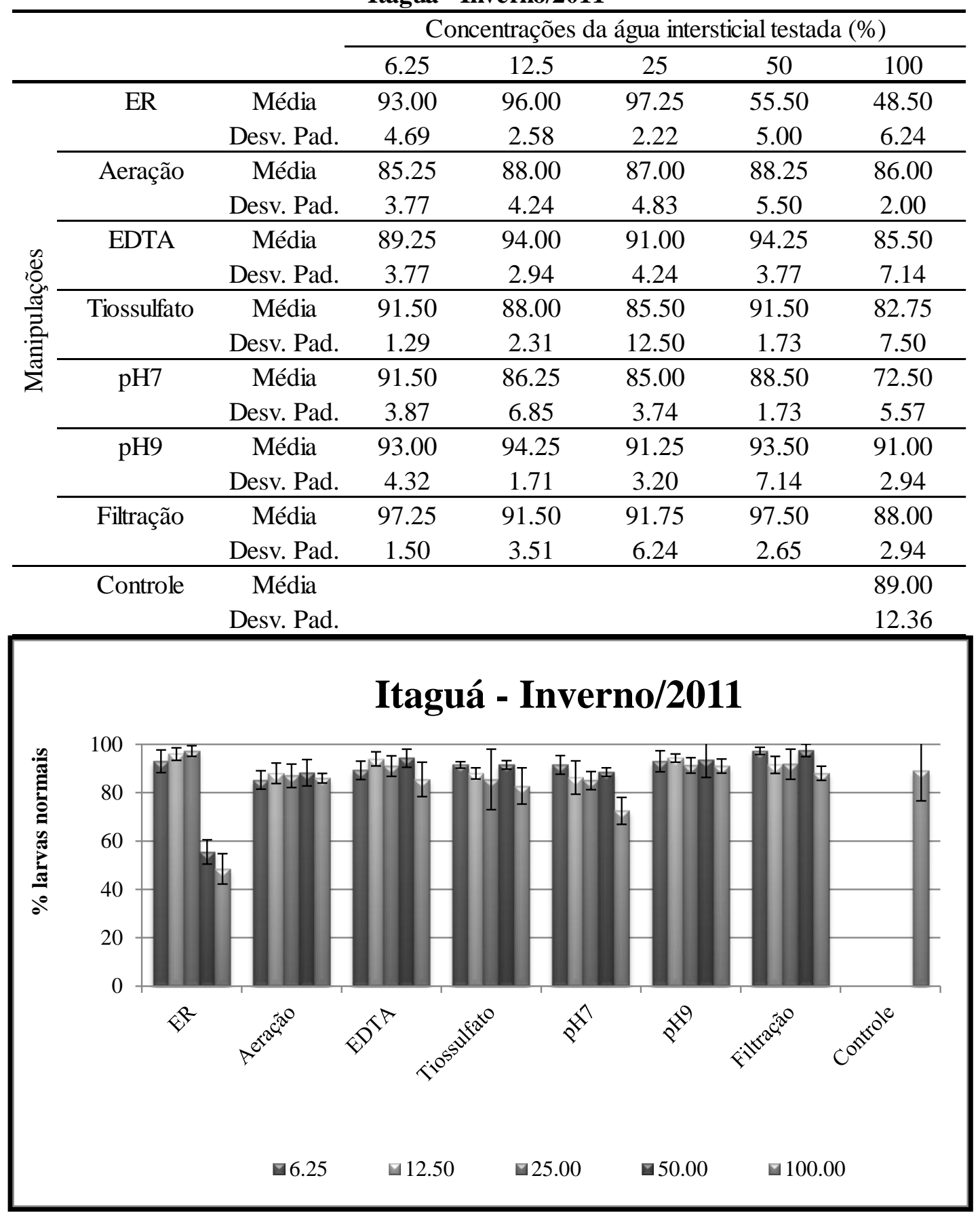

Figura 16. Resultados dos ensaios ecotoxicológicos do Inverno 2011, nas várias concentrações testadas em cada manipulação da água intersticial do Itaguá.

Nesta amostra todas as manipulações foram consideradas válidas. O Ensaio referência apresentou diferença significativa, p < 0,05, nas concentrações 50 e 100\%, 
sendo assim consideradas concentrações tóxicas. Já as demais manipulações realizadas não apresentaram nenhuma das suas concentrações testadas com diferença significativa em relação ao controle, portanto não foram tóxicas.

\section{Primavera de 2011}

Foram medidos na concentração $100 \%$, de cada manipulação, no início dos ensaios ecotoxicológicos, as variáveis físico e químicas $\mathrm{pH}$, salinidade e amônia total. A temperatura do ensaio foi mantida constante em $25^{\circ} \mathrm{C}$. A partir destes valores, a amônia não ionizada foi calculada.. Os resultados dessas variáveis da amostra e em cada manipulação da campanha da Primavera 2011 estão apresentados na Tabela 13.

Tabela 13. Resultado das análises das variáveis da amostra de água intersticial e nas diferentes manipulações da campanha da Primavera de 2011, coletada no Itaguá.

\section{Itaguá - Primavera/2011}

\begin{tabular}{ccccc}
\hline manipulação & Salinidade & Amônia total & $\mathrm{pH}$ & Am. N Ionizada \\
\hline ER & 36 & $>3,0$ & 8.23 & 0.22 \\
Aeração & 36 & $>3,0$ & 8.54 & 0.41 \\
EDTA & 36 & $>3,0$ & 7.93 & 0.11 \\
Tiossulfato & 36 & $>3,0$ & 8.44 & 0.34 \\
pH 7 & 36 & $>3,0$ & 8.32 & 0.26 \\
pH 9 & 36 & $>3,0$ & 8.84 & 0.73 \\
Filtração & 36 & $>3,0$ & 8.64 & 0.50 \\
Controle & 36 & 0.20 & 8.77 & 0.04 \\
\hline \multicolumn{5}{c}{ valor acima do limite de sensibilidade para a espécie } \\
Am. N Ionizada - Amônia não ionizada
\end{tabular}

Não houve variação da salinidade nas manipulações e no controle. Com relação à amônia total, todas as manipulações apresentaram maiores valores acima 3,0, exceto o controle. 
$\mathrm{O}$ pH apresentou pequena variação nas manipulações, exceto naquelas que são alterados os valor propositadamente, manipulações $\mathrm{pH} 7 \mathrm{e}$.

A amônia não ionizada com valores > 0,05 está acima do limite de sensibilidade para as larvas de Lytechinus variegatus, o que ocorreu em todas as manipulações, exceto para o controle.

A porcentagem média e o desvio padrão, de larvas normais de Lytechinus variegatus para cada concentração testada e para cada manipulação da campanha de Outono de 2011 estão apresentados na Tabela 14 e representados na Figura 17.

Tabela 14. Porcentagem média e desvio padrão de larvas normais de Lytechinus variegatus na Primavera de 2011, nas várias concentrações testadas em cada manipulação da água intersticial do Itaguá.

Itaguá - Primavera/2011

\begin{tabular}{ccccccc}
\hline & & \multicolumn{5}{c}{ Concentrações da água intersticial testada (\%) } \\
\cline { 3 - 7 } & & 6.25 & 12.5 & 25 & 50 & 100 \\
\hline \multirow{2}{*}{ ER } & Média & 84.75 & 86.50 & 86.50 & 78.25 & 50.75 \\
& Desv. Pad. & 7.80 & 2.65 & 4.73 & 2.50 & 6.65 \\
\hline \multirow{2}{*}{ Aeração } & Média & 81.00 & 82.50 & 78.75 & 77.75 & 77.00 \\
& Desv. Pad. & 7.26 & 1.29 & 4.65 & 8.62 & 8.04 \\
\hline \multirow{2}{*}{ EDTA } & Média & 86.00 & 83.25 & 85.00 & 82.75 & 71.50 \\
& Desv. Pad. & 2.94 & 4.11 & 14.00 & 7.41 & 7.33 \\
\hline \multirow{2}{*}{ Tiossulfato } & Média & 76.50 & 82.50 & 88.50 & 87.00 & 65.75 \\
& Desv. Pad. & 2.38 & 2.38 & 4.36 & 8.12 & 9.22 \\
\hline \multirow{2}{*}{ pH7 } & Média & 85.50 & 76.75 & 73.00 & 66.50 & 61.00 \\
& Desv. Pad. & 4.20 & 9.07 & 5.72 & 4.65 & 8.08 \\
\hline \multirow{2}{*}{ pH9 } & Média & 84.25 & 90.25 & 88.25 & 87.25 & 81.25 \\
& Desv. Pad. & 16.30 & 5.85 & 6.90 & 6.08 & 3.59 \\
\hline Filtração & Média & 77.25 & 81.25 & 77.25 & 70.50 & 85.25 \\
& Desv. Pad. & 7.14 & 7.18 & 10.90 & 6.14 & 4.11 \\
\hline \multirow{2}{*}{ Controle } & Média & & & & & 88.25 \\
& Desv. Pad. & & & & & 2.75 \\
\hline
\end{tabular}




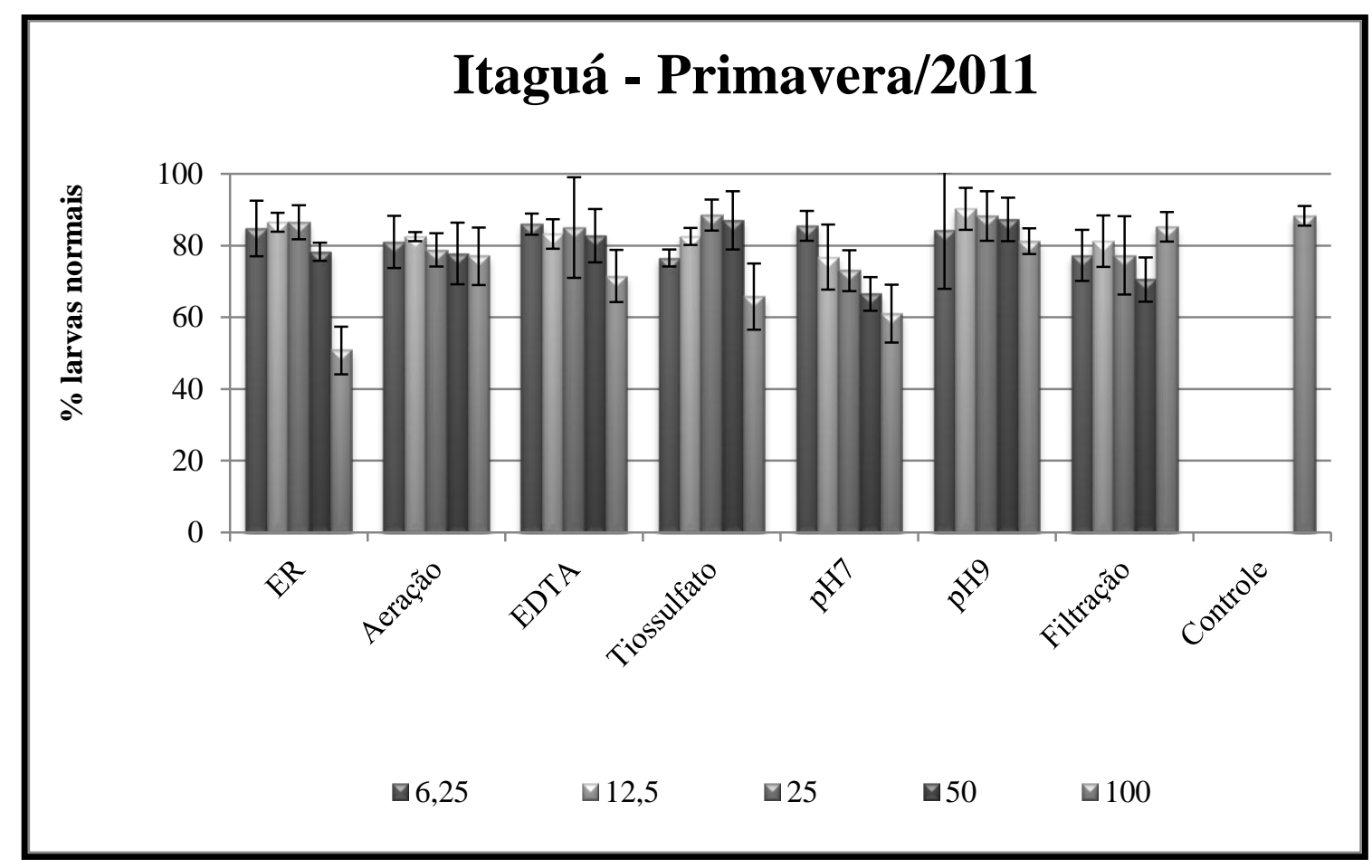

Figura 17. Resultados dos ensaios ecotoxicológicos da Primavera 2011, nas várias concentrações testadas em cada manipulação da água intersticial do Itaguá.

Nesta amostra todas as manipulações foram consideradas válidas. O Ensaio Referência apresentou toxicidade nas concentrações 50 e 100\%, mas verificou-se que na concentração de $50 \%$ ocorreu alta porcentagem média de larvas normais.

A manipulação Aeração apresentou toxicidade nas concentrações 12,5; 25 e $100 \%$, mesmo com alta porcentagem média de larvas normais.

Na manipulação EDTA, a concentração $100 \%$ apresentou-se com diferença significativa em relação ao controle, sendo a única concentração com toxicidade.

Diferença significativa em relação ao controle foi obtida nas concentrações 6,$25 ; 12,5$ e $100 \%$ na manipulação Tiossulfato, sendo que nas duas concentrações mais baixas foi verificada alta porcentagem média de larvas normais.

As concentrações 25, 50 e 100\% da manipulação pH7 apresentaram diferença significativa em relação ao controle, sendo consideradas tóxicas. Com a manipulação 
pH9, as concentrações 6,25 e $100 \%$ foram tóxicas mesmo com alta porcentagem média de larvas normais.

A manipulação Filtração apresentou diferença significativa em relação ao controle nas concentrações 6,25 e $50 \%$, sendo tóxicas, mesmo com alta porcentagem média de larvas normais na menor concentração.

\section{Verão de 2012}

Foram medidos na concentração $100 \%$, de cada manipulação, no início dos ensaios ecotoxicológicos, as variáveis físico e químicas $\mathrm{pH}$, salinidade e amônia total, a amônia não ionizada foi calculada. A temperatura do ensaio foi mantida constante em $25^{\circ} \mathrm{C}$. Os resultados dessas variáveis da amostra, em cada manipulação da campanha do Verão de 2012 estão apresentados na Tabela 15.

Tabela 15. Resultado das análises das variáveis da amostra de água intersticial e nas diferentes manipulações da campanha do Verão de 2012, coletada no Itaguá.

\begin{tabular}{ccccc}
\multicolumn{5}{c}{ Itaguá - Verão/2012 } \\
\hline manipulação & Salinidade & Amônia total & $\mathrm{pH}$ & Am. N Ionizada \\
\hline ER & 35 & $>6,0$ & 7.73 & $>0.15$ \\
Aeração & 35 & $>6,0$ & 7.52 & $>0.09$ \\
EDTA & 35 & $>6,0$ & 7.54 & $>0.09$ \\
Tiossulfato & 35 & 0.20 & 7.69 & 0.00 \\
pH 7 & 35 & $>6,0$ & 7.00 & $>0.03$ \\
pH 9 & 35 & $>6,0$ & 8.64 & $>1.01$ \\
Filtração & 35 & $>6,0$ & 7.85 & $>0.19$ \\
Controle & 35 & 0.00 & 7.91 & 0.00 \\
\hline
\end{tabular}

valor acima do limite de sensibilidade para a espécie

Am. N Ionizada - Amônia não ionizada

Não houve variação da salinidade nas manipulações e no controle apresentando o valor de 35 de salinidade. Com relação à amônia total, a manipulação tiossulfato 
apresentou o menor valor, $0,20 \mathrm{mg} \cdot \mathrm{L}^{-1} \mathrm{e}$ as demais manipulações obtiveram valores superiores a $6,0 \mathrm{mg} \cdot \mathrm{L}^{-1}$.

$\mathrm{O}$ pH apresentou pequena variação nas manipulações, exceto naquelas que são alterados os valor propositadamente. A temperatura do ensaio manteve-se constante em $25^{\circ} \mathrm{C}$.

A amônia não ionizada com valores acima de 0,05 está acima do limite de sensibilidade para as larvas de Lytechinus variegatus, o que ocorreu na maioria das manipulações, exceto na manipulação Tiossulfato e pH7.

A porcentagem média e o desvio padrão, de larvas normais de Lytechinus variegatus para cada concentração testada e para cada manipulação da campanha de Verão de 2012 estão apresentados na tabela 16 e representados na figura 18.

Tabela 16. Porcentagem média e desvio padrão de larvas normais de Lytechinus variegatus no Verão de 2012, nas várias concentrações testadas em cada manipulação da água intersticial do Itaguá.

\section{Itaguá - Verão/2012}

\begin{tabular}{|c|c|c|c|c|c|c|c|}
\hline & & & \multicolumn{5}{|c|}{ Concentrações da água intersticial testada (\%) } \\
\hline & & & 6.25 & 12.5 & 25 & 50 & 100 \\
\hline \multirow{16}{*}{ 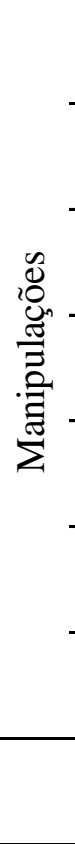 } & \multirow[t]{2}{*}{ ER } & Média & 78.00 & 82.00 & 84.50 & 87.75 & 38.50 \\
\hline & & Desv. Pad. & 6.00 & 7.16 & 5.97 & 6.08 & 4.51 \\
\hline & \multirow{2}{*}{ Aeração } & Média & 87.75 & 86.25 & 79.75 & 84.75 & 71.25 \\
\hline & & Desv. Pad. & 2.75 & 2.22 & 2.63 & 4.99 & 2.87 \\
\hline & \multirow[t]{2}{*}{ EDTA } & Média & 81.50 & 79.25 & 78.75 & 78.00 & 64.00 \\
\hline & & Desv. Pad. & 4.80 & 2.99 & 2.99 & 4.83 & 9.87 \\
\hline & \multirow[t]{2}{*}{ Tiossulfato } & Média & 79.75 & 75.00 & 85.75 & 80.75 & 80.50 \\
\hline & & Desv. Pad. & 6.29 & 3.65 & 4.27 & 15.97 & 3.32 \\
\hline & \multirow[t]{2}{*}{$\mathrm{pH} 7$} & Média & 95.25 & 96.75 & 97.00 & 96.00 & 65.50 \\
\hline & & Desv. Pad. & 5.25 & 2.50 & 2.31 & 2.16 & 6.24 \\
\hline & \multirow[t]{2}{*}{$\mathrm{pH} 9$} & Média & 88.00 & 88.00 & 90.75 & 92.25 & 0.00 \\
\hline & & Desv. Pad. & 4.24 & 3.27 & 2.75 & 0.96 & 0.00 \\
\hline & \multirow[t]{2}{*}{ Filtração } & Média & 71.25 & 74.00 & 67.00 & 72.25 & 48.25 \\
\hline & & Desv. Pad. & 3.30 & 4.24 & 11.75 & 7.50 & 3.77 \\
\hline & \multirow[t]{2}{*}{ Controle } & Média & & & & & 89.75 \\
\hline & & Desv. Pad. & & & & & 1.71 \\
\hline
\end{tabular}




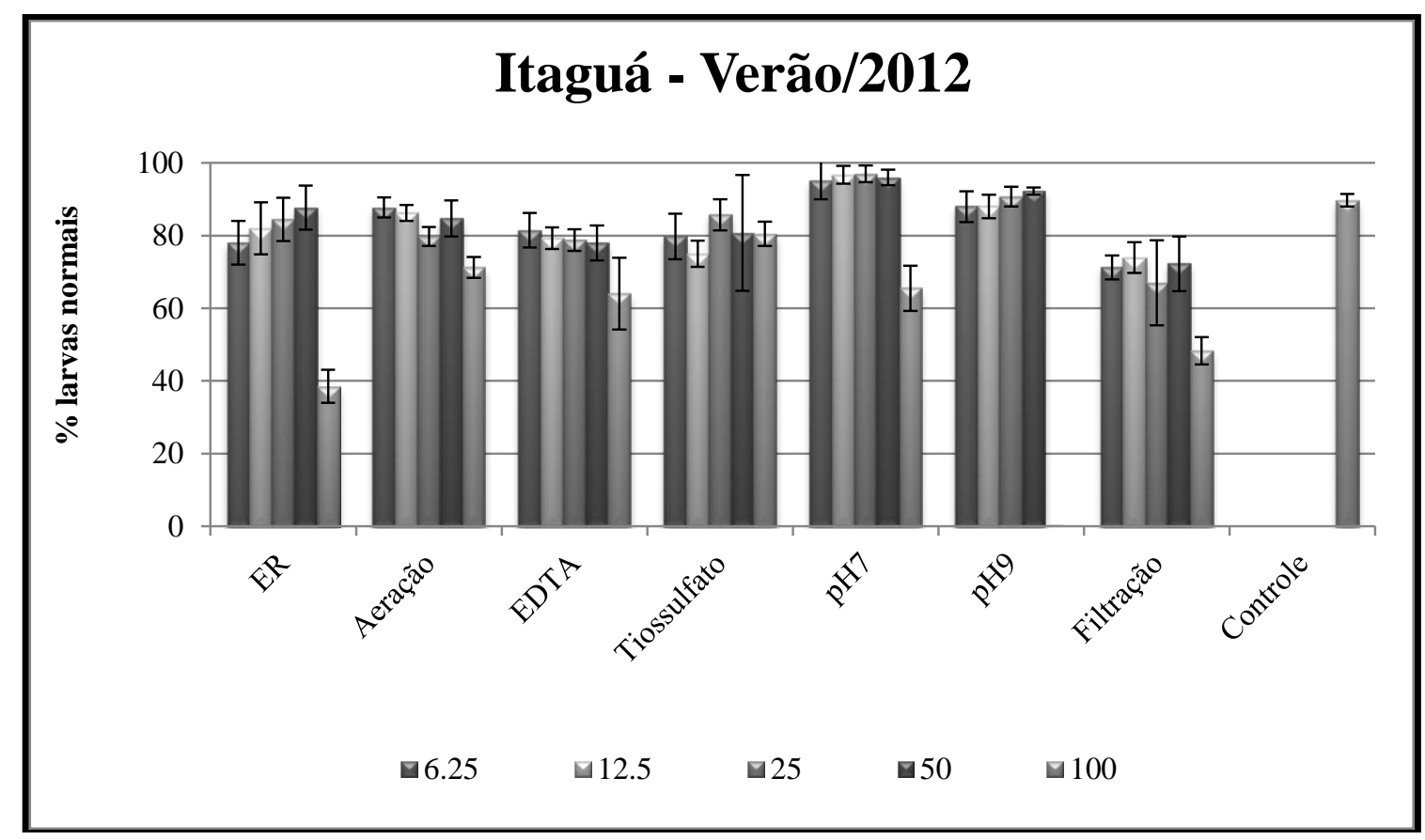

Figura 18. Resultados dos ensaios ecotoxicológicos do Verão de 2012, nas várias concentrações testadas em cada manipulação da água intersticial do Itaguá.

Nesta amostra a manipulação EDTA foi considerada não válida.

O Ensaio Referência apresentou toxicidade nas concentrações 6,25 e 100\%, sendo que a concentração $6,25 \%$ apresentou alta porcentagem média de larvas normais.

As concentrações 25 e $100 \%$ da manipulação Aeração apresentaram-se tóxicas inclusive a concentração $25 \%$ com alta porcentagem de larvas normais.

As concentrações 6,25; 12,5 e 100\% da manipulação Tiossulfato apresentaram toxicidade mesmo que com alta porcentagem de larvas normais.

Nas manipulações pH7 e pH9 foram obtidas toxicidade somente na concentração $100 \%$. A única manipulação que obteve toxicidade em todas as concentrações foi a Filtração. 


\subsubsection{Saco da Ribeira}

\section{Outono de 2011}

Foram medidos na concentração $100 \%$, de cada manipulação, no início dos ensaios ecotoxicológicos, as variáveis físicas e químicas $\mathrm{pH}$, salinidade e amônia total. A temperatura do ensaio foi mantida constante em $25^{\circ} \mathrm{C}$. A partir destes valores, a amônia não ionizada foi calculada. Os resultados dessas variáveis da amostra e em cada manipulação da campanha do Outono 2011 estão apresentados na Tabela 17.

Tabela 17. Resultado das análises das variáveis da amostra de água intersticial e nas diferentes manipulações da campanha de Outono de 2011, coletada no Saco da Ribeira.

Saco da Ribeira - Outono/2011

\begin{tabular}{ccccc}
\hline manipulação & Salinidade & Amônia total & $\mathrm{pH}$ & Am. N Ionizada \\
\hline ER & 33 & 1.00 & 8.51 & 0.13 \\
Aeração & 33 & 1.00 & 8.23 & 0.07 \\
EDTA & 33 & 1.00 & 7.83 & 0.03 \\
Tiossulfato & 33 & 0.50 & 7.99 & 0.02 \\
pH 7 & 33 & 1.00 & 7.00 & 0.02 \\
pH 9 & 33 & 0.00 & 9.00 & 0.00 \\
Filtração & 33 & 1.00 & 7.95 & 0.04 \\
Controle & 33 & 0.05 & 8.05 & 0.00 \\
\hline
\end{tabular}

valor acima do limite de sensibilidade para a espécie

Am. N Ionizada - Amônia não ionizada

Não houve variação da salinidade nas diferentes manipulações e no controle, com 33 de salinidade. Com relação à amônia total, as manipulações Tiossulfato e pH9 apresentaram menores valores, 0,50 e 0,00 respectivamente.

$\mathrm{O}$ pH apresentou pequena variação nas manipulações, exceto naquelas onde os valores foram alterados propositadamente.. 
A amônia não ionizada, com valores > 0,05, está acima do limite de sensibilidade para as larvas de Lytechinus variegatus, o que ocorreu apenas no Ensaio Referência e na manipulaçãoAeração.

A porcentagem média e o desvio padrão, de larvas normais de Lytechinus variegatus para cada concentração testada e para cada manipulação da campanha de Outono de 2011 estão apresentados na Tabela 18 e representados na Figura 19.

Tabela 18. Porcentagem média e desvio padrão de larvas normais de Lytechinus variegatus no Outono de 2011, nas várias concentrações testadas em cada manipulação da água intersticial do Saco da Ribeira.

Saco da Ribeira - Outono/2011

\begin{tabular}{ccccccc}
\hline & & \multicolumn{5}{c}{ Concentrações da água intersticial testada (\%) } \\
\cline { 3 - 7 } & & 6.25 & 12.5 & 25 & 50 & 100 \\
\hline \multirow{2}{*}{ ER } & Média & 95.75 & 95.00 & 81.67 & 0.00 & 0.00 \\
& Desv. Pad. & 2.87 & 2.16 & 3.79 & 0.00 & 0.00 \\
\hline \multirow{2}{*}{ Aeração } & Média & 96.25 & 88.75 & 86.25 & 0.00 & 0.00 \\
& Desv. Pad. & 1.50 & 15.84 & 4.11 & 0.00 & 0.00 \\
\hline \multirow{2}{*}{ EDTA } & Média & 96.75 & 97.00 & 84.00 & 0.00 & 0.00 \\
& Desv. Pad. & 1.71 & 1.41 & 11.11 & 0.00 & 0.00 \\
\hline \multirow{2}{*}{ Tiossulfato } & Média & 93.25 & 97.75 & 55.25 & 0.00 & 0.00 \\
& Desv. Pad. & 2.06 & 0.96 & 13.05 & 0.00 & 0.00 \\
\hline \multirow{2}{*}{ pH7 } & Média & 93.50 & 92.00 & 76.25 & 0.00 & 0.00 \\
& Desv. Pad. & 2.89 & 3.46 & 6.85 & 0.00 & 0.00 \\
\hline \multirow{2}{*}{ pH9 } & Média & 95.25 & 97.25 & 91.50 & 0.00 & 0.00 \\
& Desv. Pad. & 2.63 & 0.50 & 5.57 & 0.00 & 0.00 \\
\hline Filtração & Média & 96.75 & 97.00 & 82.00 & 0.75 & 0.00 \\
& Desv. Pad. & 1.71 & 1.41 & 11.05 & 1.50 & 0.00 \\
\hline Controle & Média & & & & 96.00 \\
& Desv. Pad. & & & & 1.63 \\
\hline
\end{tabular}




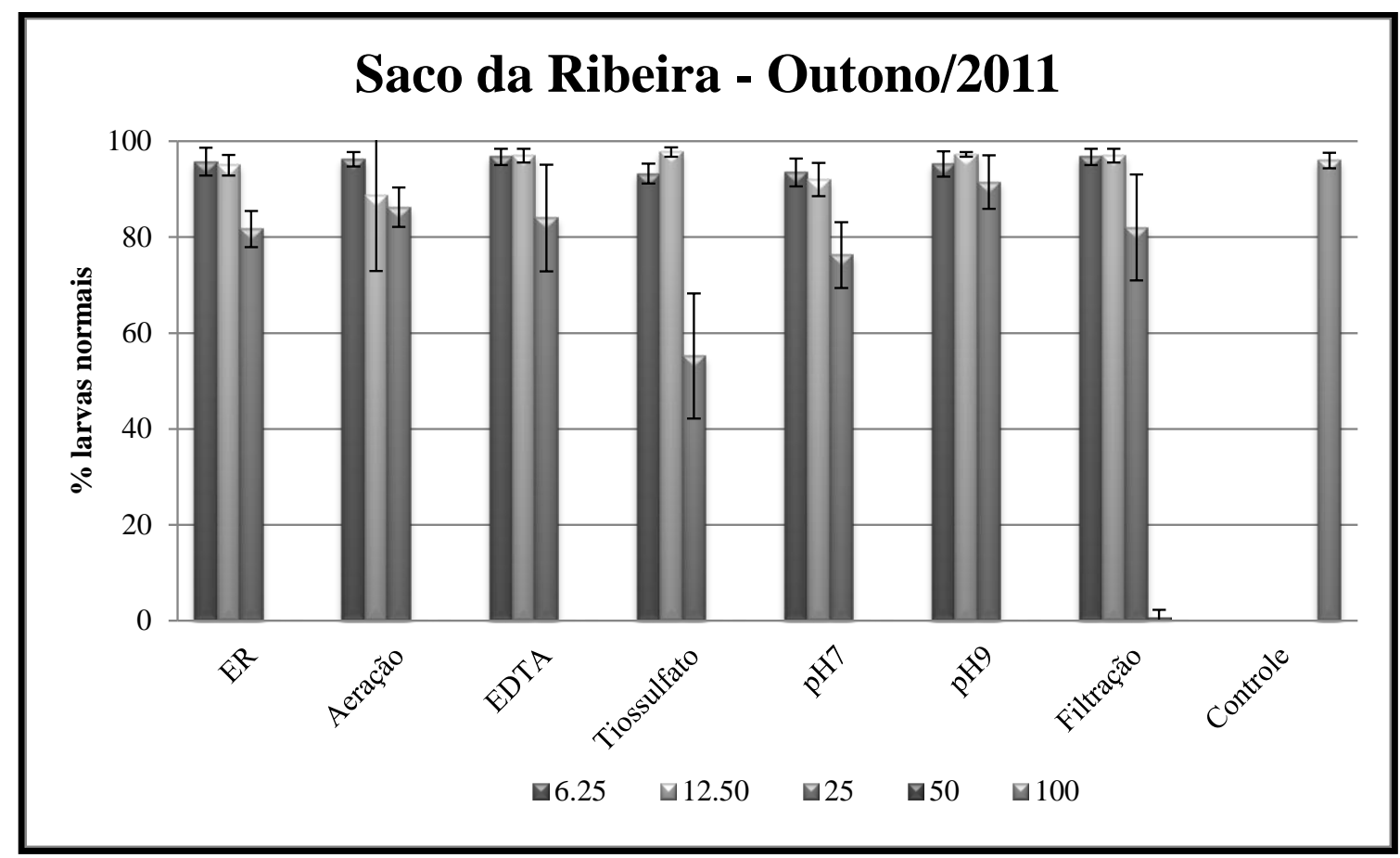

Figura 19. Resultados dos ensaios ecotoxicológicos do Outono 2011, nas várias concentrações testadas em cada manipulação da água intersticial do Saco da Ribeira.

Nesta amostra a manipulação pH7 foi não considerada válida. As manipulações Ensaio Referência, Aeração, EDTA e Filtração apresentaram resultados das concentrações 25,50 e $100 \%$ com toxicidade. E também apresentam na mesma concentração, $25 \%$, que apresentam valor alto da porcentagem média de larvas normais.

Na manipulação Tiossulfato, as concentrações 25, 50 e 100\% foram tóxicas. A manipulações pH9 apresentou as concentrações 50 e 100\% com toxicidade.

\section{$\underline{\text { Inverno de } 2011}$}

Foram medidos na concentração $100 \%$, de cada manipulação, no início dos ensaios ecotoxicológicos, as variáveis físico e químicas $\mathrm{pH}$, salinidade e amônia total. A temperatura do ensaio foi mantida constante em $25^{\circ} \mathrm{C}$. A partir destes valores, a amônia não ionizada foi calculada. Os resultados dessas variáveis da amostra e em cada manipulação da campanha do Inverno 2011 estão apresentados na Tabela 19. 
Tabela 19. Resultado das análises das variáveis da amostra de água intersticial e nas diferentes manipulações da campanha de Inverno de 2011, coletada no Saco da Ribeira.

Saco da Ribeira - Inverno /2011

\begin{tabular}{ccccc}
\hline manipulação & Salinidade & Amônia total & $\mathrm{pH}$ & Am. N Ionizada \\
\hline ER & 35 & 3.00 & 8.22 & 0.21 \\
Aeração & 35 & 3.00 & 8.57 & 0.44 \\
EDTA & 35 & 3.00 & 8.04 & 0.14 \\
Tiossulfato & 35 & 3.00 & 8.35 & 0.28 \\
pH 7 & 35 & 3.00 & 7.00 & 0.01 \\
pH 9 & 35 & $1,0-3,0$ & 9.00 & $0,130-0,390$ \\
Filtração & 35 & $1,0-3,0$ & 8.51 & $0,130-0,390$ \\
Controle & 35 & $<0,01$ & 8.57 & 0.01 \\
\hline
\end{tabular}

valor acima do limite de sensibilidade para a espécie

Am. N Ionizada - Amônia não ionizada

Não houve variação da salinidade nas manipulações e no controle, apresentando o valor de 35. Com relação à amônia total, o Ensaio Referência e as manipulações Aeração, EDTA, Tiossulfato e pH7 apresentaram os maiores valores, com $3,0 \mathrm{mg} \cdot \mathrm{L}^{-1}$

$\mathrm{O}$ pH apresentou pequena variação nas manipulações, exceto naquelas onde os valores foram alterados propositadamente.

A amônia não ionizada, com valores > 0,05, está acima do limite de sensibilidade para as larvas de Lytechinus variegatus, o que ocorreu na maioria das manipulações, exceto na manipulação pH7.

A porcentagem média e o desvio padrão de larvas normais de Lytechinus variegatus para cada concentração testada e para cada manipulação da campanha de Outono de 2011 estão apresentados na Tabela 20 e representados na Figura 20. 
Tabela 20. Porcentagem média e desvio padrão de larvas normais de Lytechinus variegatus no Inverno de 2011, nas várias concentrações testadas e em cada manipulação da água intersticial do Saco da Ribeira.

Saco da Ribeira - Inverno/2011

\begin{tabular}{ccccccc}
\hline & & \multicolumn{5}{c}{ Concentrações da água intersticial testada (\%) } \\
\cline { 3 - 7 } & & 6.25 & 12.5 & 25 & 50 & 100 \\
\hline \multirow{2}{*}{ ER } & Média & 94.00 & 97.00 & 95.75 & 94.50 & 0.00 \\
& Desv. Pad. & 4.69 & 1.41 & 3.20 & 1.00 & 0.00 \\
\hline \multirow{2}{*}{ Aeração } & Média & 94.00 & 96.25 & 96.00 & 95.00 & 89.25 \\
& Desv. Pad. & 2.94 & 2.63 & 2.00 & 1.83 & 8.54 \\
\hline \multirow{2}{*}{ EDTA } & Média & 95.50 & 94.25 & 96.25 & 92.25 & 0.00 \\
& Desv. Pad. & 2.08 & 2.99 & 0.96 & 0.96 & 0.00 \\
\hline \multirow{2}{*}{ Tiossulfato } & Média & 92.25 & 90.25 & 95.25 & 94.50 & 2.25 \\
& Desv. Pad. & 0.96 & 2.50 & 4.03 & 1.29 & 2.63 \\
\hline \multirow{2}{*}{ pH7 } & Média & 93.50 & 94.00 & 90.75 & 77.75 & 77.50 \\
& Desv. Pad. & 1.91 & 2.16 & 1.71 & 7.76 & 4.73 \\
\hline \multirow{2}{*}{ pH9 } & Média & 91.50 & 95.25 & 94.50 & 89.25 & 3.75 \\
& Desv. Pad. & 7.19 & 4.50 & 1.91 & 9.74 & 4.11 \\
\hline Filtração & Média & 90.25 & 93.00 & 89.75 & 92.50 & 72.25 \\
& Desv. Pad. & 4.11 & 3.56 & 3.86 & 3.11 & 9.46 \\
\hline \multirow{2}{*}{ Controle } & Média & & & & 91.75 \\
& Desv. Pad. & & & & 2.22 \\
\hline
\end{tabular}

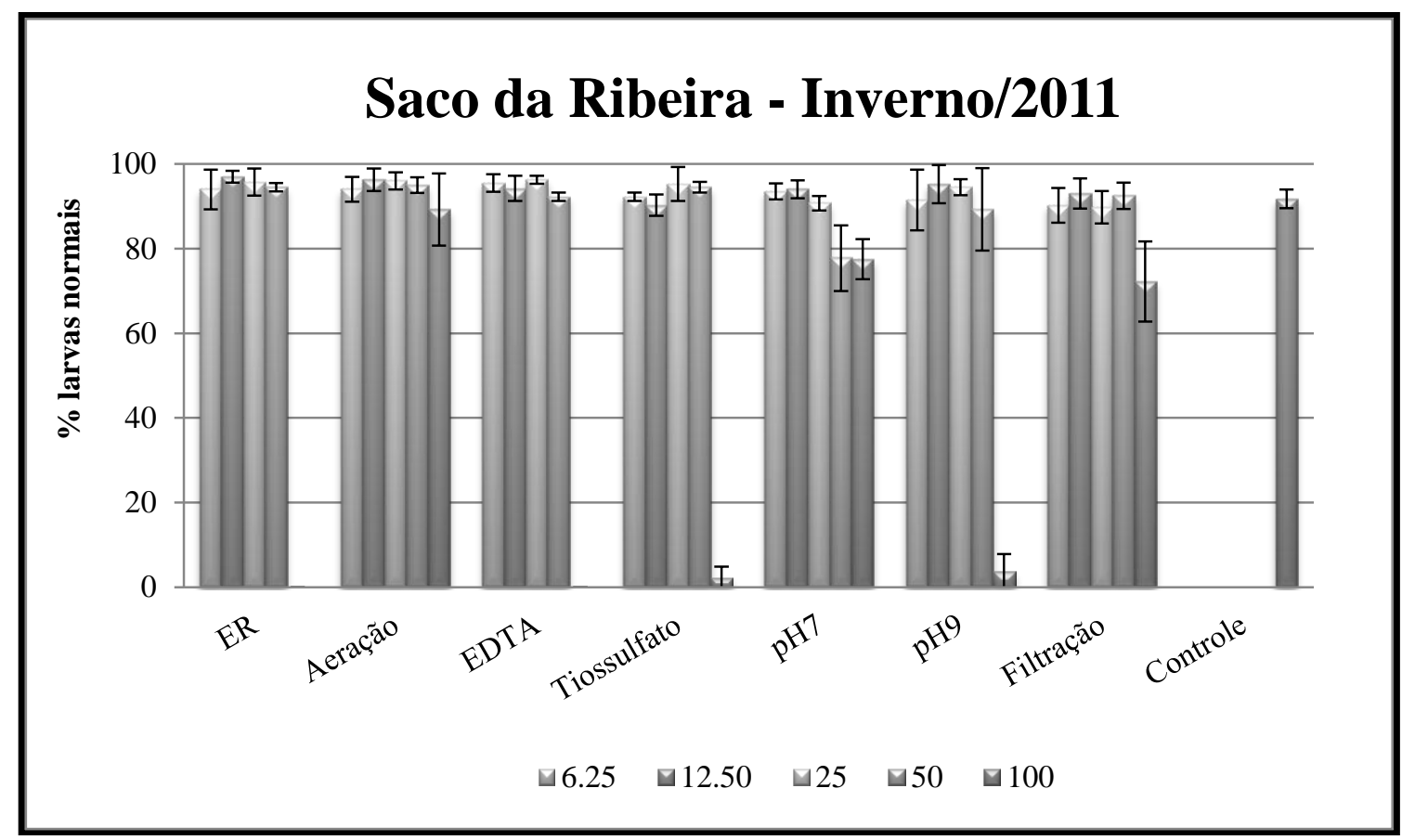

Figura 20. Resultados dos ensaios ecotoxicológicos do Inverno de 2011, nas várias concentrações testadas em cada manipulação da água intersticial do Saco da Ribeira. 
Nesta amostra todas as manipulações foram consideradas válidas. O Ensaio de Referência e as manipulações EDTA, Tiossulfato e pH9 apresentaram seus resultados, na concentração de $100 \%$, com toxicidade. Na manipulação Aeração não foi observada toxicidade.

Nesta amostra, a manipulação pH7 foi tóxica nas concentrações 50 e 100\%, sendo que nesta última, apresentou alta porcentagem média de larvas normais. O mesmo ocorreu com a concentração 100\% da manipulação Filtração, que apresentou toxicidade e alta porcentagem média de larvas normais.

\section{$\underline{\text { Primavera } 2011}$}

Foram medidos na concentração $100 \%$, de cada manipulação, no início dos ensaios ecotoxicológicos, as variáveis físicas e químicas $\mathrm{pH}$, salinidade e amônia total. A temperatura do ensaio foi mantida constante em $25^{\circ} \mathrm{C}$. A partir destes valores, a amônia não ionizada foi calculada. Os resultados dessas variáveis da amostra, em cada manipulação da campanha da Primavera 2011 estão apresentados na Tabela 21. 
Tabela 21. Resultado das análises das variáveis da amostra de água intersticial e nas diferentes manipulações da campanha de Primavera de 2011, coletada no Saco da Ribeira.

Saco da Ribeira - Primavera/2011

\begin{tabular}{ccccc}
\hline manipulação & Salinidade & Amônia total & $\mathrm{pH}$ & Am. N Ionizada \\
\hline ER & 35 & $1,0-3,0$ & 8.28 & $0,081-0,243$ \\
Aeração & 35 & 3.0 & 8.64 & 0.50 \\
EDTA & 35 & 3.0 & 8.15 & 0.18 \\
Tiossulfato & 35 & 3.00 & 8.42 & 0.33 \\
pH 7 & 35 & $>3,0$ & 7.00 & $>0,014$ \\
pH 9 & 35 & $1,0-3,0$ & 9.00 & $0,316-0,949$ \\
Filtração & 35 & $1,0-3,0$ & 8.60 & $0,155-0,466$ \\
Controle & 35 & 0 & 8.64 & 0.00 \\
\hline \multicolumn{5}{c}{ valor acima do limite de sensibilidade para a espécie }
\end{tabular}

Am. N Ionizada - Amônia não ionizada

Os resultados nos mostraram que não houve variação da salinidade nas manipulações e no controle. Com relação à amônia total, a manipulação pH7 apresentou maior valor, 3,0 mg. $\mathrm{L}^{-1}$.

$\mathrm{O}$ pH apresentou pequena variação nas manipulações, exceto naquelas em queeste foi alterado propositadamente.

A amônia não ionizada, com valores > 0,05, está acima do limite de sensibilidade para as larvas de Lytechinus variegatus, o que ocorreu na maioria das manipulações, exceto na manipulação pH7.

A porcentagem média e o desvio padrão de larvas normais de Lytechinus variegatus para cada concentração testada e para cada manipulação das campanhas de Outono de 2011 estão apresentados na Tabela 22 e representados na Figura 21 
Tabela 22. Porcentagem média e desvio padrão de larvas normais de Lytechinus variegatus na Primavera de 2011, nas várias concentrações testadas em cada manipulação da água intersticial do Saco da Ribeira.

\section{Saco da Ribeira - Primavera /2011}

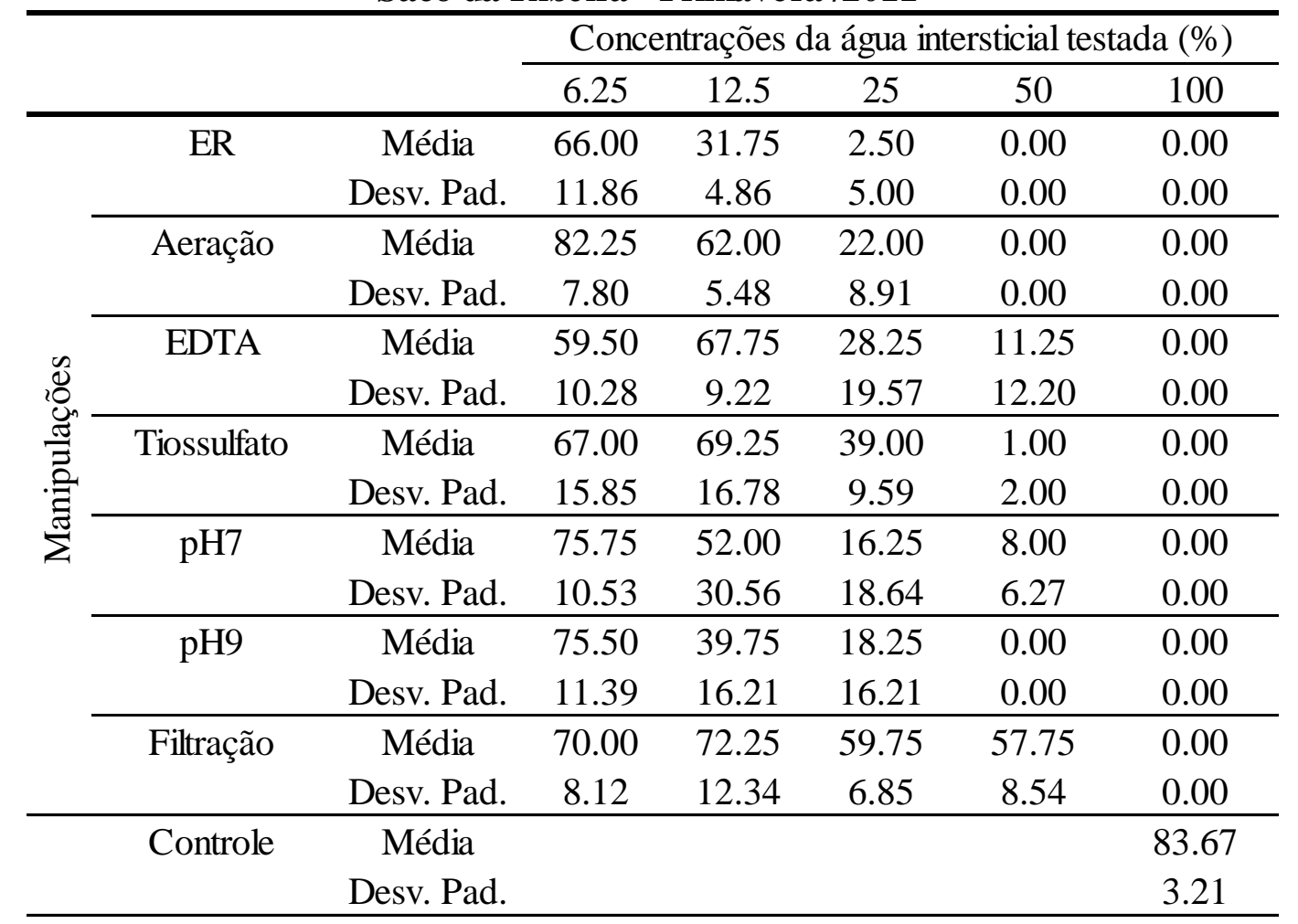

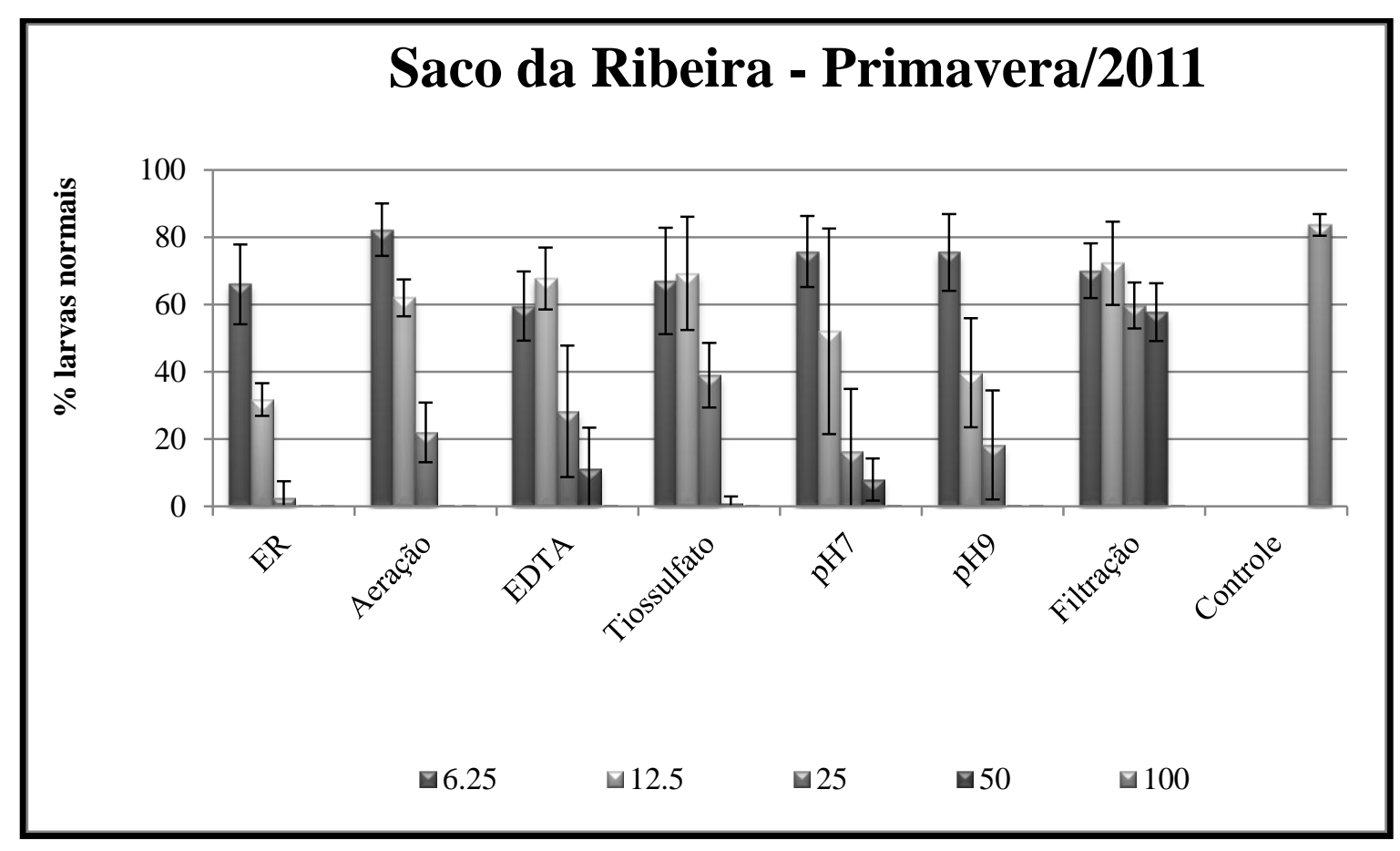

Figura 21. Resultados dos ensaios ecotoxicológicos da Primavera de 2011, nas várias concentrações testadas em cada manipulação da água intersticial do Saco da Ribeira. 
Nesta amostra os resultados da manipulação Aeração e pH7 foram considerados não válidos. O Ensaio Referência e a manipulacao pH9 apresentaram toxicidade nas concentrações 12,5; 25; 50 e 100 \%. Já a manipulação EDTA apresentou tóxicidade para todas as concentrações testadas. Com a manipulação Tiossulfato, as concentrações 25, 50 e $100 \%$ foram tóxicas. Na Filtração apenas na concentração 12,5\% não foi observada toxicidade.

\section{$\underline{\text { Verão de } 2012}$}

Foram medidas na concentração $100 \%$, de cada manipulação, no início dos ensaios ecotoxicológicos, as variáveis físicas e químicas pH, salinidade e amônia total. A temperatura do ensaio foi mantida constante em $25^{\circ} \mathrm{C}$. A partir destes valores, a amônia não ionizada foi calculada. Os resultados dessas variáveis da amostra, em cada manipulação da campanha do Verão de 2012 estão apresentados na Tabela 23.

Tabela 23. Resultado das análises das variáveis da amostra de água intersticial e nas diferentes manipulações da campanha de Verão de 2012, coletada no Saco da Ribeira.

Saco da Ribeira - Verão/2012

\begin{tabular}{ccccc}
\hline manipulação & Salinidade & Amônia total & $\mathrm{pH}$ & Am. N Ionizada \\
\hline ER & 36 & 0.60 & 7.65 & 0.01 \\
Aeração & 36 & 1.00 & 7.76 & 0.03 \\
EDTA & 36 & 1.00 & 7.63 & 0.02 \\
Tiossulfato & 36 & 0.80 & 7.58 & 0.01 \\
pH 7 & 36 & 1.00 & 7.71 & 0.02 \\
pH 9 & 36 & 0.60 & 7.92 & 0.02 \\
Filtração & 36 & 1.00 & 7.83 & 0.03 \\
Controle & 36 & 0.10 & 7.99 & 0.00 \\
\hline
\end{tabular}

valor acima do limite de sensibilidade para a espécie

Am. N Ionizada - Amônia não ionizada 
Não houve variação da salinidade nas manipulações e no controle. Com relação à amônia total, as manipulações Aeração, EDTA, pH7 e Filtração apresentaram maiores valores, $1,0 \mathrm{mg} \cdot \mathrm{L}^{-1}$.

$\mathrm{O}$ pH apresentou pequena variação nas manipulações, exceto naquelas cujos valores foram alterados propositadamente.

Nenhuma das manipulações apresentou valores da amônia não ionizada acima de 0,05, limite de sensibilidade para as larvas de Lytechinus variegatus.

A porcentagem média e o desvio padrão de larvas normais de Lytechinus variegatus para cada concentração testada e para cada manipulação da campanha de Verão de 2012 estão apresentados na tabela 24 e representados na figura 22.

Tabela 24. Porcentagem média e desvio padrão de larvas normais de Lytechinus variegatus no Verão de 2012, nas várias concentrações testadas em cada manipulação da água intersticial do Saco da Ribeira.

\section{Saco da Ribeira - Verão/2012}

\begin{tabular}{ccccccc}
\hline & & \multicolumn{5}{c}{ Concentrações da água intersticial testada (\%) } \\
\cline { 3 - 7 } & & 6.25 & 12.5 & 25 & 50 & 100 \\
\hline \multirow{2}{*}{ ER } & Média & 76.25 & 76.50 & 76.50 & 74.25 & 37.75 \\
& Desv. Pad. & 3.10 & 5.45 & 2.38 & 3.86 & 10.50 \\
\hline \multirow{2}{*}{ Aeração } & Média & 84.50 & 75.00 & 77.75 & 71.75 & 75.75 \\
& Desv. Pad. & 4.80 & 5.10 & 4.57 & 2.75 & 7.37 \\
\hline \multirow{2}{*}{ EDTA } & Média & 76.00 & 76.25 & 73.75 & 73.50 & 71.25 \\
& Desv. Pad. & 6.48 & 9.71 & 6.60 & 5.92 & 7.18 \\
\hline \multirow{2}{*}{ Tiossulfato } & Média & 81.50 & 80.00 & 80.25 & 78.25 & 78.25 \\
& Desv. Pad. & 5.07 & 8.72 & 6.45 & 3.59 & 3.59 \\
\hline \multirow{2}{*}{ pH7 } & Média & 86.25 & 84.75 & 84.25 & 84.25 & 70.00 \\
& Desv. Pad. & 2.63 & 5.56 & 2.06 & 2.06 & 6.22 \\
\hline \multirow{2}{*}{ pH9 } & Média & 78.00 & 82.75 & 82.25 & 83.25 & 49.25 \\
& Desv. Pad. & 3.74 & 3.30 & 5.68 & 4.92 & 13.45 \\
\hline \multirow{2}{*}{ Filtração } & Média & 86.75 & 84.50 & 91.00 & 89.75 & 81.75 \\
& Desv. Pad. & 3.59 & 3.70 & 1.15 & 2.50 & 1.26 \\
\hline \multirow{2}{*}{ Controle } & Média & & & & & 80.00 \\
& Desv. Pad. & & & & & 2.58 \\
\hline
\end{tabular}




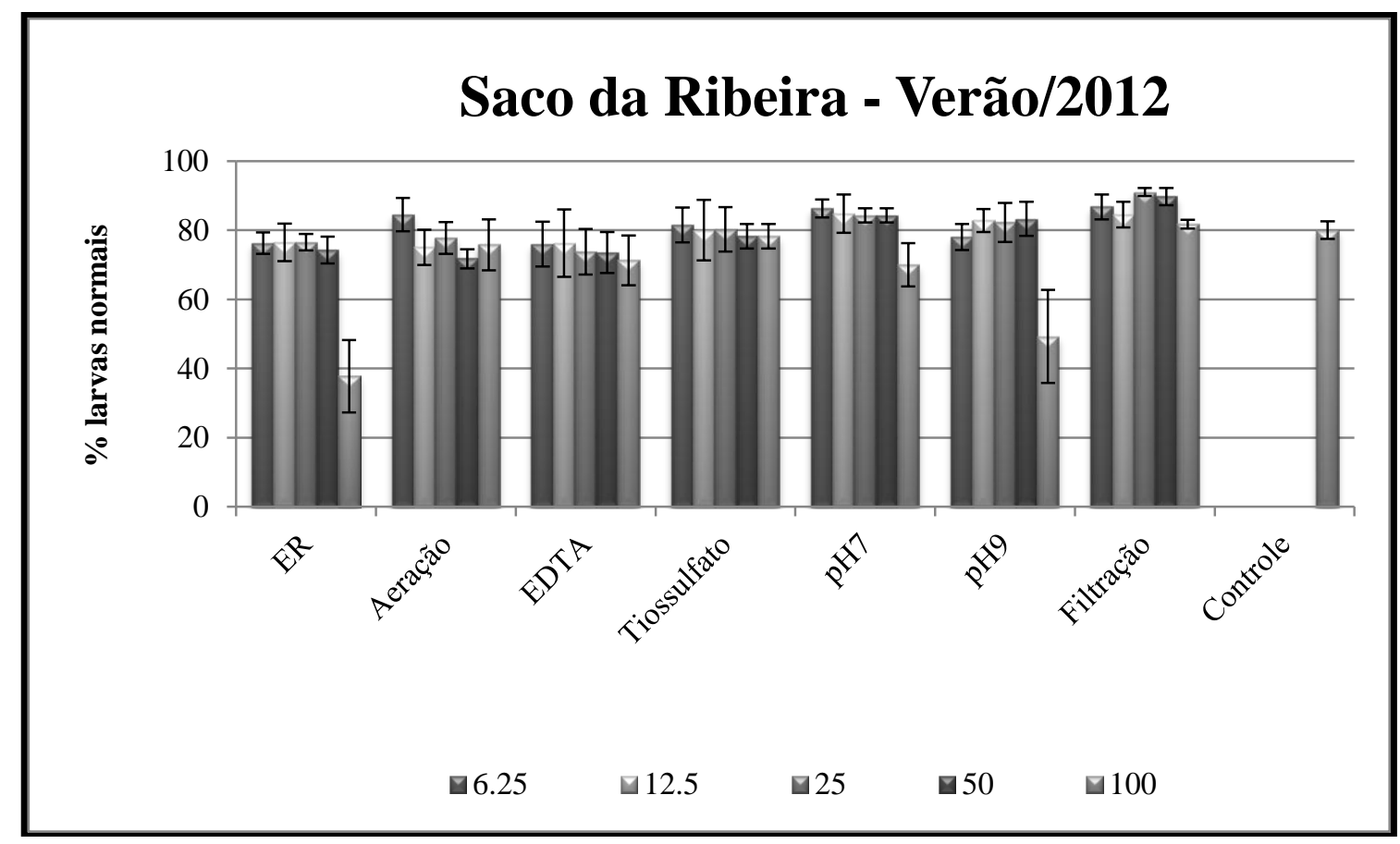

Figura 22. Resultados dos ensaios ecotoxicológicos do Verão de 2012, nas várias concentrações testadas em cada manipulação da água intersticial do Saco da Ribeira.

Nesta amostra a manipulação pH7 foi considerada não válida. A concentração 100\% das manipulações Ensaio Referência e pH9 apresentaram toxicidade.

A manipulação Aeração apresentou a concentração de 50\% tóxica mesmo com alta porcentagem média de larvas normais. As demais manipulações, EDTA, Tiossulfato e Filtração não obtiveram nenhuma concentração com toxicidade.

\subsubsection{Ilha do Mar Virado}

\section{Outono de 2011}

Foram medidos na concentração $100 \%$, de cada manipulação, no início dos ensaios ecotoxicológicos, as variáveis físico e químicas $\mathrm{pH}$, salinidade e amônia total.A amônia não ionizada foi calculada. A temperatura do ensaio foi mantida constante em 
$25^{\circ} \mathrm{C}$. Os resultados dessas variáveis da amostra, em cada manipulação da campanha do Outono 2011 estão apresentados na Tabela 25.

Tabela 25. Resultado das análises das variáveis da amostra de água intersticial nas diferentes manipulações da campanha de Outono de 2011, coletada na Ilha do Mar Virado.

Ilha do Mar Virado - Outono/2011

\begin{tabular}{ccccc}
\hline manipulação & Salinidade & Amônia total & $\mathrm{pH}$ & Am. N Ionizada \\
\hline ER & 35 & 0.50 & 7.27 & 0.00 \\
Aeração & 35 & 0.50 & 7.18 & 0.00 \\
EDTA & 35 & 0.50 & 7.02 & 0.00 \\
Tiossulfato & 35 & 0.01 & 7.09 & 0.00 \\
pH 7 & 35 & 0.50 & 7.00 & 0.00 \\
pH 9 & 35 & 0.50 & 9.00 & 0.03 \\
Filtração & 35 & 0.50 & 7.85 & 0.02 \\
Controle & 33 & 0.05 & 8.55 & 0.01 \\
\hline
\end{tabular}

valor acima do limite de sensibilidade para a espécie

Am. N Ionizada - Amônia não ionizada

Os resultados nos mostraram que não houve variação da salinidade nas manipulações com salinidade 35 e 33 no controle. Com relação à amônia total, todas as manipulações apresentaram valores iguais, $0,5 \mathrm{mg} . \mathrm{L}^{-1}$, com exceção da manipulação Tiossulfato com valor de $0,01 \mathrm{mg} \cdot \mathrm{L}^{-1}$.

$\mathrm{O}$ pH apresentou pequena variação nas manipulações, exceto naquelas cujos valores foram alterados propositadamente. A temperatura do teste manteve-se constante em $25^{\circ} \mathrm{C}$.

Nenhuma das manipulações apresentou valores da amônia não ionizada acima de $0,05 \mathrm{mg} / \mathrm{L}^{-1}$, limite de sensibilidade para as larvas de Lytechinus variegatus. 
A porcentagem média e o desvio padrão, de larvas normais de Lytechinus variegatus para cada concentração testada e para cada manipulação da campanha de Outono de 2011 estão apresentados na Tabela 26 e representados na Figura 23.

Tabela 26. Porcentagem média e desvio padrão de larvas normais de Lytechinus variegatus no Outono de 2011, nas várias concentrações testadas em cada manipulação da água intersticial da Ilha do Mar Virado.

\section{Ilha do Mar Virado - Outono/2011}

\begin{tabular}{ccccccc}
\hline & & \multicolumn{5}{c}{ Concentrações da água intersticial testada (\%) } \\
\cline { 3 - 7 } & & 6.25 & 12.5 & 25 & 50 & 100 \\
\hline \multirow{2}{*}{ ER } & Média & 79.75 & 86.00 & 83.00 & 89.50 & 89.75 \\
& Desv. Pad. & 12.31 & 3.27 & 6.68 & 2.89 & 4.92 \\
\hline \multirow{2}{*}{ Aeração } & Média & 88.50 & - & 59.00 & 73.50 & 81.25 \\
& Desv. Pad. & 2.38 & - & 13.95 & 7.05 & 2.99 \\
\hline \multirow{2}{*}{ EDTA } & Média & 94.50 & 80.50 & 83.75 & 61.50 & 86.50 \\
& Desv. Pad. & 3.32 & 8.50 & 0.96 & 13.40 & 8.27 \\
\hline \multirow{2}{*}{ Tiossulfato } & Média & 93.25 & 96.00 & 86.00 & 84.00 & 76.50 \\
& Desv. Pad. & 4.11 & 1.83 & 3.65 & 1.63 & 8.27 \\
\hline \multirow{2}{*}{ pH7 } & Média & 92.25 & 88.50 & 95.00 & 92.50 & 83.25 \\
& Desv. Pad. & 5.19 & 5.20 & 1.41 & 1.29 & 3.30 \\
\hline \multirow{2}{*}{ pH9 } & Média & 95.25 & 95.00 & 81.50 & 87.75 & 73.00 \\
& Desv. Pad. & 4.11 & 1.63 & 14.82 & 9.54 & 10.61 \\
\hline Filtração & Média & 92.25 & 92.25 & 96.00 & 94.50 & 93.25 \\
& Desv. Pad. & 0.50 & 3.59 & 2.45 & 2.52 & 4.11 \\
\hline Controle & Média & & & & 89.75 \\
& Desv. Pad. & & & & & 4.92 \\
\hline
\end{tabular}

- amostra não analisada 


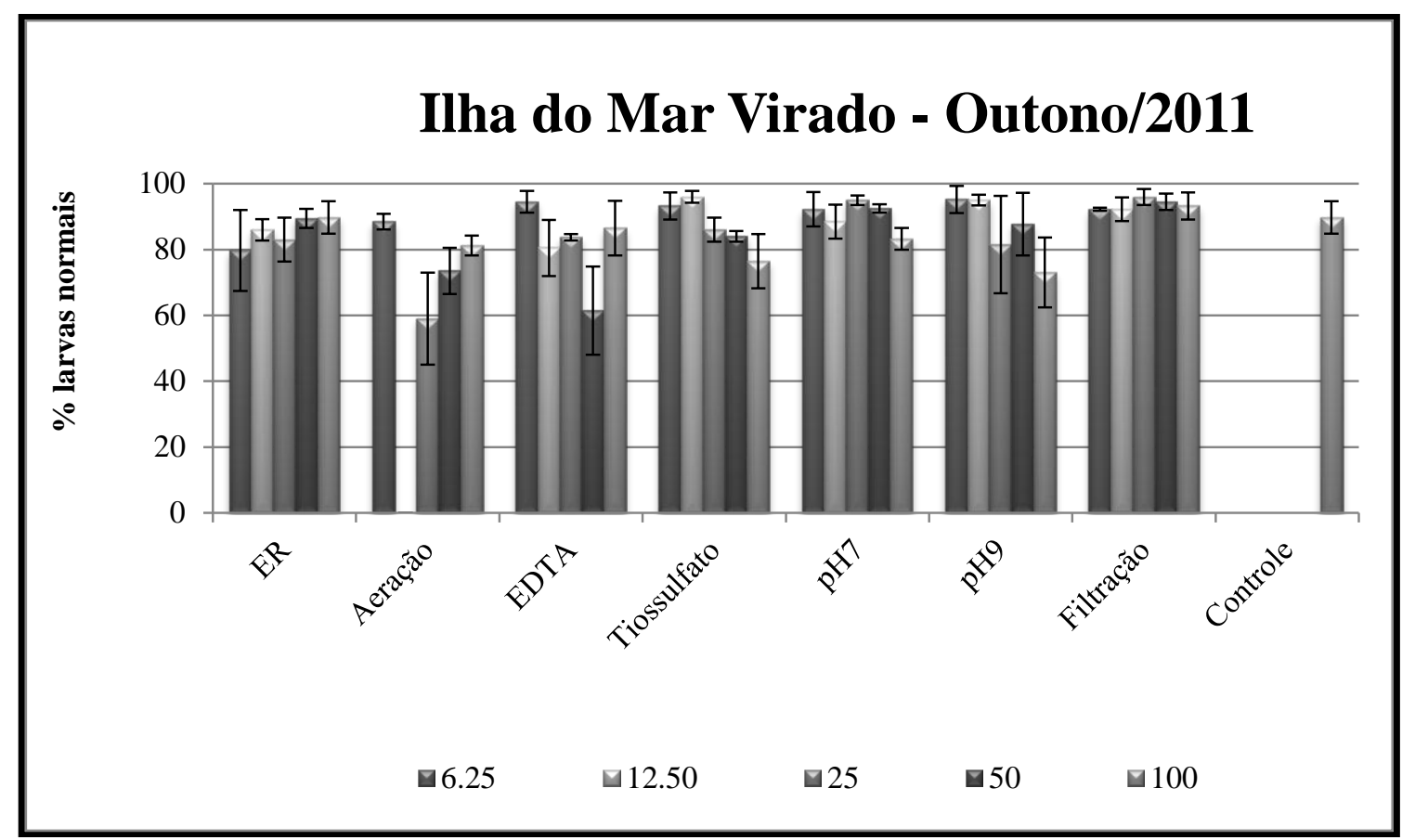

Figura 23. Resultados dos ensaios ecotoxicológicos do outono 2011, nas várias concentrações testadas em cada manipulação da água intersticial da Ilha do Mar Virado.

As manipulações Aeração, pH7 e pH9 desta amostra foram consideradas não válidas. Esta amostra não se apresentou tóxica no Ensaio Referência bem como na manipulação Filtração.

A manipulação EDTA mostrou toxicidade nas concentrações 25 e 50\%, embora tenha apresentado alta porcentagem média de larvas normais na concentração 25\%. A manipulação Tiossulfato apresentou toxicidade somente na concentração de $100 \%$.

\section{$\underline{\text { Inverno de } 2011}$}

Foram medidos na concentração $100 \%$, de cada manipulação, no início dos ensaios ecotoxicológicos, as variáveis físicas e químicas pH, salinidade e amônia total. A temperatura do ensaio foi mantida constante em $25^{\circ} \mathrm{C}$. A partir destes valores, a 
amônia não ionizada foi calculada. Os resultados dessas variáveis da amostra, em cada manipulação da campanha do Inverno 2011 estão apresentados na Tabela 27.

Tabela 27. Resultado das análises das variáveis da amostra de água intersticial e nas diferentes manipulações da campanha de Inverno de 2011, coletada na Ilha do Mar Virado.

Ilha do Mar Virado - Inverno/2011

\begin{tabular}{ccccc}
\hline manipulação & Salinidade & Amônia total & $\mathrm{pH}$ & Am. N Ionizada \\
\hline ER & 35 & 0.20 & 7.87 & 0.01 \\
Aeração & 35 & 1.00 & 7.92 & 0.04 \\
EDTA & 35 & 0.50 & 7.42 & 0.01 \\
Tiossulfato & 35 & 1.00 & 7.82 & 0.03 \\
pH 7 & 35 & 1.00 & 7.00 & 0.00 \\
pH 9 & 35 & 3.00 & 9.00 & 0.23 \\
Filtração & 35 & 0.20 & 8.25 & 0.02 \\
Controle & 35 & $<0,01$ & 8.61 & 0.00 \\
\hline
\end{tabular}

valor acima do limite de sensibilidade para a espécie

Am. N Ionizada - Amônia não ionizada

Não houve variação da salinidade nas manipulações e no controle. Com relação à amônia total, a manipulação pH9 apresentou o maior valor, 3,0 mg. $\mathrm{L}^{-1}$.

$\mathrm{O}$ pH apresentou pequena variação nas manipulações, exceto naquelas em que foi alterado propositadamente.

A amônia não ionizada, com valores acima de $0,05 \mathrm{mg} / \mathrm{L}^{-1}$, está acima do limite de sensibilidade para as larvas de Lytechinus variegatus, o que ocorreu somente na manipulação pH9.

A porcentagem média e o desvio padrão de larvas normais de Lytechinus variegatus para cada concentração testada e para cada manipulação da campanha de Outono de 2011 estão apresentados na Tabela 28 e representados na Figura 24. 
Tabela 28. Porcentagem média e desvio padrão de larvas normais de Lytechinus variegatus no Inverno de 2011, nas várias concentrações testadas em cada manipulação da água intersticial da Ilha do Mar Virado.

Ilha do Mar Virado - Inverno/2011

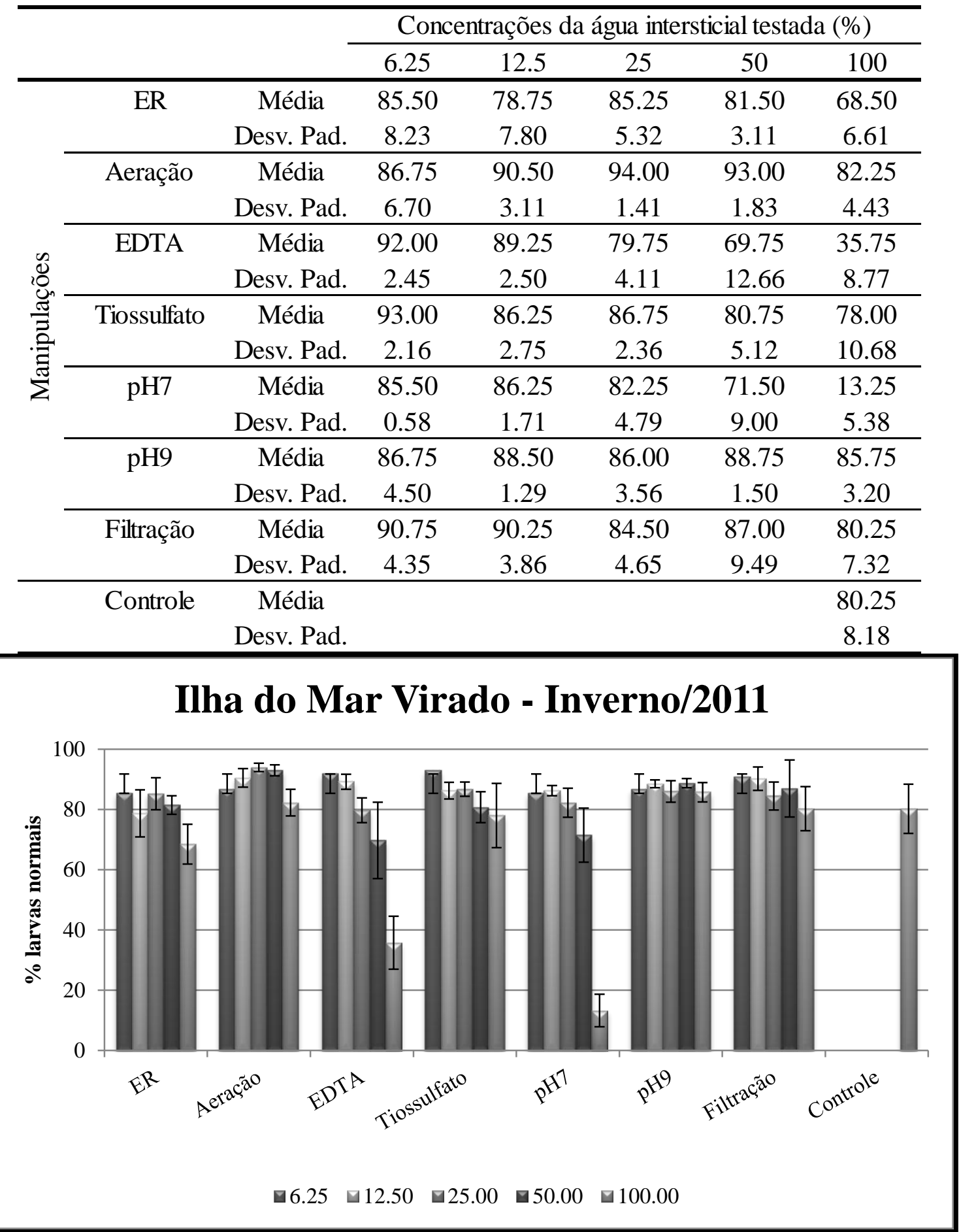

Figura 24. Resultados dos ensaios ecotoxicológicos do Inverno de 2011, nas várias concentrações testadas em cada manipulação da água intersticial da Ilha do Mar Virado. 
A manipulação pH7 dessa amostra foi considerada não válida. As demais manipulações não apresentaram toxicidade, exceto a concentração $100 \%$ da manipulação EDTA.

\section{Primavera de 2011}

Nesta amostra apenas o Ensaio Referência e a manipulação Filtração apresentaram-se válidas, assim somente estes resultados foram descritos.

Foram medidos na concentração $100 \%$, dessas manipulações, no início dos ensaios ecotoxicológicos, as variáveis físico e químicas $\mathrm{pH}$, salinidade e amônia total. A temperatura do ensaio foi mantida constante em $25^{\circ} \mathrm{C}$. A partir destes valores, a amônia não ionizada foi calculada. Os resultados dessas variáveis da amostra, em cada manipulação da campanha da Primavera 2011 estão apresentados na Tabela 29.

Tabela 29. Resultado das análises das variáveis da amostra de água intersticial e nas manipulações Ensaio Referência e Filtração da campanha de Primavera de 2011, coletada na Ilha do Mar Virado.

\section{Ilha do Mar Virado - Primavera/2011}

\begin{tabular}{ccccc}
\hline manipulação & Salinidade & Amônia total & $\mathrm{pH}$ & Am. N Ionizada \\
\hline ER & 36 & 0.50 & 8.30 & 0.04 \\
Filtração & 36 & 0.20 & 8.57 & 0.03 \\
Controle & 35 & 0.00 & 8.61 & 0.00 \\
\hline \multicolumn{5}{c}{ valor acima do limite de sensibilidade para a espécie }
\end{tabular}

Am. N Ionizada - Amônia não ionizada

Não houve variação da salinidade nas manipulações . Com relação à amônia total, o Ensaio Referência apresentou maior valor com 0,5 mg. $\mathrm{L}^{-1}$.

$\mathrm{O}$ pH apresentou pequena variação nas manipulações. 
Não foram verificados, em nenhuma das manipulações, valores de amônia não ionizada, acima de $0,05 \mathrm{mg} / \mathrm{L}^{-1}$, limite de sensibilidade para as larvas de Lytechinus variegatus.

A porcentagem média e o desvio padrão de larvas normais de Lytechinus variegatus para cada concentração testada e para o Ensaio Referência e a manipulação Filtração da campanha da Primavera de 2011 estão apresentados na Tabela 30 e representados na Figura 25.

Tabela 30. Porcentagem média e desvio padrão de larvas normais de Lytechinus variegatus na Primavera de 2011, nas várias concentrações testadas das manipulações Ensaio Referência e Filtração da água intersticial da Ilha do Mar Virado.

\begin{tabular}{|c|c|c|c|c|c|c|c|}
\hline \multicolumn{8}{|c|}{ Ilha do Mar Virado - Primavera/2011 } \\
\hline & & & \multicolumn{5}{|c|}{ Concentrações da água intersticial testada (\%) } \\
\hline & & & 6.25 & 12.5 & 25 & 50 & 100 \\
\hline \multirow{4}{*}{ 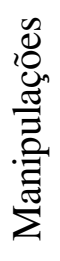 } & ER & Média & 55.50 & 43.00 & 12.50 & 8.00 & 35.00 \\
\hline & & Desv. Pad. & 6.56 & 12.03 & 7.51 & 5.42 & 4.83 \\
\hline & Filtração & Média & 41.50 & 40.00 & 30.00 & 28.50 & 83.00 \\
\hline & & Desv. Pad. & 13.82 & 14.05 & 9.13 & 11.27 & 6.16 \\
\hline & Controlar & Média & & & & & 83.25 \\
\hline & & Desv. Pad. & & & & & 4.03 \\
\hline
\end{tabular}




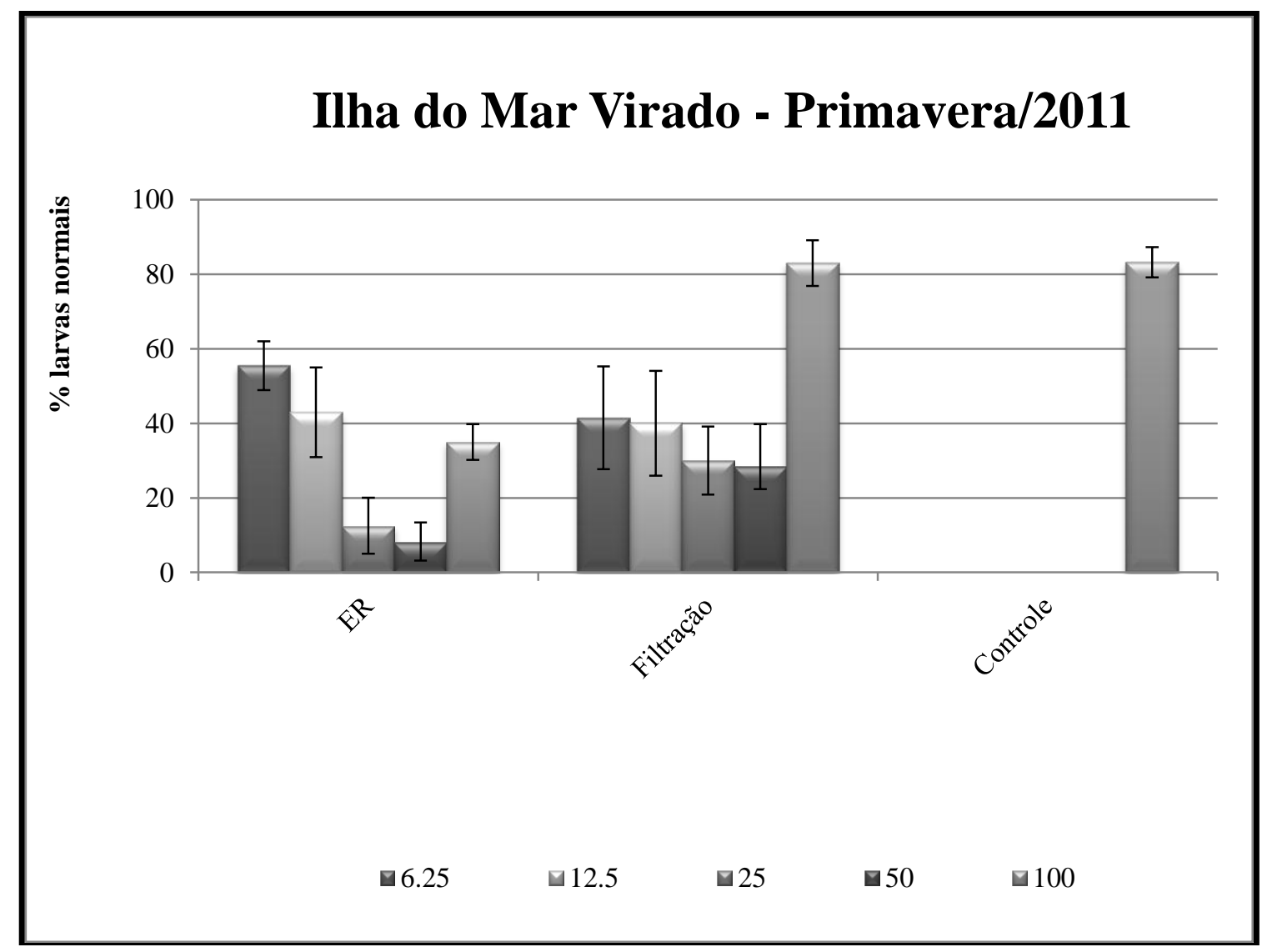

Figura 25. Resultados dos ensaios ecotoxicológicos da Primavera de 2011, nas várias concentrações testadas das manipulações Ensaio Referência e Filtração da água intersticial da Ilha do Mar Virado.

O Ensaio Referência e a manipulação Filtração apresentaram toxicidade em todas as concentrações testadas, exceto na concentração $100 \%$ da manipulação Filtração.

\section{Verão de 2012}

Foram medidos na concentração $100 \%$ de cada manipulação, no início dos ensaios ecotoxicológicos, as variáveis físicas e químicas pH, salinidade e amônia total. A temperatura do ensaio foi mantida constante em $25^{\circ} \mathrm{C}$. A partir destes valores, a amônia não ionizada foi calculada. Os resultados dessas variáveis da amostra, em cada manipulação da campanha do Verão de 2012 estão apresentados na Tabela 31. 
Tabela 31. Resultado das análises das variáveis da amostra de água intersticial nas diferentes manipulações da campanha de Verão de 2012, coletada na Ilha do Mar Virado.

\section{Ilha do Mar Virado - Verão/2012}

\begin{tabular}{ccccc}
\hline manipulação & Salinidade & Amônia total & $\mathrm{pH}$ & Am. N Ionizada \\
\hline ER & 36 & $0,2-0,5$ & 7.58 & $0,003-0,009$ \\
Aeração & 36 & 0.50 & 7.89 & 0.02 \\
EDTA & 36 & 0.50 & 7.47 & 0.01 \\
Tiossulfato & 36 & 0.50 & 7.65 & 0.01 \\
pH 7 & 36 & 0.50 & 7.00 & 0.00 \\
pH 9 & 36 & 0.50 & 8.73 & 0.10 \\
Filtração & 36 & $0,2-0,5$ & 7.87 & $0,007-0,017$ \\
Controle & 36 & 0.00 & 7.89 & 0.00 \\
\hline
\end{tabular}

valor acima do limite de sensibilidade para a espécie

Am. N Ionizada - Amônia não ionizada

Não houve variação da salinidade nas manipulações e no controle. Com relação à amônia total, o Ensaio Referência e a manipulação Filtração apresentaram menores valores, entre 0,2 e 0,5 .

$\mathrm{O}$ pH apresentou pequena variação nas manipulações, exceto naquelas cujos valores foram alterados propositadamente.

A amônia não ionizada, com valores acima de $0,05 \mathrm{mg} / \mathrm{L}^{-1}$, está acima do limite de sensibilidade para as larvas de Lytechinus variegatus, o que ocorreu somente na manipulação pH9.

A porcentagem média e o desvio padrão de larvas normais de Lytechinus variegatus para cada concentração testada e para cada manipulação da campanha de Verão de 2012 estão apresentados na Tabela 32 e representados na Figura 26. 
Tabela 32. Porcentagem média e desvio padrão de larvas normais de Lytechinus variegatus no Verão de 2012, nas várias concentrações testadas em cada manipulação da água intersticial da Ilha do Mar Virado.

Illha do Mar Virado - Verão/2012

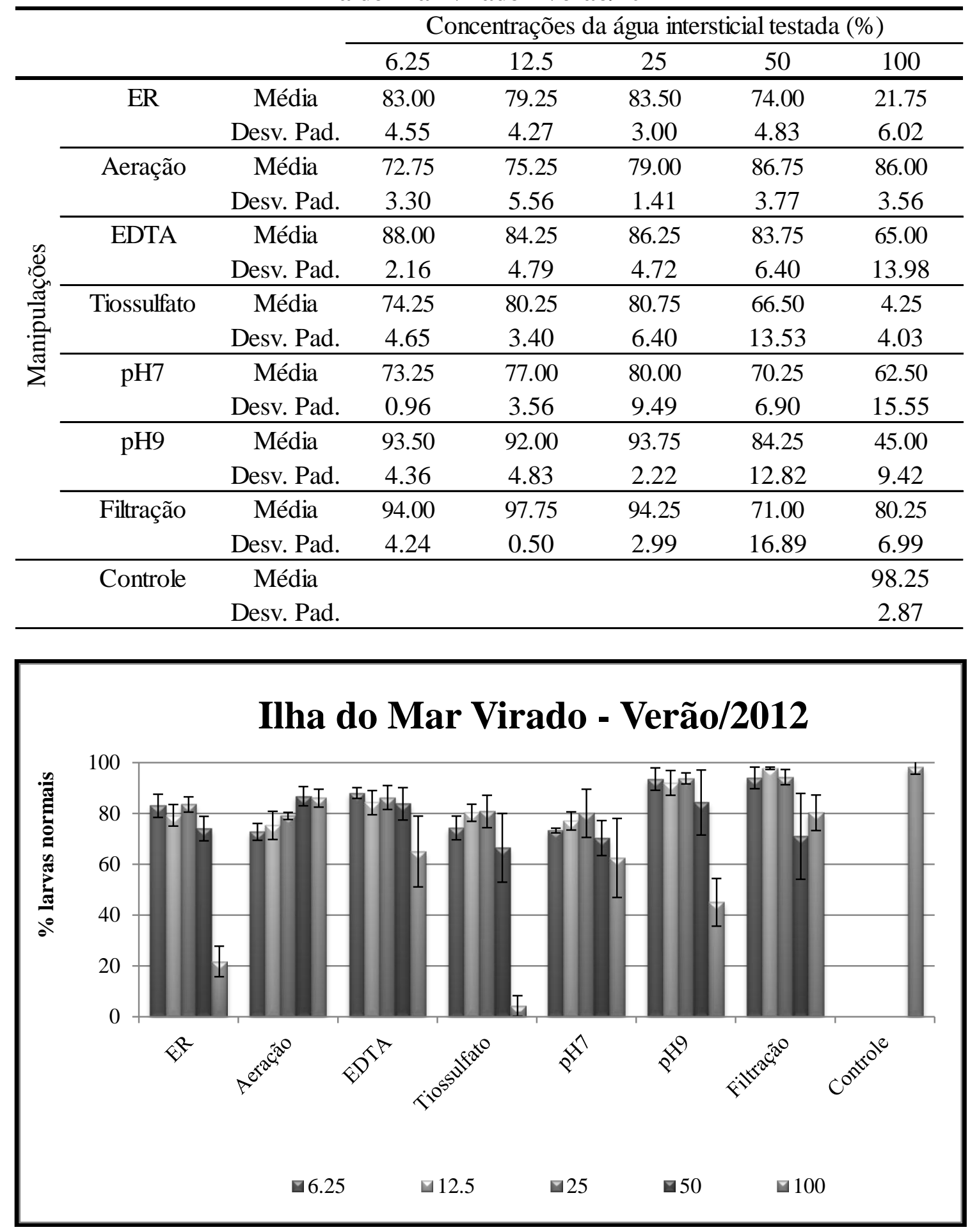

Figura 26. Resultados dos ensaios ecotoxicológicos do Verão de 2012, nas várias concentrações testadas em cada manipulação da água intersticial da Ilha do Mar Virado. 
Todas as manipulações dessa amostra se apresentaram válidas. O Ensaio Referência e as manipulações Aeração, EDTA, Tiossulfato e pH7 apresentaram toxicidade em todas as concentrações analisadas, embora em pelo menos uma concentração testada a porcentagem média de larvas normais tenha sido alta.

As manipulações pH9 e Filtração apresentaram toxicidade nas concentrações 50 e $100 \%$, apesar da alta porcentagem média de larvas normais na concentração de 50\% na manipulação pH9., e na concentração 100\% da Filtração.

\subsubsection{Caraguatatuba}

\section{$\underline{\text { Outono de } 2011}$}

Foram medidos na concentração $100 \%$ de cada manipulação, no início dos ensaios ecotoxicológicos, as variáveis físicas e químicas $\mathrm{pH}$, salinidade e amônia total. A temperatura do ensaio foi mantida constante em $25^{\circ} \mathrm{C}$. A partir destes valores, a amônia não ionizada foi calculada. Os resultados dessas variáveis da amostra, em cada manipulação da campanha do Outono 2011 estão apresentados na Tabela 33. 
Tabela 33. Resultado das análises das variáveis da amostra de água intersticial e nas diferentes manipulações da campanha de Outono de 2011, coletada em Caraguatatuba.

Caraguatatuba - Outono/2011

\begin{tabular}{ccccc}
\hline manipulação & Salinidade & Amônia total & $\mathrm{pH}$ & Am. N Ionizada \\
\hline ER & 33 & 1.00 & 7.40 & 0.01 \\
Aeração & 33 & 1.00 & 7.48 & 0.01 \\
EDTA & 33 & 1.00 & 7.17 & 0.01 \\
Tiossulfato & 33 & 0.50 & 7.63 & 0.01 \\
pH 7 & 33 & 1.00 & 7.00 & 0.01 \\
pH 9 & 33 & 0.00 & 9.00 & 0.00 \\
Filtração & 33 & 1.00 & 7.90 & 0.04 \\
Controle & 33 & 0.05 & 8.05 & 0.00 \\
\hline
\end{tabular}

valor acima do limite de sensibilidade para a espécie

Am. N Ionizada - Amônia não ionizada

Não houve variação da salinidade nas manipulações e no controle. Com relação à amônia total, a manipulação pH9 apresentou o menor valor.

$\mathrm{O}$ pH apresentou pequena variação nas manipulações, exceto naquelas cujos valores foram alterados propositadamente.

A amônia não ionizada, com valores $>0,05 \mathrm{mg} / \mathrm{L}^{-1}$, está acima do limite de sensibilidade para as larvas de Lytechinus variegatus, o que não ocorreu em nenhuma manipulação.

A porcentagem média e o desvio padrão de larvas normais de Lytechinus variegatus para cada concentração testada e para cada manipulação da campanha de Outono de 2011 estão apresentados na Tabela 34 e representados na Figura 27. 
Tabela 34. Porcentagem média e desvio padrão de larvas normais de Lytechinus variegatus no Outono de 2011, nas várias concentrações testadas em cada manipulação da água intersticial de Caraguatatuba.

\section{Caraguatatuba - Outono/2011}

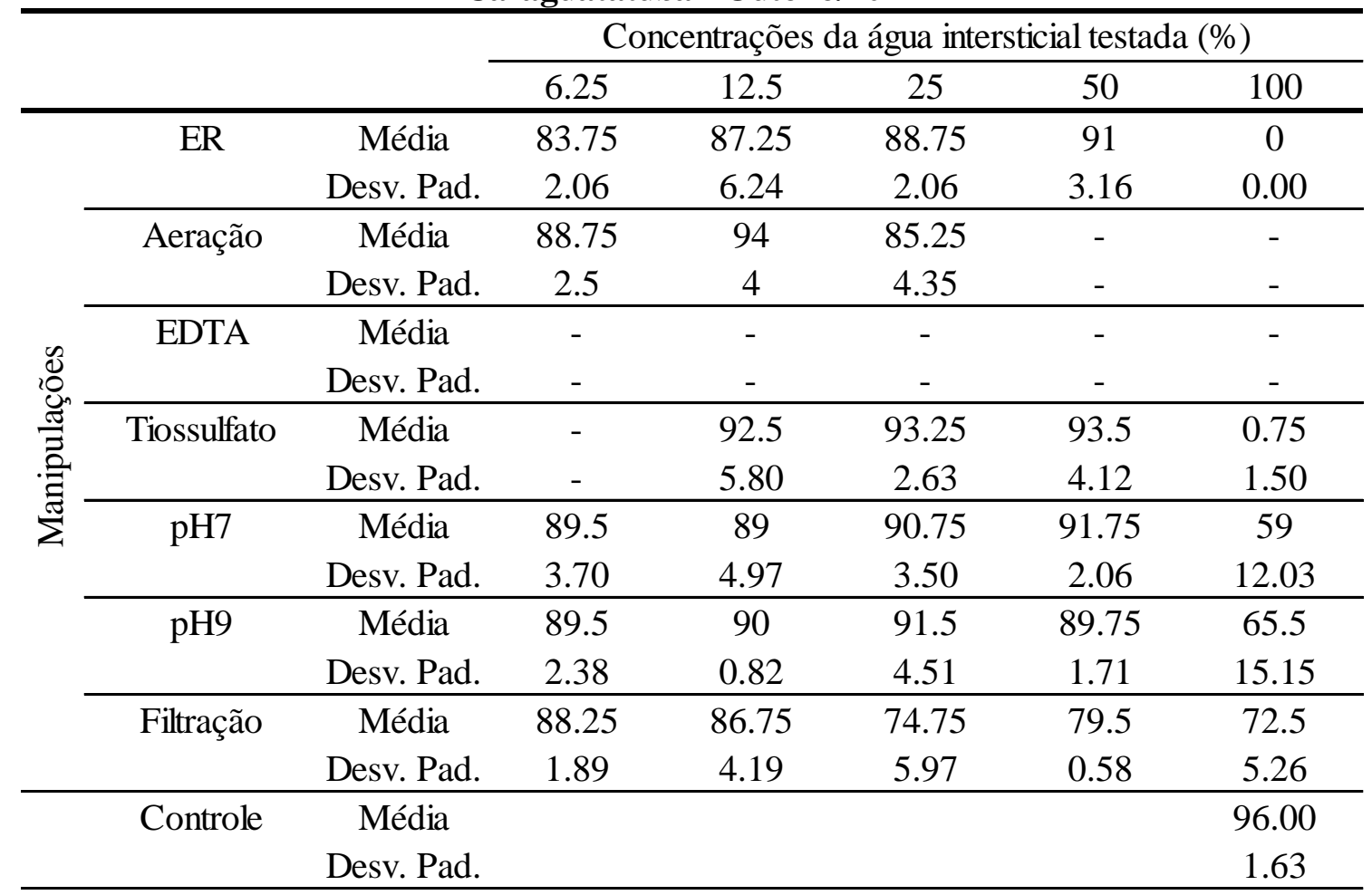

- amostra não analisada

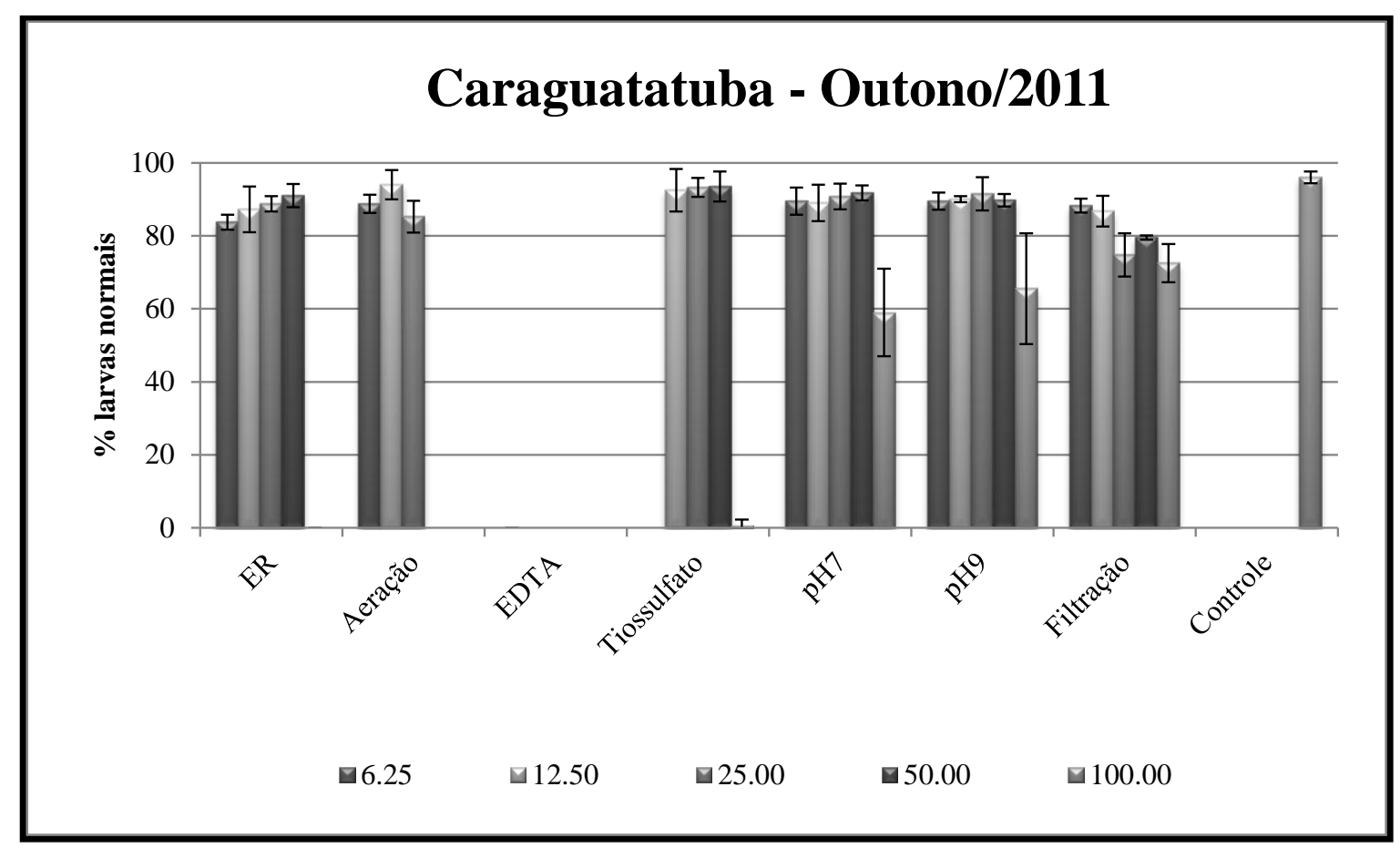

Figura 27. Resultados dos ensaios ecotoxicológicos do Outono de 2011, nas várias concentrações testadas em cada manipulação da água intersticial de Caraguatatuba. 
A manipulação pH7 dessa amostra não foi considerada válida. A EDTA não foi analisada.

O Ensaio Referência apresentou toxicidade em todas as concentrações analisadas, mesmo com alta porcentagem média de larvas normais em algumas das concentrações testadas. Isso também ocorreu na manipulação Filtração.

$\mathrm{Na}$ Aeração, as concentrações 50 e 100\% não foram analisadas, enquanto que nas concentrações 6,25 e $25 \%$ houve toxicidade.

A concentração $100 \%$ foi tóxica na manipulação Tiossulfato e a concentração $6,25 \%$ não foi analisada.

Com a manipulação pH9, todas as concentrações, com exceção da 25\%, foram tóxicas. Eesta amostra também apresentou concentrações com alta porcentagem média de larvas normais.

\section{$\underline{\text { Inverno de } 2011}$}

Foram medidos na concentração $100 \%$ de cada manipulação, no início dos ensaios ecotoxicológicos, as variáveis físicas e químicas $\mathrm{pH}$, salinidade e amônia total. A temperatura do ensaio foi mantida constante em $25^{\circ} \mathrm{C}$. A partir destes valores, a amônia não ionizada foi calculada. Os resultados dessas variáveis da amostra, em cada manipulação da campanha do Inverno 2011 estão apresentados na Tabela 35. 
Tabela 35. Resultado das análises das variáveis da amostra de água intersticial e nas diferentes manipulações da campanha de Inverno de 2011, coletada em Caraguatatuba.

\section{Caraguatatuba - Inverno/2011}

\begin{tabular}{ccccc}
\hline manipulação & Salinidade & Amônia total & pH & Am. N Ionizada \\
\hline ER & 35 & $1,0-3,0$ & 8.49 & $0,125-0,375$ \\
Aeração & 35 & $1,0-3,0$ & 8.07 & $0,052-0,155$ \\
EDTA & 35 & $>3,0$ & 7.21 & $>0,022$ \\
Tiossulfato & 35 & $1,0-3,0$ & 7.93 & $0,038-0,114$ \\
pH 7 & 35 & $>3,0$ & 7.00 & $>0,014$ \\
pH 9 & 35 & $1,0-3,0$ & 9.00 & $0,039-0,116$ \\
Filtração & 35 & 1.00 & 7.94 & 0.04 \\
Controle & 35 & $<0,01$ & 8.61 & $<0,002$ \\
\hline
\end{tabular}

valor acima do limite de sensibilidade para a espécie

Am. N Ionizada - Amônia não ionizada

Não houve variação da salinidade nas manipulações e no controle. As manipulações EDTA e pH7 apresentaram maiores valores de amônia total, acima de 3,0 mg. $\mathrm{L}^{-1}$.

$\mathrm{O}$ pH apresentou variação nas manipulações, sendo que a maior variação ocorreu na manipulação EDTA.

A amônia não ionizada, com valores $>0,05 \mathrm{mg} / \mathrm{L}^{-1}$, está acima do limite de sensibilidade para as larvas de Lytechinus variegatus, o que não ocorreu nas manipulações EDTA, pH7 e Filtração.

A porcentagem média e o desvio padrão de larvas normais de Lytechinus variegatus para cada concentração testada e para cada manipulação da campanha de Inverno de 2011 estão apresentados na Tabela 36 e representados na Figura 28. 
Tabela 36. Porcentagem média e desvio padrão de larvas normais de Lytechinus variegatus no Inverno de 2011, nas várias concentrações testadas em cada manipulação da água intersticial de Caraguatatuba..

\section{Caraguatatuba - Inverno/2011}

\begin{tabular}{|c|c|c|c|c|c|c|c|}
\hline & \multicolumn{5}{|c|}{ Concentrações da água intersticial testada (\%) } \\
\hline & & & 6.25 & 12.5 & 25 & 50 & 100 \\
\hline \multirow{16}{*}{ 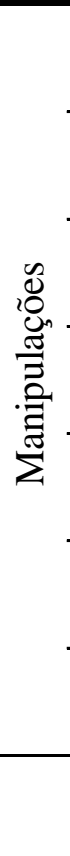 } & \multirow[t]{2}{*}{ ER } & Média & 70.75 & 27.00 & 16.00 & 0.00 & 0.00 \\
\hline & & Desv. Pad. & 13.05 & 10.49 & 18.49 & 0.00 & 0.00 \\
\hline & \multirow[t]{2}{*}{ Aeração } & Média & 77.25 & 73.00 & 68.50 & 54.75 & 0.25 \\
\hline & & Desv. Pad. & 8.73 & 3.37 & 8.19 & 6.70 & 0.50 \\
\hline & \multirow[t]{2}{*}{ EDTA } & Média & 80.50 & 74.25 & 73.75 & 81.75 & 59.75 \\
\hline & & Desv. Pad. & 11.47 & 4.43 & 4.92 & 4.86 & 9.91 \\
\hline & \multirow[t]{2}{*}{ Tiossulfato } & Média & 97.50 & 95.50 & 92.00 & 82.50 & 74.75 \\
\hline & & Desv. Pad. & 1.29 & 1.73 & 4.24 & 9.15 & 10.05 \\
\hline & \multirow[t]{2}{*}{$\mathrm{pH} 7$} & Média & 86.25 & 85.25 & 72.75 & 31.25 & 3.00 \\
\hline & & Desv. Pad. & 3.50 & 6.65 & 3.10 & 9.54 & 1.41 \\
\hline & \multirow[t]{2}{*}{ pH9 } & Média & 87.00 & 84.25 & 85.50 & 87.50 & 85.50 \\
\hline & & Desv. Pad. & 4.62 & 5.50 & 4.43 & 6.14 & 6.76 \\
\hline & \multirow[t]{2}{*}{ Filtração } & Média & 92.25 & 92.25 & 79.25 & 73.00 & 52.00 \\
\hline & & Desv. Pad. & 3.86 & 4.99 & 20.02 & 11.63 & 3.56 \\
\hline & \multirow[t]{2}{*}{ Controle } & Média & & & & & 80.25 \\
\hline & & Desv. Pad. & & & & & 8.18 \\
\hline
\end{tabular}

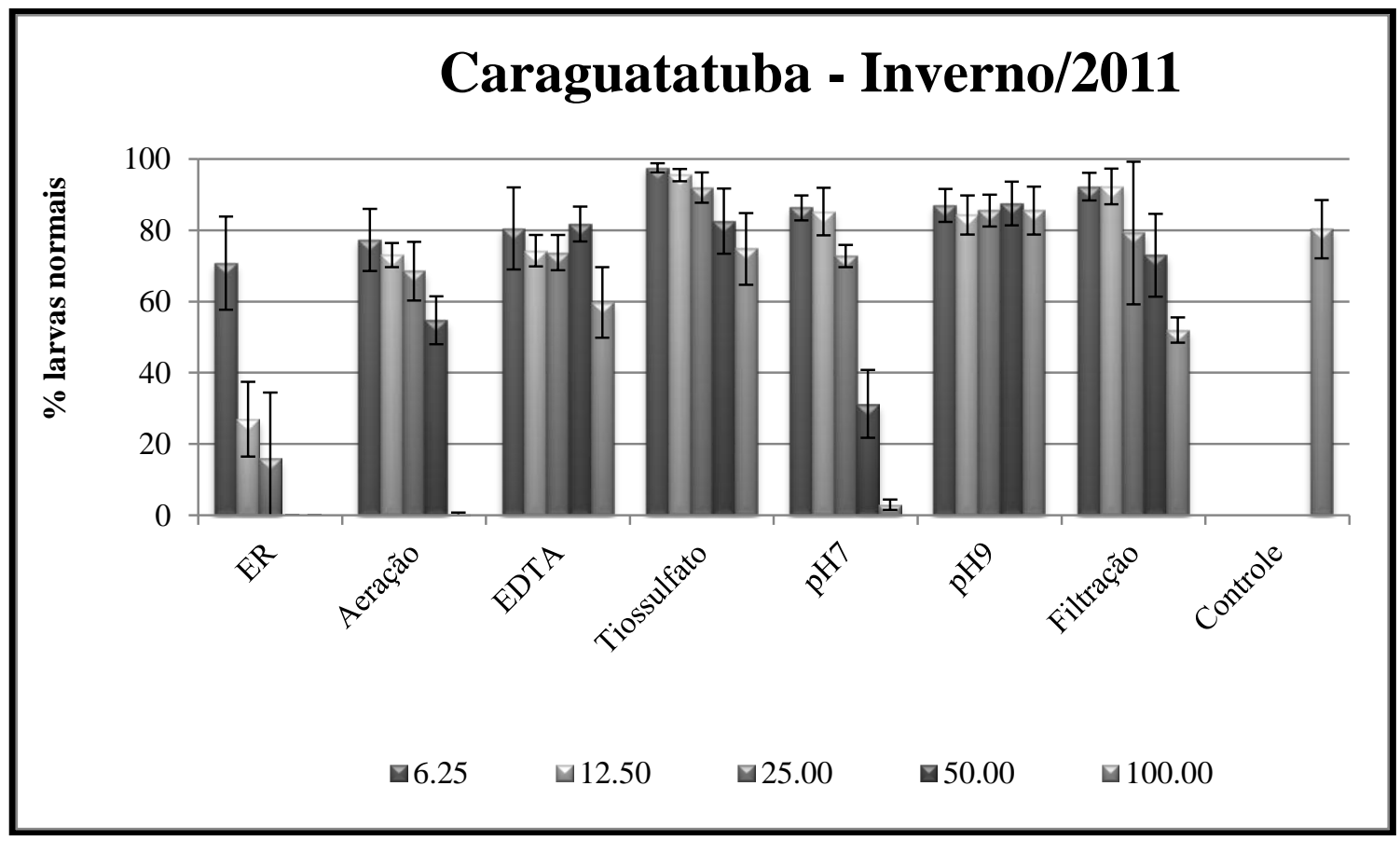

Figura 28. Resultados dos ensaios ecotoxicológicos do Inverno de 2011, nas várias concentrações testadas em cada manipulação da água intersticial de Caraguatatuba. 
A manipulação pH7 dessa amostra foi considerada não válida. No Ensaio Referência somente a concentração $6,25 \%$ não apresentou diferença significativa em relação ao controle. Na manipulação Aeração as concentrações 50\% e 100\% foram diferentes significativamente em relação ao controle.

As manipulações EDTA e Filtração apresentaram a concentração 100\% com diferença significativa em relação ao controle. Tiossulfato e pH9 foram as manipulações que não apresentaram diferença significativa com relação ao controle.

\section{Primavera de 2011}

Foram medidos na concentração $100 \%$ de cada manipulação, no início dos ensaios ecotoxicológicos, as variáveis físicas e químicas $\mathrm{pH}$, salinidade e amônia total. A temperatura do ensaio foi mantida constante em $25^{\circ} \mathrm{C}$. A partir destes valores, a amônia não ionizada foi calculada. Os resultados dessas variáveis da amostra, em cada manipulação da campanha da Primavera de 2011 estão apresentados na Tabela 37.

Tabela 37. Resultado das análises das variáveis da amostra de água intersticial nas diferentes manipulações da campanha de Primavera de 2011, coletada em Caraguatatuba.

Caraguatatuba - Primavera/2011

\begin{tabular}{ccccc}
\hline manipulação & Salinidade & Amônia total & $\mathrm{pH}$ & Am. N Ionizada \\
\hline ER & 36 & 0.50 & 8.12 & 0.03 \\
Aeração & 36 & 1.00 & 8.42 & 0.11 \\
EDTA & 36 & 0.50 & 7.92 & 0.02 \\
Tiossulfato & 36 & 0.20 & 8.26 & 0.02 \\
pH 7 & 36 & $1,0-3,0$ & 7.00 & $0,005-0,014$ \\
pH 9 & 36 & $0,5-1,0$ & 9.00 & $0,158-0,316$ \\
Filtração & 36 & 0.50 & 8.30 & 0.04 \\
Controle & 35 & 0.00 & 8.64 & 0.00 \\
\hline
\end{tabular}

valor acima do limite de sensibilidade para a espécie

Am. N Ionizada - Amônia não ionizada 
Não houve variação da salinidade nas manipulações. Com relação à amônia total, a manipulação pH7 apresentou o maior valor, entre 1,0 e 3,0 mg. $\mathrm{L}^{-1}$.

$\mathrm{O}$ pH apresentou pequena variação nas manipulações, exceto naquelas que os valores foram alterados propositadamente.

A amônia não ionizada, com valores $>0,05 \mathrm{mg} / \mathrm{L}^{-1}$, está acima do limite de sensibilidade para as larvas de Lytechinus variegatus, o que ocorreu nas manipulações Aeração e pH9.

A porcentagem média e o desvio padrão de larvas normais de Lytechinus variegatus para cada concentração testada e para cada manipulação da campanha da Primavera de 2011 estão apresentados na Tabela 38 e representados na Figura 29.

Tabela 38. Porcentagem média e desvio padrão de larvas normais de Lytechinus variegatus na Primavera de 2011, nas várias concentrações testadas em cada manipulação da água intersticial de Caraguatatuba.

\section{Caraguatatuba - Primavera/2011}

\begin{tabular}{|c|c|c|c|c|c|c|c|}
\hline & \multicolumn{5}{|c|}{ Concentrações da água intersticial testada (\%) } \\
\hline & & & 6.25 & 12.5 & 25 & 50 & 100 \\
\hline \multirow{16}{*}{ 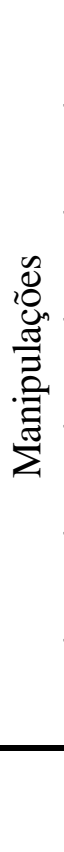 } & ER & Média & 87.5 & 84.25 & 85.75 & 47.75 & 74.75 \\
\hline & & Desv. Pad. & 2.52 & 2.99 & 7.63 & 17.59 & 6.02 \\
\hline & Aeração & Média & 87.25 & 76.75 & 87.5 & 60.75 & 34.75 \\
\hline & & Desv. Pad. & 4.19 & 15.86 & 1.91 & 4.99 & 8.38 \\
\hline & EDTA & Média & 88 & 84.5 & 85 & 71.25 & 52.75 \\
\hline & & Desv. Pad. & 0.82 & 3.32 & 3.92 & 10.87 & 8.06 \\
\hline & Tiossulfato & Média & 78.25 & 78.5 & 82.75 & 62.25 & 49 \\
\hline & & Desv. Pad. & 6.08 & 5.80 & 4.99 & 2.75 & 15.12 \\
\hline & $\mathrm{pH} 7$ & Média & 79.25 & 84.5 & 65 & 34.75 & 7 \\
\hline & & Desv. Pad. & 1.71 & 3.79 & 5.60 & 4.57 & 8.25 \\
\hline & pH9 & Média & 81.75 & 77.5 & 79.25 & 77.5 & 64 \\
\hline & & Desv. Pad. & 4.79 & 4.93 & 8.02 & 3.11 & 7.87 \\
\hline & Filtração & Média & 79.25 & 72 & 81 & 67.25 & 49.5 \\
\hline & & Desv. Pad. & 6.02 & 4.32 & 5.35 & 6.70 & 7.14 \\
\hline & Controle & Média & & & & & 83.50 \\
\hline & & Desv. Pad. & & & & & 2.65 \\
\hline
\end{tabular}




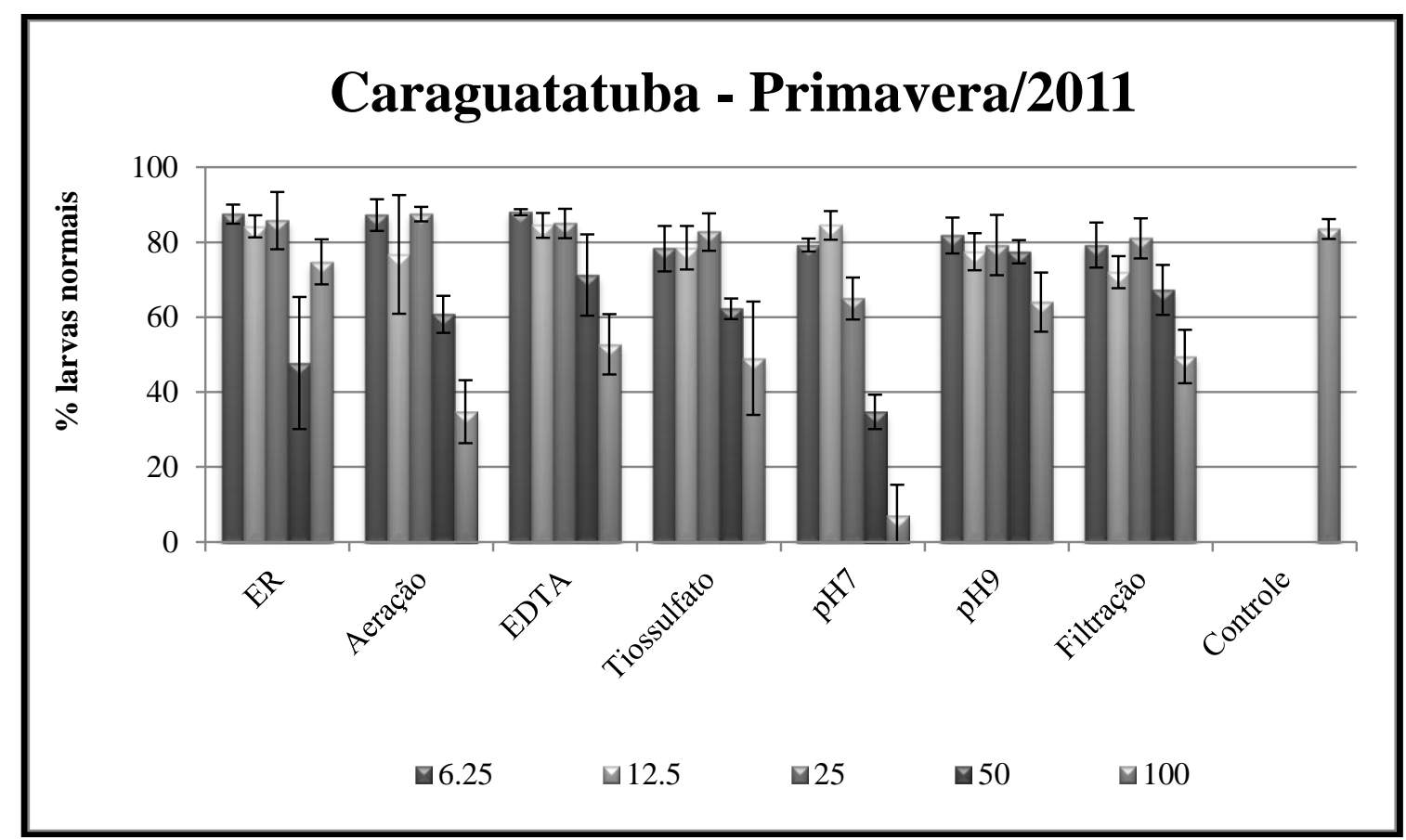

Figura 29. Resultados dos ensaios ecotoxicológicos da Primavera de 2011, nas várias concentrações testadas em cada manipulação da água intersticial de Caraguatatuba.

As manipulações Aeração e pH7 foram consideradas não válidas. O Ensaio Referência e as manipulações Tiossulfato e pH9 apresentaram toxicidade nas concentrações 50 e $100 \%$.

O EDTA foi a manipulação que apresentou toxicidade somente na concentração $100 \%$. A manipulação Filtração apresentou-se tóxica nas concentrações 12,$5 ; 50$ e $100 \%$.

\section{Verão de 2012}

Foram medidos na concentração $100 \%$ de cada manipulação, no início dos ensaios ecotoxicológicos, as variáveis físicas e químicas pH, salinidade e amônia total. A temperatura do ensaio foi mantida constante em $25^{\circ} \mathrm{C}$. A partir destes resultados, a amônia não ionizada foi calculada. Os resultados dessas variáveis da amostra, em cada manipulação da campanha do Verão de 2012 estão apresentados na Tabela 39. 
Tabela 39. Resultado das análises das variáveis da amostra de água intersticial nas diferentes manipulações da campanha de Verão de 2012, coletada em Caraguatatuba.

Caraguatatuba - Verão/2012

\begin{tabular}{ccccc}
\hline manipulação & Salinidade & Amônia total & $\mathrm{pH}$ & Am. N Ionizada \\
\hline ER & 36 & $2,5-5,0$ & 7.56 & $0,041-0,083$ \\
Aeração & 36 & $2,5-5,0$ & 7.47 & $0,034-0,067$ \\
EDTA & 36 & $2,5-5,0$ & 7.38 & $0,027-0,055$ \\
Tiossulfato & 36 & $2,5-5,0$ & 7.74 & $0,062-0,124$ \\
pH 7 & 36 & $2,5-5,0$ & 7.00 & $0,012-0,023$ \\
pH 9 & 36 & $2,5-5,0$ & 9.00 & $0,791-1,581$ \\
Filtração & 36 & $2,5-5,0$ & 7.79 & $0,069-0,139$ \\
Controle & 36 & 0.00 & 7.89 & 0 \\
\hline
\end{tabular}

valor acima do limite de sensibilidade para a espécie

Am. N Ionizada - Amônia não ionizada

Não houve variação da salinidade nas manipulações e no controle. Com relação à amônia total, todas as manipulações apresentaram valores iguais, entre 2,5 e 5,0.

$\mathrm{O}$ pH apresentou pequena variação nas manipulações, exceto naquelas cujos valores foram alterados propositadamente.

A amônia não ionizada, com valores $>0,05 \mathrm{mg} / \mathrm{L}^{-1}$, está acima do limite de sensibilidade para as larvas de Lytechinus variegatus, o que ocorreu na maioria das manipulações, exceto na EDTA e pH7.

A porcentagem média e o desvio padrão de larvas normais de Lytechinus variegatus para cada concentração testada e para cada manipulação da campanha de Verão de 2012 estão apresentados na Tabela 40 e representados na Figura 30. 
Tabela 40. Porcentagem média e desvio padrão de larvas normais de Lytechinus variegatus no Verão de 2012, nas várias concentrações testadas em cada manipulação da água intersticial de Caraguatatuba.

Caraguatatuba - Verão/2012

\begin{tabular}{ccccccc}
\hline & & \multicolumn{5}{c}{ Concentrações da água intersticial testada (\%) } \\
\cline { 3 - 7 } & & 6.25 & 12.5 & 25 & 50 & 100 \\
\hline \multirow{2}{*}{ ER } & Média & 95.50 & 96.00 & 96.25 & 66.50 & 44.75 \\
& Desv. Pad. & 1.73 & 2.71 & 2.63 & 3.32 & 4.35 \\
\hline \multirow{2}{*}{ Aeração } & Média & 95.50 & 96.50 & 91.75 & 95.25 & 92.50 \\
& Desv. Pad. & 3.32 & 1.73 & 4.11 & 2.22 & 1.91 \\
\hline \multirow{2}{*}{ EDTA } & Média & 97.25 & 97.00 & 95.25 & 95.50 & 90.00 \\
& Desv. Pad. & 1.50 & 1.63 & 2.50 & 1.73 & 3.37 \\
\hline \multirow{2}{*}{ Tiossulfato } & Média & 94.00 & 91.75 & 93.25 & 93.25 & 88.50 \\
& Desv. Pad. & 4.08 & 3.30 & 2.99 & 3.86 & 4.43 \\
\hline \multirow{2}{*}{ pH7 } & Média & 94.25 & 96.00 & 94.75 & 96.25 & 97.25 \\
& Desv. Pad. & 1.50 & 2.45 & 4.50 & 2.50 & 1.89 \\
\hline \multirow{2}{*}{ pH9 } & Média & 90.75 & 86.50 & 91.50 & 89.75 & 0.25 \\
& Desv. Pad. & 3.77 & 2.38 & 2.52 & 2.06 & 0.50 \\
\hline Filtração & Média & 95.25 & 95.50 & 94.75 & 94.25 & 96.00 \\
& Desv. Pad. & 2.22 & 2.38 & 2.99 & 2.75 & 1.41 \\
\hline Controle & Média & & & & 98.25 \\
& Desv. Pad. & & & & & \\
\hline
\end{tabular}

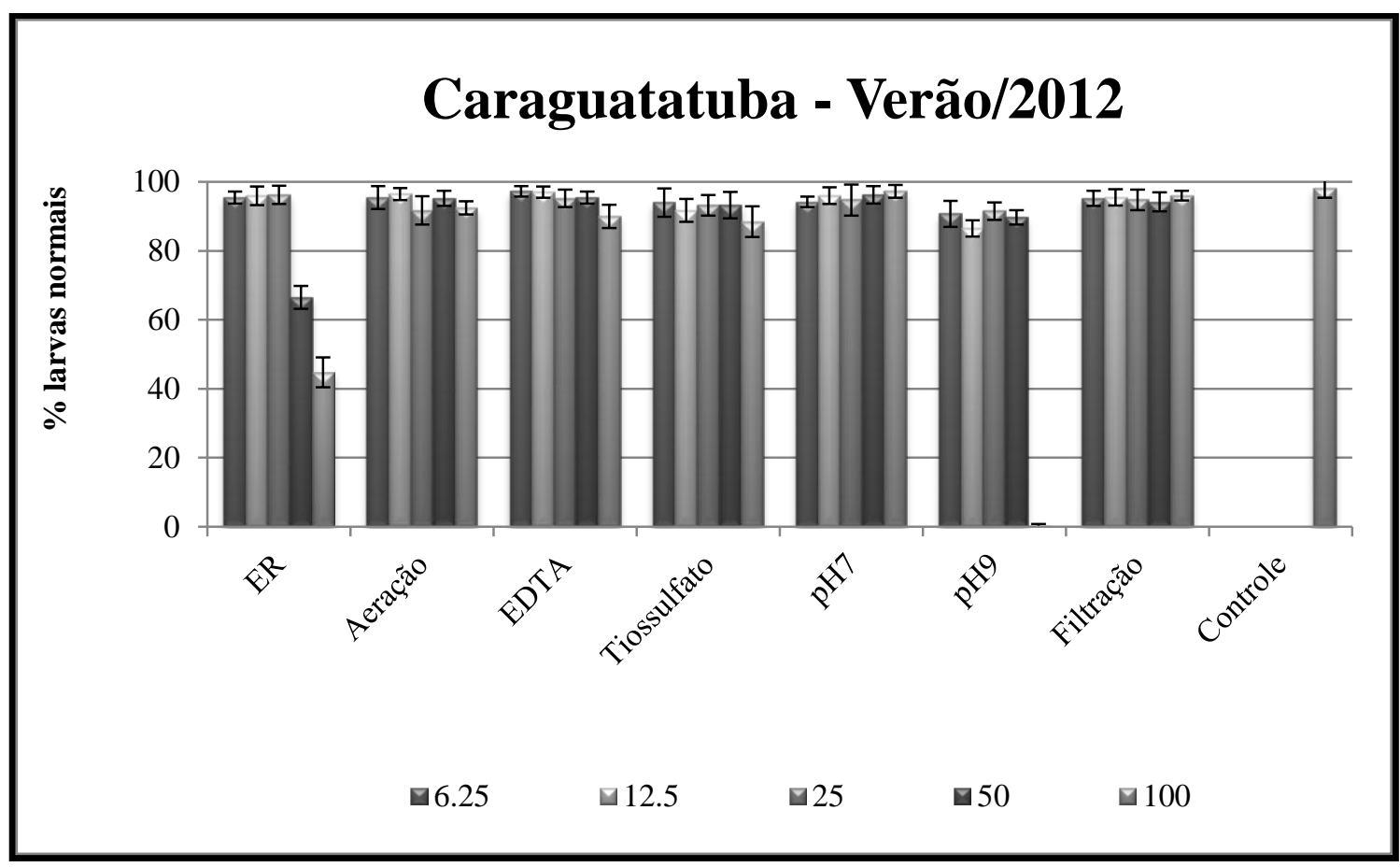

Figura 30. Resultados dos ensaios ecotoxicológicos do Verão de 2012, nas várias concentrações testadas em cada manipulação da água intersticial de Caraguatatuba. 
O Ensaio Referência apresentou toxicidade nas concentrações 12,5; 50 e 100\%, sendo que na concentração $12,5 \%$ apresentou alta porcentagem média de larvas normais.

Com a manipulação Aeração, as concentrações 25 e 100\%, apresentaram-se tóxicas, embora com alta porcentagem média de larvas normais.

Na manipulação EDTA somente a concentração $50 \%$ foi tóxica, entretanto, apresentou alta porcentagem de larvas normais.

As concentrações 25 e $100 \%$ das manipulações Tiossulfato e pH7 também foram consideradas tóxicas apesar da alta porcentagem média de larvas normais.

Todas as concentrações da manipulação pH9 foram tóxicas e as concentrações 6,$25 ; 12,5 ; 25$ e $50 \%$ apresentaram alta porcentagem média de larvas normais. A Filtração foi a única manipulação desta amostra que não foi considerada tóxica.

\subsection{Compilação dos resultados da AIT}

A Tabela 41 mostra as porcentagens das frequências de toxicidade obtidas, para todas as concentrações das amostras testadas de todas as campanhas realizadas em todas as estações de coleta. Em destaque estão às amostras com menores e maiores porcentagens. 
Tabela 41. Frequência de toxicidade (\%) para cada manipulação das amostras em todas as campanhas realizadas e em todas as concentrações testadas.

\begin{tabular}{cccccc} 
Manipulação Perequê-Açú & Itaguá & Saco da Ribeira & Ilha do Mar Virado & Caraguatatuba \\
\hline ER & 73.33 & 35.00 & 50.00 & 45.00 & 70.00 \\
Aeração & $\mathbf{8 0 . 0 0}$ & 30.00 & 26.67 & 50.00 & 44.44 \\
EDTA & 20.00 & 26.67 & 45.00 & 53.33 & 20.00 \\
Tiossulfato & 53.33 & 35.00 & 35.00 & 40.00 & 26.32 \\
pH7 & 20.00 & 30.00 & 40.00 & $\mathbf{1 0 0 . 0 0}$ & $\mathbf{6 0 . 0 0}$ \\
pH9 & 64.29 & 20.00 & 40.00 & 50.00 & 55.00 \\
Filtração & 46.67 & $\mathbf{4 5 . 0 0}$ & 40.00 & 30.00 & 45.00 \\
\hline
\end{tabular}

Menor frequência

negrito $=$ Maior frequência

As amostras coletadas no ponto Perequê-Açu localizado na Enseada de Ubatuba apresentaram, nas manipulações EDTA e graduação do $\mathrm{pH}$, menores porcentagens de frequências de toxicidade e a Aeração foi a manipulação com a maior porcentagem de frequência de toxicidade. Também localizada na Enseada de Ubatuba, as amostras do Itaguá apresentaram, nas manipulações EDTA e graduação do pH9, menores porcentagens de frequências de toxicidade e a Filtração foi a manipulação com a maior frequência de toxicidade. Entre os dois pontos de coleta da Enseada de Ubatuba, o ponto Perequê-Açu foi o que obteve maior frequência de toxicidade com $73,33 \%$ enquanto que no ponto Itaguá foi de 35,00\%.

Os resultados de todas as manipulações do ponto de coleta Saco da Ribeira, localizado na Enseada do Flamengo, apresentaram menores porcentagens de frequências de toxicidade que o Ensaio Referência (50\%) enquanto a manipulação Aeração apresentou a menor porcentagem de frequência entre todas as manipulações, com $26,67 \%$.

Localizada na parte externa da Enseada do Mar Virado, o ponto de coleta Ilha do Mar Virado apresentou menor porcentagem de frequência de toxicidade na 
manipulação Filtração, com 30,00\% e a manipulação pH7 obteve maior porcentagem, com $100 \%$, de frequência de toxicidade.

As amostras coletadas na Enseada de Caraguatatuba apresentaram menores reduções da toxicidade nas manipulações EDTA e Tiossulfato com 20,00 e 26,33\%, respectivamente. A maior frequência da toxicidade foi obtida no Ensaio Referência (70\%), seguido da manipulação pH7 (60,00\%).

\subsection{Toxicidade das amostras e a sazonalidade da toxicidade}

As amostras foram consideradas tóxicas de acordo com os critérios descritos anteriormente, caracterizando a amostra como tóxica aquela que for diferente significativamente em relação ao controle em três das cinco concentrações testadas ou em duas concentrações tóxicas entre 25, 50 e 100\% no Ensaio Referência. As classificações das amostras, em cada coleta, estão apresentadas na tabela 42.

Tabela 42. Identificação das amostras tóxicas (T) e não tóxicas (NT), nas quatro campanhas de coleta.

\begin{tabular}{ccccc} 
& Outono & \multicolumn{2}{c}{ Inverno Primavera } & Verão \\
\hline Perequê-Açú & $\mathbf{T}$ & $\mathbf{T}$ & - & $\mathbf{T}$ \\
Itaguá & NT & $\mathbf{T}$ & $\mathbf{T}$ & NT \\
Saco da Ribeira & $\mathbf{T}$ & $\mathrm{NT}$ & $\mathbf{T}$ & NT \\
Ilha do Mar Virado & NT & NT & $\mathbf{T}$ & $\mathbf{T}$ \\
Caraguatatuba & $\mathbf{T}$ & $\mathbf{T}$ & $\mathbf{T}$ & $\mathbf{T}$ \\
\hline
\end{tabular}

As amostras dos pontos Perequê-Açu e Caraguatatuba apresentaram toxicidade em todas as amostras testadas. No Itaguá, as amostras coletadas no Inverno e na Primavera de 2011 foram tóxicas. Com as amostras coletadas no Saco da Ribeira, a 
toxicidade foi obtida em duas de quatro amostras testadas, Outono e Primavera de 2011. As amostras testadas no ponto Ilha do Mar Virado apresentaram toxicidade nas campanhas de coleta da Primavera de 2011 e Verão de 2012.

As amostras coletadas na Primavera de 2011 foram tóxicas em todos os pontos testados e nas demais estações do ano apresentaram toxicidade em três de cinco pontos de coleta. 


\section{DISCUSSÃO}

\subsection{Considerações sobre o Local de Estudo}

A ideia de crescimento é comumente associada à ideia de desenvolvimento, estando ambas relacionadas à evolução positiva. Parte do embate ambiental tem sido questionar tal associação direta, mostrando que nem todo desenvolvimento é positivo, o que não raro tem sido feito destacando-se os efeitos negativos do crescimento sem limite (Marandola Jr et al., 2013).

A ocupação e o desenvolvimento urbano do litoral norte paulista foram marcados por estes impulsos que grandes obras produziram na região. $O$ primeiro grande empreendimento foi a implantação do Porto de São Sebastião em 1963, seguido do Terminal Marítimo Almirante Barroso (TEBAR) que começou a funcionar em 1969. Além disso, com a construção da Rodovia dos Tamoios, que faz ligação do planalto com o litoral, e especialmente a construção e asfaltamento da Rodovia Rio-Santos, que estabeleceu uma ligação perene por terra de todo o litoral norte, foram os principais vetores que induziram o desenvolvimento de uma região de aldeias e vilarejos tradicionais, para uma área urbanizada voltada para exploração turística (Luchiari, 1999 apud Marandola Jr et al., 2013).

O desenvolvimento nacional na área petrolífera, a descoberta da camada de pré-sal, a construção da Unidade de Tratamento de Gás Monteiro Lobato, de Caraguatatuba (UTGCA), e a ampliação do Porto de São Sebastião fizeram da região um polo atrativo para uma grande quantidade de pessoas em busca de trabalho (Rocha, 2011 apud Marandola Jr. et al, 2013). 
Essa nova realidade soma-se aos já insuficientes serviços urbanos prestados no litoral. $\mathrm{O}$ saneamento básico é um dos pontos críticos. Historicamente precária, a rede coletora de esgoto cobria, em 2003, apenas 25\% dos domicílios urbanos em Caraguatatuba e 17\% em Ubatuba, segundo a Pesquisa Nacional de Saneamento básico (Marandola Jr et al., 2013) chegando a cobrir em $2010,57,94 \%$ para Caraguatatuba e $27,94 \%$ para o município de Ubatuba (SEDAE) e, segundo Sousa (2013) Caraguatatuba já apresenta $100 \%$ do seu esgoto doméstico coletado.

De acordo com Burone (2002), em Ubatuba, nos meses de janeiro, fevereiro e julho estima-se que a população se triplique, enquanto que em feriados prolongados como Carnaval, Semana Santa, Finados e "Reveillon" o número de habitantes aumenta em torno de cinco vezes. Isso se agrava ao nos depararmos com os dados do crescimento populacional, que apresentou um crescimento enorme nas ultimas décadas. Segundo site IBGE, Caraguatatuba apresentou crescimento da população de 52.878 habitantes em 1991 para 109.678 habitantes em 2013 e em Ubatuba de 47.398 habitantes em 1991 para 84.377 habitantes em 2013 (IBGE), apresentando uma população flutuante acima de 100.000 para ambas as cidades em 2013.

As consequências do processo inadequado de crescimento são a falta de condições sanitárias mínimas; ausência de serviços indispensáveis à vida das pessoas nas cidades; ocupação de áreas inadequadas; destruição de recursos de valor ecológico; poluição do meio ambiente; habitações em condições precárias de vida (Villaschi, 2003, apud Marandola Jr et al., 2013).

Outro problema que nos chama a atenção em relação a esses dois municípios, Caraguatatuba e Ubatuba, é a carência de estudos pretéritos e dos impactos antrópicos, principalmente das condições da qualidade dos ambientes marinhos relacionados à poluição marinha. A CETESB é responsável pelos estudos de monitoramento ambiental 
para essas duas cidades, principalmente balneabilidade de 41 pontos localizados em praias e qualidade das águas e dos sedimentos situados em 18 pontos da rede costeira.

\subsection{Testes de Toxicidade e AIT}

A qualidade das águas costeiras brasileiras é consequência direta e indireta das medidas de infraestrutura sanitária adotadas pelo país. O rápido crescimento das cidades gera uma demanda crescente por obras de saneamento básico, que não acompanham o crescimento e a necessidade, principalmente nas cidades litorâneas. Com isso a ocupação urbana tem implicações diretas na saúde pública, sendo esta prejudicada pelo inadequado ou insuficiente sistema sanitário local e, à medida que a qualidade das águas das praias e rios dessas cidades fica inadequada, pode acarretar doenças e prejudicar o turismo (CETESB, 2008).

A adoção de critérios de qualidade de sedimento baseados nas concentrações de substâncias químicas individualmente não oferece proteção adequada em locais onde a poluição é causada por mais de uma substância, como a grande maioria das áreas contaminadas (Swartz et al., 1988). Tal fato ocorre nas áreas estudadas, como na Enseada de Ubatuba, Enseadas do Flamengo a do Flamengo não é Ubatuba?? FICOU CONFUSO e de Caraguatatuba, com descartes de esgoto in natura, presença de marinas e posto de combustíveis flutuante.

De acordo com USEPA (1991) os ensaios de toxicidade são considerados os melhores métodos disponíveis para identificar, de forma integrada, os efeitos dos múltiplos contaminantes presentes no ambiente marinho. A água intersticial é uma das vias de exposição dos contaminantes para alguns organismos associados aos sedimentos. A este respeito, o ensaio com água intersticial e utilização da metodologia da AIT pode ser um 
passo efetivo para distinguir efeitos tóxicos causados pelo sedimento aos organismos (Chapman et al., 2002).

Neste estudo, foram verificados os efeitos adversos das amostras da fase líquida do sedimento, via água intersticial, aos embriões de ouriço-do-mar, utilizando a técnica de Avaliação e Identificação da Toxicidade (fase1) em cinco localidades do litoral norte paulista, sendo quatro locais no Município de Ubatuba e um no Município de Caraguatatuba.

\subsection{Caracterização das classes de contaminantes responsáveis pela toxicidade}

\subsubsection{Perequê-Açu}

Para este ponto de coleta foram realizados os ensaios ecotoxicológicos em três campanhas - Outono/2011, Inverno/2011 e Verão/2012 - e as amostras, Ensaio Referência, foram tóxicas.

Na amostra de Outono de 2011 houve redução da toxicidade em todas as manipulações válidas, sendo que a manipulação que resultou em uma menor toxicidade foi a Tiossulfato, que de acordo com Badaró-Pedroso (1999) é um agente redutor de compostos oxidantes e de alguns metais como cobre, cádmio e mercúrio, com poder de redução menor da toxicidade na presença de zinco, chumbo e níquel. Para as demais campanhas o tiossulfato apresentou pequena redução da toxicidade.

Com a campanha realizada no Inverno de 2011 a Filtração foi a manipulação que apresentou redução total da toxicidade (em todas as concentrações), a manipulação pH9 apresentou redução da toxicidade, apresentando toxicidade somente na maior concentração testada, o que caracterizou a manipulação sem toxicidade. Esses 
resultados evidenciaram que na campanha de Inverno o agente tóxico estava associado ao material particulado, compostos $\mathrm{pH}$ dependentes (USEPA, 1991a) como ocorre com sulfetos e metais como zinco e níquel que apresentam maior toxicidade em $\mathrm{pH}$ alcalinos. Reforçando as evidências para a presença de metais a manipulação EDTA reduziu a toxicidade (USEPA, 2007).

No Verão de 2012, a Filtração diminuiu a toxicidade da amostra, demonstrando que os compostos tóxicos estavam associados ao material em suspensão. A maior redução da toxicidade ocorreu com a manipulação pH7, o que nos evidenciou como responsável pela toxicidade os compostos $\mathrm{pH}$ dependentes e também sinalizaram para a amônia e/ou metais. A diminuição da toxicidade na manipulação Tiossulfato trouxe indícios de presença de metais como agentes tóxicos.

Os resultados das três campanhas realizadas no Perequê-Açu apontam que a toxicidade da água intersticial estava associada ao material particulado em suspensão, metais, amônia e sulfetos. Estes resultados corroboram com a literatura em estudo de AIT onde, geralmente, esses são os responsáveis pela toxicidade na água intersticial como evidenciado nos estudos de Matos (2011) realizados em ambientes dulcícolas e nos estudos realizados em ambientes marinhos por Ho et al. (2002), que concluíram que para ambos os ambientes,os metais e amônia, além dos compostos orgânicos são os principais responsáveis pela toxicidade de sedimentos.

\subsubsection{Itaguá}

Para esse ponto de coleta foram realizadas quatro campanhas - Outono/2011, Inverno/2011, Primavera/2011 e Verão/2012 - apresentando apenas duas campanhas com toxicidade, Inverno e Primavera de 2011. 
Na primeira campanha, Outono/2011, apesar da amostra se apresentar tóxica somente na concentração $100 \%$, não caracterizando toxicidade da amostra, foi realizado os procedimentos da AIT. As manipulações Aeração, Tiossulfato e pH9 descartaram como possíveis agentes causadores da toxicidade os compostos voláteis, como por exemplo, hidrocarbonetos voláteis, $\mathrm{H}_{2} \mathrm{~S}$ e amônia, além dos compostos oxidantes, metais e compostos pH dependentes. Como o Ensaio Referência não apresentou toxicidade, os dados obtidos não trouxeram maiores detalhes conclusivos para a AIT.

A amostra coletada no Inverno de 2011 apresentou-se tóxica, caracterizada pela toxicidade nas concentrações 50 e 100\%. As demais manipulações não apresentaram toxicidade tornando assim difícil se evidenciar os responsáveis pela toxicidade, mas sim que há mais de um agente causador da toxicidade.

Na campanha realizada na Primavera de 2011, o Ensaio Referência apresentou toxicidade. Houve redução da toxicidade apenas na manipulação EDTA, que é um agente quelante de metais muito forte, evidenciando assim a presença de metais.

Nesta campanha, a manipulação de alteração do pH para 7 apresentou maior toxicidade, evidenciando compostos $\mathrm{pH}$ dependentes, como sulfeto de hidrogênio $\left(\mathrm{H}_{2} \mathrm{~S}\right)$, onde a sua toxicidade é maior em pH ácido.

Os dados de toxicidade para as demais manipulações realizadas com essa amostra nessa campanha não apresentaram evidências conclusivas para o método de AIT.

A campanha do Verão de 2012 não apresentou toxicidade, mesmo com as concentrações $100 \%$ e $6,25 \%$ sendo estatisticamente diferentesdo controle. Todas as manipulações apresentaram um aumento da porcentagem média de larvas normais na maior concentração testada, exceto na manipulação onde o $\mathrm{pH}$ foi alterado para 9 e apresentou $0 \%$ (zero) de média de larvas normais, indicando a presença de compostos 
pH dependentes (USEPA, 1991a) como amônia $\left(\mathrm{NH}_{3}{ }^{+}\right)$que na forma não ionizada $\left(\mathrm{NH}_{3}\right)$, mais tóxica, predomina em $\mathrm{pH}$ básico.

Das quatro campanhas realizadas em Itaguá, em apenas uma foi possível se caracterizar que metais e compostos $\mathrm{pH}$ dependentes foram os responsáveis pela toxicidade obtida. Nas demais campanhas desta estação os dados foram inconclusivos para a AIT.

\subsubsection{Saco da Ribeira}

Para esse ponto de coleta foram realizadas quatro campanhas - Outono/2011, Inverno/2011, Primavera/2011 e Verão/2012 - apresentando apenas duas campanhas com toxicidade, Outono e Primavera de 2011.

A amostra coletada no Outono de 2011 apresentou a maioria de suas manipulações com as mesmas concentrações tóxicas 25,50 e $100 \%$. Apenas a manipulação pH9 obteve toxicidade nas concentrações 50 e $100 \%$, indicando uma diminuição da toxicidade em relação ao Ensaio Referência. Essa diminuição evidencia a possível presença de compostos pH dependentes, segundo USEPA (1991a), como ocorre com sulfetos que apresentam alteração de toxicidade dependendo do $\mathrm{pH}$ e pode também evidenciar a presença de metais em concentrações tóxicas, sabendo que alguns metais apresentam maior toxicidade em pH alcalinos (USEPA, 2007; Matos, 2011).

Na campanha realizada no Inverno de 2011, a amostra não foi tóxica, pois apresentou somente a concentração 100\% tóxica, o que também ocorreu com as manipulações EDTA, Tiossulfato, pH9 e Filtração. 
A Aeração foi responsável pela eliminação da toxicidade na concentração $100 \%$, tal fato evidencia a presença de compostos voláteis como hidrocarbonetos e $\mathrm{H}_{2} \mathrm{~S}$ ou oxidáveis presentes na amostra.

Com a alteração do $\mathrm{pH}$, de 8,22 para 7,00 , houve um aumento da toxicidade da amostranas concentrações 50 e 100\%. Isso evidencia a presença de sulfeto de hidrogênio $\left(\mathrm{H}_{2} \mathrm{~S}\right)$ onde a sua toxicidade é maior em $\mathrm{pH}$ ácido corroborando com o resultado da manipulação Aeração.

O ensaio ecotoxicológico realizado na campanha da Primavera de 2011 resultou em toxicidade, constatada pela diferença significativa no Ensaio Referência, em todas as concentrações exceto a $6,25 \%$. A única manipulação que reduziu a toxicidade foi a adição do tiossulfato de sódio, evidenciando assim a presença de compostos metais e/ou oxidantes.

A toxicidade da amostra coletada no Verão de 2012 foi verificada apenas na maior concentração do Ensaio Referência(100\%), portanto não foi considerada tóxica. Apesar deste resultado as manipulações foram realizadas e a Aeração, EDTA, Tiossulfato e Filtração reduziram a toxicidade na concentração $100 \%$, evidenciando a presença de compostos voláteis ou oxidáveis, metais, surfactantes catiônicos, oxidantes e compostos aderidos em material em suspensão (USEPA, 1991b). A manipulação pH9 não apresentou alteração da toxicidade, demonstrando indícios da presença de compostos pH dependentes (USEPA, 1991a) como amônia $\left(\mathrm{NH}_{3}{ }^{+}\right)$que na forma não ionizada $\left(\mathrm{NH}_{3}\right)$, mais tóxica, predomina em $\mathrm{pH}$ básico o que corrobora com os resultados da Aeração que eliminou a toxicidade.

Os resultados das campanhas realizadas no ponto Saco da Ribeira demonstraram que de modo geral, a responsabilidade da toxicidade esta associada principalmente os compostos $\mathrm{pH}$ dependentes, além da presença de metais e material 
em suspensão (particulado). Estes resultados corroboram tanto com os estudos de Matos (2011) em ambientes dulcícolas quanto com os de ambientes marinhos realizados por Ho et al. (2002) ao concluírem que, geralmente os metais e amônia, além de compostos orgânicos, são os principais responsáveis pela toxicidade de sedimentos.

\subsubsection{Ilha do Mar Virado}

As duas primeiras campanhas, Outono e Inverno de 2011, realizadas nesse ponto de amostragem não apresentaram toxicidade no Ensaio Referência e suas manipulações, evidenciando assim a ausência de compostos tóxicos disponíveis nesta fração do sedimento.

Já na campanha da Primavera, a toxicidade foi constatada no Ensaio Referência, entretanto, a Filtração reduziu a toxicidade, resultando somente a concentração $100 \%$ como tóxica. As demais manipulações não foram consideradas válidas. Desta forma, os responsáveis pela toxicidade foram o material particulado e/ou os compostos adsorvidos a estas partículas (USEPA, 1991b).

Na Campanha do Verão o Ensaio Referência, as manipulações Aeração, EDTA, Tiossulfato e pH7 apresentaram todas as concentrações testadas com toxicidade, enquanto que em pH9 houve redução da toxicidade, evidenciando a presença de compostos $\mathrm{pH}$ dependentes, como sulfeto de hidrogênio $\left(\mathrm{H}_{2} \mathrm{~S}\right)$ onde a sua toxicidade é maior em pH ácido. Com a Filtração também se obteve redução da toxicidade, indicando a presença de compostos tóxicos associados ao material particulado e/ou adsorvido a estas partículas.

Os resultados nas quatro campanhas realizadas no ponto Ilha do mar Virado demonstraram que de modo geral, os indícios da responsabilidade da toxicidade nesse 
local estavam associados ao material particulado em suspensão e a compostos pH dependentes.

Estes resultados estão de acordo com a literatura que relaciona esses compostos como sendo alguns dos responsáveis pela toxicidade de sedimentos, tanto para ambientes dulcícolas (Matos, 2011) quanto para ambientes marinhos (Ho et al., 2002).

\subsubsection{Caraguatatuba}

Para esse ponto de coleta foram realizadas quatro campanhas - Outono/2011, Inverno/2011, Primavera/2011 e Verão/2012 - sendo que a toxicidade foi verificada em todas as campanhas.

Para a campanha realizada em outubro de 2011, a amostra coletada apresentou toxicidade em todas as concentrações do Ensaio Referência, demonstrando ser uma amostra tóxica. A Filtração também resultou em toxicidade para todas as concentrações, evidenciando assim que os compostos responsáveis pela toxicidade não estavam relacionados ao material particulado.

Com a manipulação pH9, com exceção da concentração 25\%, as demais apresentaramse tóxicas, o que descarta a responsabilidade da toxicidade estar relacionada aos compostos $\mathrm{pH}$ dependentes, que neste caso em $\mathrm{pH}$ alcalino.

Com a Aeração, foi verificado que não houve redução de toxicidade e descartaram-se os compostos voláteis ou oxidáveis desta responsabilidade, principalmente da amônia em sua fração mais tóxica, a amônia não ionizada, como corroboram os resultados das análises das variáveis ambientais, onde foram obtidos valores abaixo da sensibilidade para as larvas de Lytechinus variegatus (ABNT NBR 15XXX:2006). 
A única manipulação que apresentou redução da toxicidade foi a adição do Tiossulfato. Este resultado traz indícios da presença dos compostos oxidantes e alguns metais que também podem ter sido quelados pelo tiossulfato de sódio, reduzindo a toxicidade (USEPA, 1991b).

O Ensaio Referência da amostra coletada no Inverno de 2011 apresentou toxicidade em quatro das cinco concentrações testadas, demonstrando uma amostra tóxica. Com a Aeração, houve redução da toxicidade evidenciando assim a presença de compostos voláteis ou oxidáveis das amostras, tais como hidrocarbonetos voláteis e $\mathrm{H}_{2} \mathrm{~S}$. Já a manipulação pH9 por não apresentar $r$ toxicidade, indicou que o sulfeto de hidrogênio $\left(\mathrm{H}_{2} \mathrm{~S}\right)$, mais tóxico em $\mathrm{pH}$ ácido, pode ser o responsável pela toxicidade(USEPA, 1991b) bem como outros compostos $\mathrm{pH}$ dependentes.

A manipulação EDTA reduziu a toxicidade, ou seja, há indícios de que um dos responsáveis pela toxicidade podem ser metais já que de acordo com os protocolos de USEPA (2007), o EDTA é um quelante forte para metais. Isso corrobora com os resultados da manipulação tiossulfato que eliminou a toxicidade na amostra, sendo que esta manipulação é responsável por reduzir a toxicidade de alguns metais como cobre, cádmio, mercúrio, prata e selênio (USEPA, 1991b). Além disso, quando esta manipulação reduz a toxicidade, evidencia a presença de compostos oxidantes e alguns orgânicos hidrofílicos.

Na campanha realizada na Primavera de 2011 a amostra foi tóxica, o mesmo ocorreu com as manipulações Tiossulfato, pH9 e Filtração. Tal fato evidencia que compostos oxidantes, $\mathrm{pH}$ dependentes e a presença de material particulado e/ou adsorvido a estas partículas, não são os responsáveis pela toxicidade dessa amostra. A manipulação Tiossulfato também indica a presença de metais, os quais não podem ser descartados como possíveis responsáveis, pois o resultado da manipulação EDTA demonstra 
redução da toxicidade e evidencia a redução da biodisponibilidade de metais na amostra (USEPA, 1991b).

No Verão de 2012, a amostra apresentou toxicidade no Ensaio Referência. A Aeração mesmo apresentando duas concentrações com toxicidade apresentou uma redução da toxicidade o que evidencia a presença de compostos voláteis.

Os resultados da manipulação EDTA apresentou redução na toxicidade, evidenciando a presença de metais, pois reduzem a disponibilidade de metais, corroborando com isso, os resultados obtidos na manipulação Tiossulfato, que também pode afetar a biodisponibilidade de alguns metais catiônicos (Hockett \& Mont, 1996). Alguns metais podem apresentar alteração da solubilidade e a especiação pela gradação do pH (USEPA, 1991b).

De acordo com Ankley \& Schubauer-Berigan (1995) a alteração de pH pode apresentar mudanças significativas na proporção de formas ionizadas e não ionizadas, trazendo assim alterações na toxicidade. A alteração do pH para 9, apresenta um aumento da toxicidade, indicando a presença de amônia $\left(\mathrm{NH}_{3}{ }^{+}\right)$que, na forma não ionizada $\left(\mathrm{NH}_{3}\right)$, portanto mais tóxica, predomina em $\mathrm{pH}$ básico, corroborado pelo resultado da variável ambiental amônia não ionizada onde o maior valor foi obtido na manipulação $\mathrm{pH} 9$ e o menor valor em $\mathrm{pH} 7$.

A presença de compostos tóxicos aderidos ao material particulado e/ou adsorvido a estas partículas são evidenciados através da redução da toxicidade na manipulação Filtração.

6.4. Toxicidade dos sedimentos e a variação ao longo do ano (2011/2012). 
Os estudos nos mostram que todos os pontos de coleta apresentaram toxicidade de suas amostras, em pelo menos duas estações do ano.

As amostras de sedimento do Perequê-Açu e Caraguatatuba apresentaram toxicidade da água intersticial em todas as campanhas e de acordo com a frequência de concentrações tóxicas ao longo de todo o estudo, estas estações também foram as que apresentaram maiores valores, com 73,33\% para as amostras do Perequê-Açu e 70,00\% para Caraguatatuba. Segundo CETESB (2012), em seus estudos de toxicidade crônica não apresentaram resultados tóxicos, mas verificaram uma diminuição da qualidade do sedimento em comparação aos resultados de 2010, 2011 e 2012.

Estudos realizados pela CETESB (2011 e 2012) na região do Saco da Ribeira apresentaram do ensaio de toxicidade crônica sem toxicidade, apesar da constatação da contaminação local decorrente da alteração na qualidade do sedimento ter sido verificada pela presença do arsênio, chumbo, zinco e o cobre com concentrações entre ISQG e PEL (critérios internacionais). Também foi detectados abaixo dos critérios internacionais os HPAs benzo(a)antraceno, benzo(a)pireno, benzo(b)fluoranteno, benzo(k)fluoranteno, fenantreno, fluoranteno e pireno. Já o presente estudo verificou que as amostras deste local foram tóxicas em duas campanhas, sendo que a frequência de toxicidade, considerando todas as concentrações testadas no Ensaio Referência foi de $50 \%$, valor este que, aliado aos estudos pretéritos, deve ser considerado como um alerta de contaminação para a região. Tal fato demonstra que, nessa região, o impacto por voláteis e alguns metais verificados com a redução de concentrações tóxicas nas manipulações Aeração e Tiossulfato, reforçam que o problema desse local pode ser oriundo de atividades relacionadas a embarcações, visto que nessa área está a maior marina da Cidade de Ubatuba, o Píer do Saco da Ribeira, além de outras menores. 
Nessa região os resultados obtidos pela CETESB (2012) apesar de não apresentaram toxicidade para o ensaio crônico, apresentaram uma diminuição da qualidade do sedimento em comparação aos resultados dos anos anteriores. Esse cenário pode ter piorado uma vez que a água intersticial do sedimento do Itaguá foi tóxica às larvas de Lytechinus variegatus, nas campanhas do Inverno e Primavera.

Como não há atividades antropogênicas neste local e as amostras da Ilha do Mar Virado foram 50\% tóxicas, sendo as da Primavera de 2011 e a do Verão de 2012, época do início de chuva, na primavera, chegando à época de maior pluviosidade, no verão, e as correntes marítimas regionais pode ter carreado os contaminantes provenientes de outras localidades, e que ainda, o tráfego de embarcações não pode ser desconsiderado com uma fonte de contaminação para este local

\subsection{Sazonalidade da toxicidade}

Ao longo do ano, a campanha da Primavera apresentou maior número de amostras tóxicas, com 100\%. Segundo Sousa (2013), os ensaios realizados com amostras de água intersticial do sedimento do Canal de São Sebastião, indicaram 63,8\% de suas amostras de Primavera como tóxicas para as larvas de Lytechinus variegatus.

As campanhas de Outono, Inverno de 2011 e Verão de 2012 apresentaram toxicidade em três campanhas. Os resultados do estudo de Sousa (2013) apresentaram toxicidade nas amostras analisadas para o Outono, $56,1 \%$ o Inverno e $71,1 \%$ toxicidade para amostras no Verão, o que demonstra que nas estações do ano que apresentam aumento da população flutuante (Marandola Jr., et al., 2013) oriundas do veraneio e férias escolares de julho há presença maior da toxicidade. 


\section{CONCLUSÃO}

A avaliação da toxicidade das amostras de água intersticial apresentou os pontos Perequê-Açu e Caraguatatuba como dois pontos de coleta mais críticos, devido a presença de toxicidade em todas as amostras analisadas. Nos pontos Itaguá, Saco da Ribeira e Ilha do Mar Virado apresentaram toxicidade na metade das amostras coletadas.

E a aplicação dos procedimentos da AIT nessas amostras de agua intersticial de sedimentos marinhos demonstrou que esses procedimentos foram satisfatórios e trouxeram evidencias acordadas com a literatura.

A Identificação dos grupos de compostos químicos responsáveis pela toxicidade da água intersticial corroborou com a literatura, pois nas manipulações analisas evidenciaram como responsáveis pela toxicidade, ao longo de todo o estudo, os metais e os compostos $\mathrm{pH}$ dependentes ( $\mathrm{pH} 7$ - com redução) para o ponto Perequê-Açu. Para o ponto Itaguá também foram evidenciados como responsáveis pela toxicidade os metais e compostos $\mathrm{pH}$ dependentes ( $\mathrm{pH} 9$ - com redução). No Saco da Ribeira os resultados da AIT evidenciaram os compostos voláteis como responsáveis pela toxicidade da amostra. Na Ilha do Mar Virado as evidencias trazem os compostos relacionados ao material em suspensão devido a redução da toxicidade na manipulação Filtração e evidencia compostos pH dependentes com o aumento da toxicidade na manipulação pH7. As manipulações realizadas nas amostras de Caraguatatuba demonstram evidencias de que os metais foram os responsáveis pela toxicidade, visto que houve redução da mesma nas manipulações EDTA e Tiossulfato. 
De acordo com a variabilidade sazonal dos efeitos observados, podemos verificar que não houve um padrão sazonal de toxicidade em todas as estações do ano e somente na Primavera obteve toxicidade em todas as amostras testadas e nas demais épocas de coleta houve variação dos pontos tóxicos. 


\section{REFERÊNCIAS BIBLIOGRÁFICAS}

Abessa, D.M.S. 2002. Avaliação da qualidade de sedimentos do Sistema Estuarino de Santos, SP, Brasil. Dissertação de Mestrado. Universidade de São Paulo. Instituto Oceanográfico. 340pp.

ABNT Associação Brasileira de Normas Técnicas 2006. ABNT/NBR 15350:2006. Ecotoxicologia Aquática - Toxicidade crônica de curta duração - Método de bioensaio com ouriço-do-mar (Echinodermata: Echinoidea).17pp.

Adams, W.J.; Kimerle, R.A.; Barnett Jr., J.W. 1992. Sediment quality and aquatic life assessment. Environmental Science and Technology, 26(10):1864-1875.

Amato, JR; Mount, DI; Durhan, EJ; Lukasewycz, MT; Ankley, GT; Robert, ED. 1992. An example of the identification of Diazinont as a primary toxicant in an effluent. Environ Toxicol Chem 11:209-216.

Anderson R.J., Bolton J.J., Molloy F.J. \& Rothman K.W.G. (2003) Commercial seaweeds in southern Africa. In: Proceedings of the 17th International Seaweed Symposium, (ed. by R.O. Chapman, R.J. Anderson, V.J. Vreeland \& I.R. Davison), pp. 1-512. Oxford University Press, Oxford

Ankley, GT; Katko, A; Arthur, JW. 1990. Identification of ammonia as an important sediment-associated toxicant in the lower Fox River and Green Bay, Wisconsin. Environ Toxicol Chem 9:313-322.

Ankley, GT; Schubauer-Berigan, MK; Dierkes, JR; and Lukasewycz, MT. 1991. Sediment toxicity identification evaluation: Phase I, Phase II, and Phase III. U.S. Environmental Protection Agency. Draft Report 08-91. National Effluent Toxicity Assessment Center.

Ankley, GT; Schubauer-Berigan, MK. 1995. Background and overview of current sediment toxicity identification evaluation procedures. J Aquat Ecosystem Health 4:133-149.

Badaró-Pedroso, C. 1999. Avaliação dos efeitos tóxicos e identificação da toxicidade da ahua de produçãp de petróleo sobre algumas espécies marinhas. Tese de Doutorado. Escola de Engenharia de São Carlos. Universidade de SãoPaulo.242p.

Bocchetti, R., Fattorini, D., Pisanelli, B., Macchia, S., Oliviero, L., Pilato, F., Pellegrini, D., Regoli, F., 2008. Contaminant accumulation and biomarker responses in caged 
mussels, Mytilus galloprovincialis, to evaluate bioavailability and toxicological effects of remobilized chemicals during dredging and disposal operations in harbor areas. Aquat. Toxicol. 89 (4), 257-266

Burgess, RM; Ho, KT; Tagliabue, MD; Kuhn, A; Comeleo, R; Comeleo, P; Modica, G; Morrison, GE. 1995. Toxicity characterization of an industrial and a municipal effluent discharging to the marine environment. Mar Pollut Bull 30:524-535.

Burgess RM, Ho KT, Morrison GE, Chapman G, Denton DL (1996) Marine toxicity identification evaluation (TIE). Phase I guidance document, EPA/600/R-96/054, US Environmental Protection Agency, Washington, DC

Burgess, RM; Cantwell, MG; Pelletier, MC; Ho, KT; Serbst, JR; Cook, HF; Kuhn A. 2000. Development of toxicity identification evaluation procedure for characterizing metal toxicity in marine sediments. Environ. Toxicol. Chem. 19:981991.

Burone, L., 2002. Foraminíferos bentônicos e parâmetros físico-químicos da Enseada de Ubatuba, São Paulo: Estudo ecológico em uma área com poluição orgânica. Tese de Doutorado. Instituto Oceanográfico da Universidade de São Paulo. 279p.

Cariello, M.S. 2012. Efeito do naftaleno na microalga marinha Dunaliella tertiolecta, ouriço-do-mar Lytechinus variegatus e nos microcrustáceos estuarinos Nitokra sp e Leptocheirus plumulosus. Dissertação de mestrado aprestada ao Instituto Oceanográfico da Universidade de São Paulo.

Carr, R.S.; E.R. Long; H.L. Windon; D.C. Chapman; T. Thursby; G.M. Sloane \& D.A. Wolfe. 1996a. Sediment quality triad studies of Tampa Bay, Florida. Environmental Toxicology and Chemistry, 15(7):1218- 1231.

Carr, R.S.; Long, E.R.; Chapman, D.C.; Thursby, G; Biedenbach, J.M.; Windom, H.L.; Sloane, G.M.; Wolfe, D.A. 1996b. Sediment quality assessmentstudies of Tampa Bay. Florida. Environ Toxicol Chem15:1218-1231.

Carr, R.S.; Montagna, P.A.; Biedenbach, J.M.; Kalke, R.; Kennicutt, M.C.; Hooten, R.; Cripe, G. (2000). Impact of storm water outfalls on sediment quality in Corpus Christi Bay, Texas. Environ Toxicol Chem 19:561-574

Carr, R. S.; Nipper, M.; Biedenbach J. M.; Hooten, R. L.; Miller, K.; Saepoff, S.. 2001. Sediment Toxicity Identification Evaluation (TIE) Studies at Marine Sites Suspected of Ordnance Contamination. Arch. Environ. Contam. Toxicol. 41, 298307 
CETESB, Companhia de Tecnologia de Saneamento Ambiental. 2008. Relatório de qualidade das águas litorâneas no Estado de São Paulo: balneabilidade das praias 2007. São Paulo, CETESB, 294p.

CETESB, Companhia de Tecnologia de Saneamento Ambiental. 2011. Qualidade das águas superficiais no estado de São Paulo 2011.São Paulo : CETESB, 2012. 356 p.

CETESB, Companhia de Tecnologia de Saneamento Ambiental. 2012. Qualidade das águas superficiais no estado de São Paulo 2012. São Paulo : CETESB, 2013.370 p.

CGEE, 2008. Projetos estruturantes e horizontes temporais. In: Mar e Ambientes Costeiros.323p.

Chapman, P.M.; Mann, G.S. 1999. Sediment Quality Values (SQVs) and Ecological Risk Assessment (ERA). Mar. Pollut. Bull., 38(5):339-344.

Chapman, P.M.; Wang, F.; Germano, J.D.; Batley, G.. 2002. Pore water testing and analysis: the good, the bad, and the ugly. Marine Pollution Bulletin 44, 359-366.

DelValls, T.A., Andres, A., Belzunce, M.J., Buceta, J.L., Casado-Martínez, M.C., Castro, R., Riba, I., Viguri, J.R., Blasco, J., 2004. Chemical and ecotoxicological guidelines used for managing disposal of dredged material. Trends Anal. Chem. 23 (10-11), 819-828

Eicheler, B.B.. 1982. Caracterização sedimentológica e algumas considerações sobre foraminíferos na enseada do Flamengo, Ubatuba (23 $\left.30^{\prime} \mathrm{S}-45^{\circ} 06^{\prime} \mathrm{W}\right)$, SP. Tese de doutorado. Instituto Oceanográfico da Universidade de São Paulo. 109p.

Fernández, N., Bellas, J., Lorenzo, J.I., Beiras, R., 2008. Complementary approaches to assess the environmental quality of estuarine sediments. Water Air Soil Pollut. 189, $163-177$

Furtado, V.V., 1995. Sedimentação quaternária do Canal de São Sebastião. Publicação Esp. Inst. Oceanogr. S. Paulo 11: 27-35.

Furtado, V.V., Eicher, B.B., Sanches, T.M. , Tessler, M.G. 1987. Considerações sobre foraminíferos e suas relações ambientais na região de Ubatuba (SP). In: Congresso da Associação Brasileira de Estudos Quaternario, 1, Porto Alegre. Resumos. Porto Alegre, ABEQUA, p. 10.

Ghiselli Jr., R.O. 2006. Comparação ecológica da fauna de Ostracoda entre a Enseada do Flamengo, Ubatuba (S.P.) e a Baía de Guanabara (R.J.). Tese de Doutorado. Instituto Oceanográfico da Universidade de São Paulo. 95p. 
Ho, KT; McKinney, RA; Kuhn, A; Pelletier, MC; Burgess, RM. 1997. Identification of acute toxicants in New Bedford Harbor sediments. Environ Toxicol Chem 16:551558.

Ho, K.T., Burgess, R.M., 2009. Marine Sediment Toxicity Identification Evaluations (TIEs): History, Principles, Methods, and Future Research, vol. 5, Part T. pp. 7595

HO, K.T.; Burgess, R.M.; Pelletier, M.C.; Serbst, J.R.; Ryba, S.A.; Antwell, M.G.; Kuhn, A.; Raczelowski, P. 2002. An overview of toxicant identification in sediments and dredged materials. Marine Pollution Bulletin, v.44, p.286-293.

IBGE. Instituto Brasileiro de Geografia e Estatística. - Disponível em http://www.ibge.gov.br/. Acesso em 27/08/2014

Linkov, I.; von Stackelberg, K.E.J.; Burmistrov, D.; Bridges, T.S. 2001. Uncertainty and variability in risk from trophic transfer of contaminants in dredged sediments. The Science of the Total Environment. 274(2001):255-269

Macken, A., Giltrap, M., Foley, B., McGovern, E., McHugh, B., Davoren, M., 2009. An integrated approach to the toxicity assessment of Irish marine sediments: application of porewater Toxicity Identification Evaluation (TIE) to Irish marine sediments. Environ. Int. 35 (1), 98-106

Magliocca, A.; Kurtner,A.S.. 1965. Sedimentos de fundo da enseada do Flamengo Ubatuba. BOLM. INST. OCEANOGT., S. Paulo - Fis. V8:1-14.

Mahiques, M.M., 1992. Variações Temporais na Sedimentação Holocênica dos Embaiamentos da Região de Ubatuba (SP). Tese de doutorado. Instituto Oceanográfico da Universidade de São Paulo, vol. 1, 129 p. e vol. 2, 223 p.

Mahiques, M.M. 1995. Dinâmica sedimentar atual nas enseadas da Região de Ubatuba, Estado de São Paulo. Bolm. Inst. oceanogr. S Paulo, 43:111-122.

Mahiques, M.M.; Tessler, M.G; Furtado, V.V. 1998. Characterization of energy gradient in enclosed Bays of Ubatuba region, South-eastern Brazil. Estuar. Coast. Shelf Sc., 47:431-446.

Marandola Jr., E.; Marques, C.; Paula, L.T de; Cassaneli, L.B. 2013. Crescimento urbano e áreas de risco no litoral norte de São Paulo. R. bras. Est. Pop., Rio de Janeiro, v. 30, n. 1, p. 35-56. 
Matos, M.F. 2011. Avaliação e identificação da toxicidade de amostras de água e sedimento do Reservatório de Funil, RJ. Dissertação de mestrado. Universidade Federal de Itajubá. 59p.

Muniz, P.M. 2003. Comunidades macrobênticas como indicador da qualidade ambiental de ecossistemas costeiros rasos: Estudo de caso - Enseada de Ubatuaba (SP, Brasil). Tese de Doutorado. Instituto Oceanográfico da Universidade de São Paulo. 205p.

Nipper, M.G.; Greenstein, D.J; Bay, S.M. 1989. Short- and long-term sediment toxicity test methods with the amphipod Grandidierella japonica. Environ. Toxicol. and Chem., 8:1191-1200.

Nipper, M.G. 1997. The development and Application of Sediment Toxicity Tests for Regulatory Purposes. In: Wells, P.G.; K. Lee \& C. Blaise. Microscale testing in aquatic toxicology advances, techniques and practice. Florida. CRC Press. 631-643.

Norberg-King; TJ, Durhan, EJ; Ankley, GT; Robert, E. 1991. Application of toxicity identification evaluation procedures to the ambient waters of the Colusa Basin Drain, California. Environ Toxicol Chem 10:891-900.

Oliveira, L.F.J. 2009. Estudo da qualidade do sedimento através de testes de toxicidade e marcadores de esgoto na enseada de Ubatuba-SP, Brasil. Influencia do aumento da população de vernaneio. Dissertação de Mestrado apresentada ao Instituto Oceanográfico, Universidade de São Paulo. 87p.

Rachid, B.R.F. 2002. Avaliação ecotoxicológica dos efluentes domésticos lançados pelos sistemas de disposição oceânica da Baixada Santista. Tese de Doutorado. Instituto Oceanográfico. Universidade de São Paulo. 286p.

Rodríguez-Obeso, O., Alvarez-Guerra, M., Andrés, A., DelValls, T.A., Riba, I., MartínDíaz, M.L., Viguri, J.R., 2007. Monitoring and managing sediment quality and impact assessment in Spain in the past 10 years. Trends Anal. Chem. 26, 252-260

Schipper, C.A., Rietjens, I.M., Burgess, R.M., Murk, A.J., 2010. Application of bioassays in toxicological hazard, risk and impact assessments of dredged sediments. Mar. Pollut. Bull. 60 (11), 2026-2042.

SEDAE. Fundação Sistema Estadual de Análise de Dados. Disponível em http://www.seade.gov.br/. Acesso em 27/08/2014.

Simpson, S.L., Micevska, T., Adams, M.S., Stone, A., Maher, W., 2007. Establishing cause-effect relationships in PAH and hydrocarbon contaminated sediments using the benthic marine alga, Entomoneis cf punctulata. Env. Tox. Chem. 26, 163-170. 
Sousa, E.C.P.M. 2002. Toxicologia marinha: Histórico. In.: Métodos em Ecotoxicologia Marinha: Aplicações no Brasil. Nascimento, I.A., E.C.P.M Sousa, M. G Nipper (eds.). Ed. Artes Gráficas e Ind. Ltda. 262p.

Sousa, E.C.P.M. 2013. 12 anos de monitoramento ecotoxicológicos na área de disposição de um terminal petrolífero no Litoral Norte do Estado de São Paulo. Tese de Livre Docência apresentada ao Instituto Oceanográfico, Universidade de São Paulo. 146 p.

Souza, C.R.G., 1990. Considerações sobre os processos sedimentares quaternários e atuais na região de Caraguatatuba, litoral norte de São Paulo. Dissertação de Mestrado. Universidade de São Paulo, Instituto Oceanográfico. São Paulo334p.

Stronkhorst, J., Schot, M.E., Dubbeldam, M.C., Ho, K.T., 2003. A toxicity identification evaluation of silty marine harbor sediments to characterize persistent and non- persistent constituents. Mar. Pollut. Bull. 46 (1), 56-64.

Swartz, R.C.; DeBen, W.A; Jones, J.K.P; Lamberson, J.O.; Cole, F.A. 1985. Phoxocephalid amphipod bioassay for marine sediment toxicity. In: Symposium on Aquatic Toxicology and Hazard Assessment, 7, Philadelphia, ASTM, p.284-307.

U.S. EPA, 1989. Generalized Methodology for Conducting Industrial Toxicity Reduction Evaluations (TREs). EPA/600/2-88/070. 107p.

U.S. EPA, 1991a. Sediment toxicity identification evaluations: phase I (characterization), phase 1I (identification), and phase 111 (confirmation) modifications of effluent procedures, EPAJ600/6-91-007 Environmental Research Laboratory, Duluth, MN.

U.S. EPA. 1991b. Methods for Aquatic Toxicity Identification Evaluations: Phase I Toxicity Characterization Procedures. Office of Research and Development. EPA 600/6-91/003. 87p.

U.S. EPA, 1991c. Evaluation of Dredged Material Proposed for Ocean Disposal Testing Manual. EPA 503/8-91/001. U.S. Army Corps of Engineers

U.S. EPA. 1993a. Methods for Aquatic Toxicity Identification Evaluations: Phase II Toxicity Identification Procedures for samples exhibiting acute and chronic toxicity. Office of Research and Development. EPA 600/R-92/080. 70p.

U.S. EPA. 1993b. Methods for Aquatic Toxicity Identification Evaluations: Phase III Toxicity Confirmation Procedures for samples exhibiting acute and chronic toxicity. Office of Research and Development. EPA 600/R-92/081. 40p. 
U.S. EPA, 1999. Toxicity ReductionEvaluation Guidance for Mnicipal Wastewater Treatment Plants. EPA/833B-99/002. 97p.

USEPA, 2007. Sediment Toxicity Identification Evaluation (TIE) Phases I, II, and III Guidance Document EPA/600/R-07/080 Office of Research and Development. Washington, DC.

Winger, P.V. \& P.J. Lasier. 1991. A vacuum-operated pore-water extractor for estuarine and freshwater sediments. Arch. Environ. Contam. Toxicol., 21:321-324. 